\title{
WestVirginiaUniversity
}

THE RESEARCH REPOSITORY @ WVU

Graduate Theses, Dissertations, and Problem Reports

2004

\section{Design and development of a target-costing model for machining}

Ameet Kokatnur

West Virginia University

Follow this and additional works at: https://researchrepository.wvu.edu/etd

\section{Recommended Citation}

Kokatnur, Ameet, "Design and development of a target-costing model for machining" (2004). Graduate Theses, Dissertations, and Problem Reports. 1546.

https://researchrepository.wvu.edu/etd/1546

This Thesis is protected by copyright and/or related rights. It has been brought to you by the The Research Repository @ WVU with permission from the rights-holder(s). You are free to use this Thesis in any way that is permitted by the copyright and related rights legislation that applies to your use. For other uses you must obtain permission from the rights-holder(s) directly, unless additional rights are indicated by a Creative Commons license in the record and/ or on the work itself. This Thesis has been accepted for inclusion in WVU Graduate Theses, Dissertations, and Problem Reports collection by an authorized administrator of The Research Repository @ WVU. For more information, please contact researchrepository@mail.wvu.edu. 


\title{
Design and Development of a Target-Costing Model for Machining
}

\author{
Ameet Kokatnur \\ Thesis submitted to the \\ College of Engineering and Mineral Resources \\ at West Virginia University \\ in partial fulfillment of the requirements for the degree of \\ Master of Science \\ in \\ Industrial Engineering
}

Bhaskaran Gopalakrishnan, Ph.D., Chair.

Jack Byrd Jr., Ph.D.

Robert Creese, Ph.D.

Department of Industrial and Management Systems Engineering

Morgantown, West Virginia

2004

Keywords: Target-costing, Machining, Turning, Geometric Programming 


\section{ABSTRACT \\ Design and Development of a Target-Costing Model for Machining Ameet Kokatnur}

In today's intensely competitive and highly volatile business environment, consistent development of low cost and high quality products meeting the functionality requirements is a key to a company's survival. Companies continuously strive to reduce the costs while still producing quality products to stay ahead in the competition. Many companies have turned to target costing to achieve this objective. Target costing is a structured approach to determine the cost at which a proposed product, meeting the quality and functionality requirements, must be produced in order to generate the desired profits. It subtracts the desired profit margin from the company's selling price to establish the manufacturing cost of the product. Extensive literature review revealed that companies in automotive, electronic and process industries have reaped the benefits of target costing. However target costing approach has not been applied in the machining industry, but other techniques based on Geometric Programming, Goal Programming, and Lagrange Multiplier have been proposed for application in this industry. These models follow a forward approach, by first selecting a set of machining parameters, and then determining the machining cost. Hence in this study we have developed an algorithm to apply the concepts of target costing, which is a backward approach that selects the machining parameters based on the required machining costs, and is therefore more suitable for practical applications in process improvement and cost reduction. A target costing model was developed for turning operation and was successfully validated using practical data. 


\section{ACKNOWLEDGEMENTS}

I wish $\mathfrak{b}$ express my sincere gratitude and appreciation to my research advisor and committee chair Dr. Bhaskaran Gopalakrishnan for his continued support, encouragement and insightful guidance which led me throughout the course of my studies at West Virginia University. I would like to thank my committee member and IMSE Dept. graduate program coordinator Dr. Robert Creese for his valuable guidance towards the completion of this research. I would also like to thank Dr. Jack Byrd Jr. for accepting to serve on my thesis committee.

My sincere appreciation goes to Mr. Jim Williams of Devall Brothers, Morgantown, for his tremendous support and guidance in the research validation process. Validation of this model would not have been possible without his cooperation in providing us with the necessary data from one of his projects.

I would also like to acknowledge Mr. James Dalton's support and guidance during the entire period of my studies at West Virginia University. Working with him in the manufacturing lab was an invaluable learning experience and has contributed towards the

development of good work ethics. Finally I would also like to thank my dearest friend Mr. Deepak Gupta for his constructive inputs during the course of this study. 


\section{TABLE OF CONTENTS}

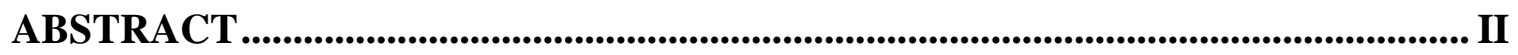

ACKNOWLEDGEMENTS ...................................................................................II

TABLE OF CONTENTS .......................................................................................

LIST OF FIGURES …....................................................................................................

LIST OF TABLES …............................................................................................... VIII

LIST OF TABLES ................................................................................................. VIII

INTRODUCTION.............................................................................................................. 1

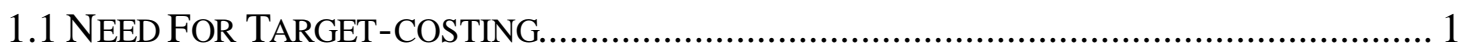

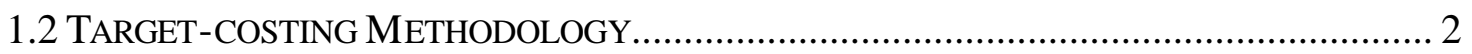

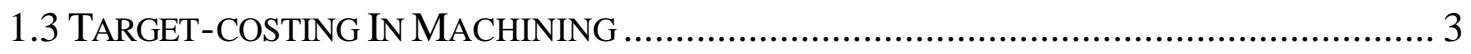

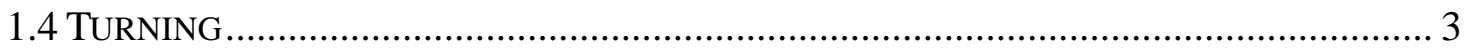

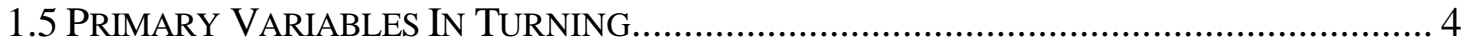

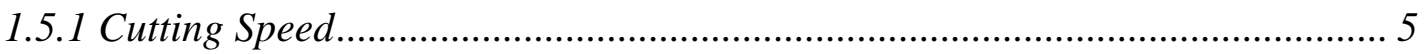

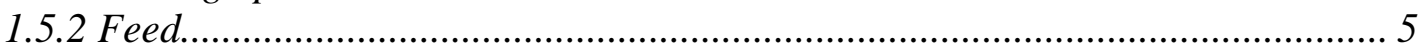

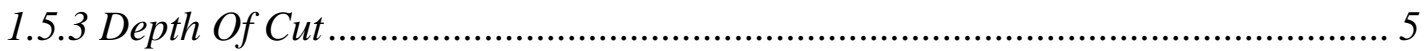

1.6 NOTATIONS USED IN THE TARGET-COSTING ALGORITHM …………........................ 5

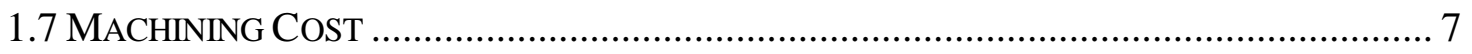

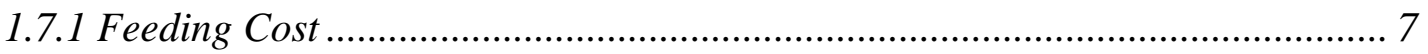

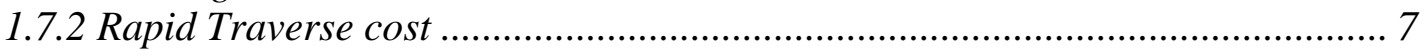

1.7.3 Loading/Unloading Cost .................................................................... 8

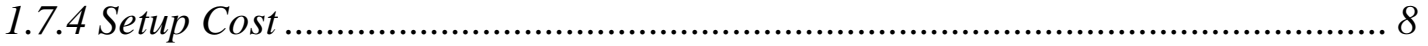

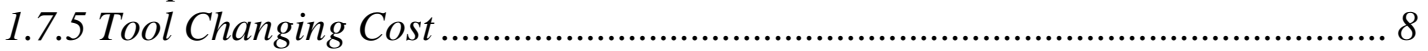

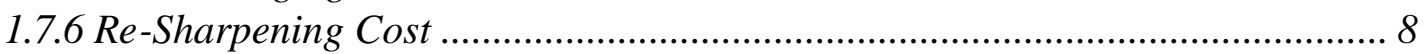

1.7.7 Re-Brazing Cost .................................................................................. 9

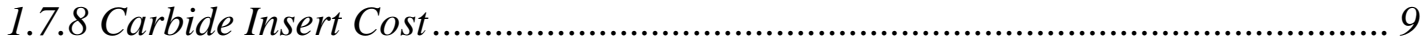

1.7.9 Grinding Wheel Cost............................................................................. 9

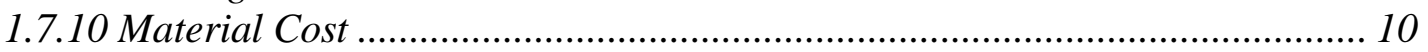

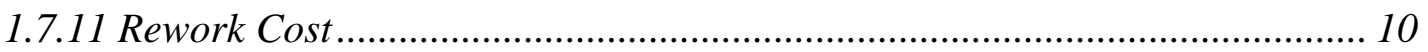

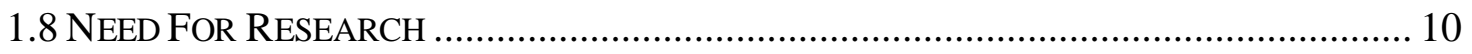

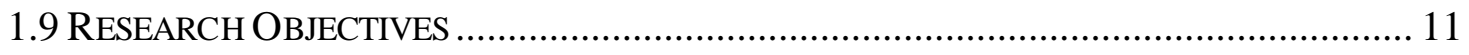

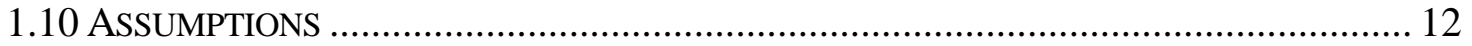

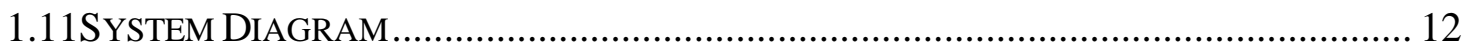

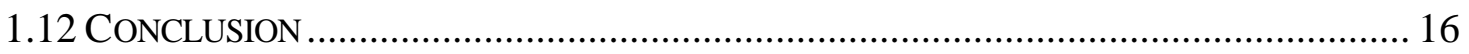

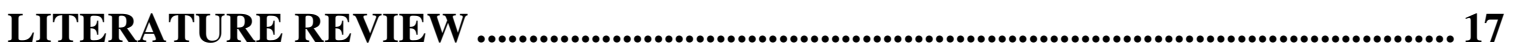

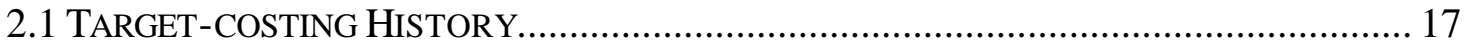

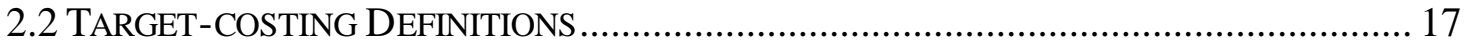

2.3 APPROACH TO TARGET-COSTING....................................................................... 18

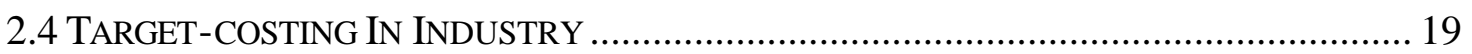

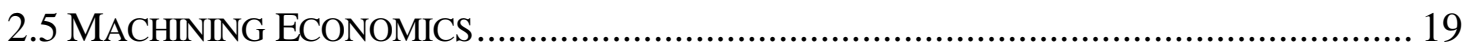

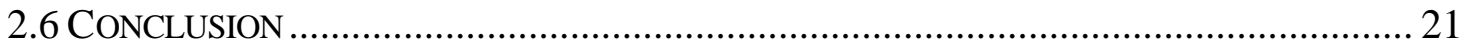


SYSTEM DEVELOPMENT ........................................................................................22

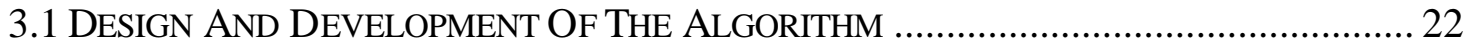

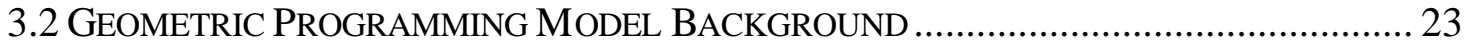

3.3 GEOMETRIC PROGRAMMING MODEL NOMENCLATURE........................................... 24

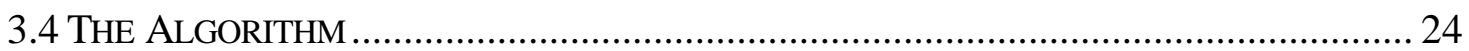

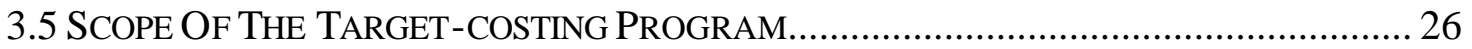

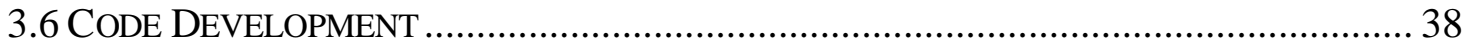

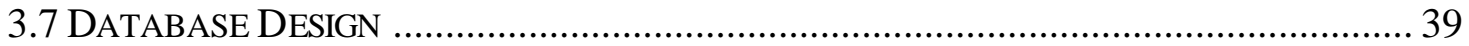

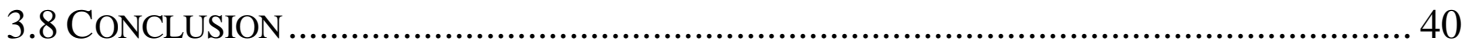

SYSTEM BEHAVIOR ANALYSIS ......................................................................... 41

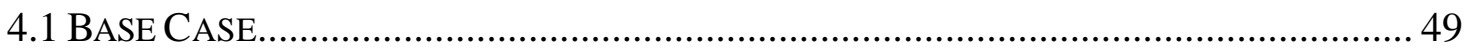

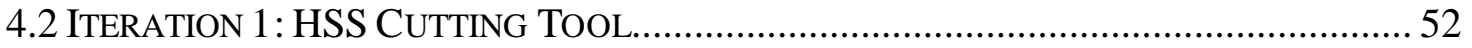

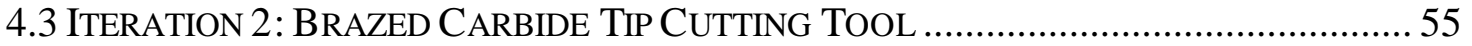

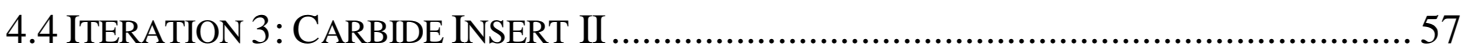

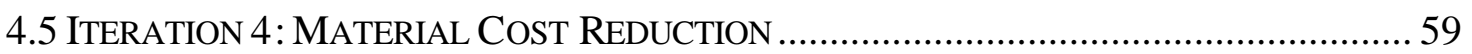

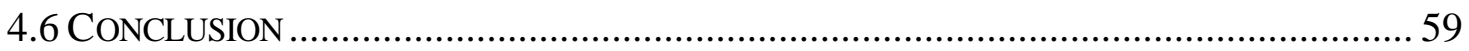

SYSTEM VALIDATION

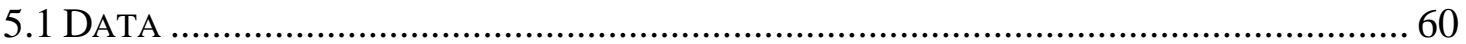

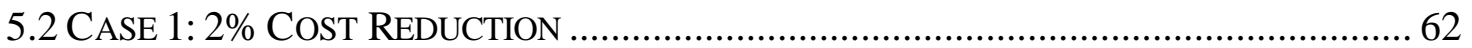

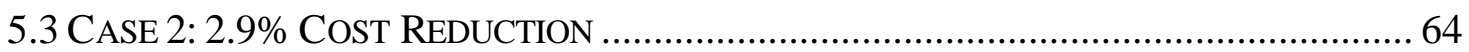

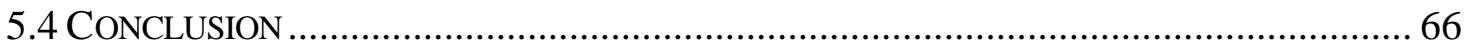

CONCLUSION AND FUTURE WORK ............................................................ 67

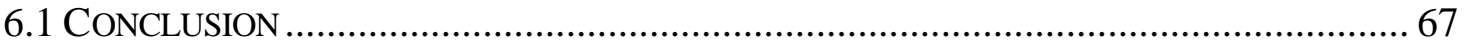

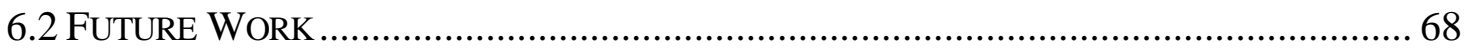

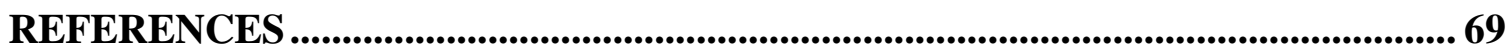

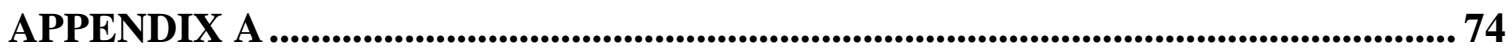

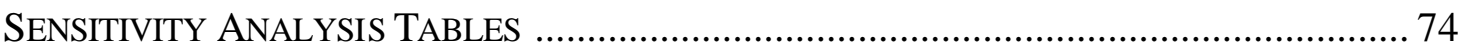

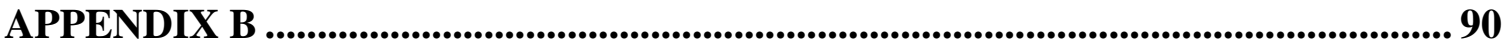

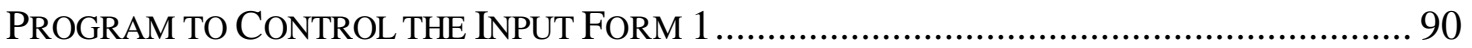

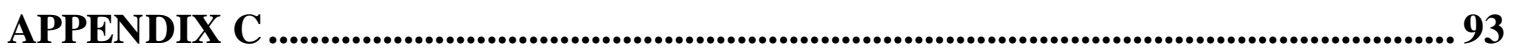

PROGRAM TO CONTROL THE INPUT FORM 2 ........................................................ 93

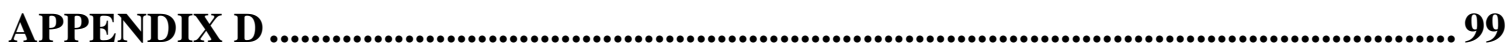

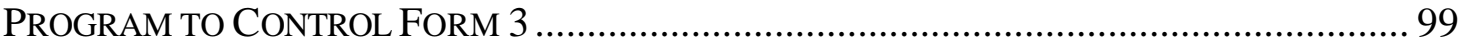

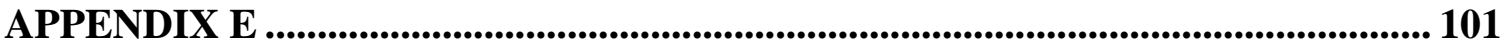

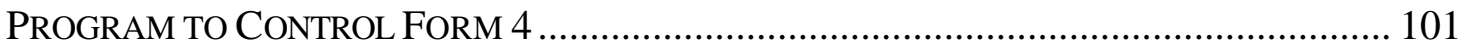

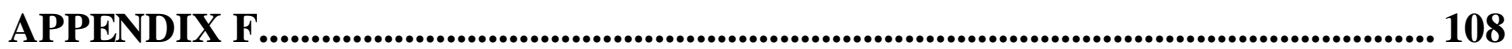

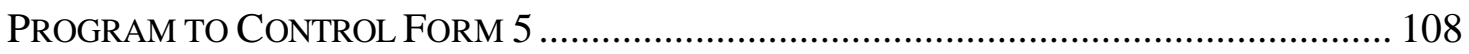




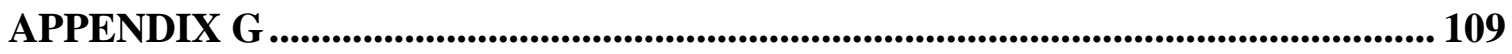

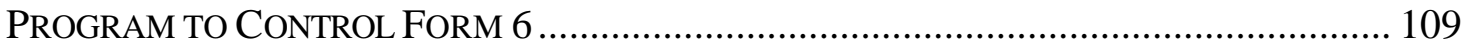

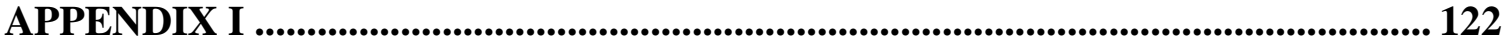

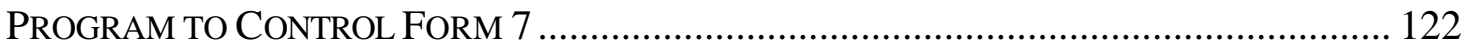

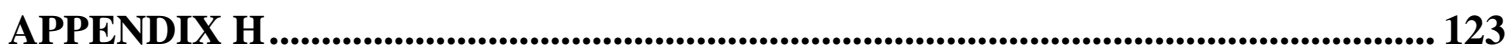

MODULE CONTAINING SUBPROGRAMS.............................................................. 123 


\section{LIST OF FIGURES}

Figure 1. UnSTRUCtured APPROACH To ACHIEVE TARget COST ............................. 14

FiguRE 2. STRUCTURED APPROACH TO ACHIEVE TARget COST.............................. 15

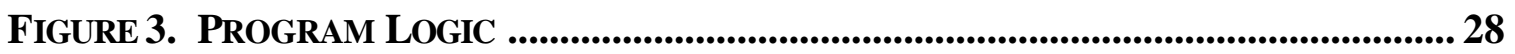

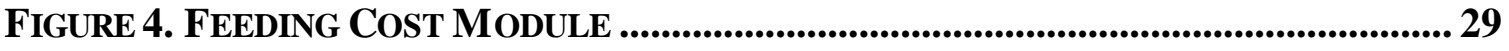

FIGURE 5. RAPID TRAVERSE COST MODULE.............................................................. 30

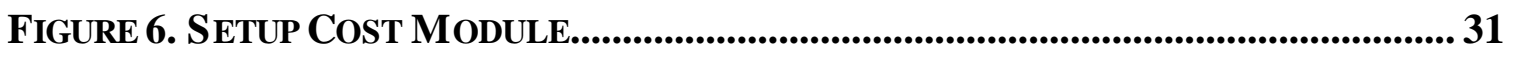

FIGURE 7. LOADING AND UNLOAdING COST MODULE..................................................... 32

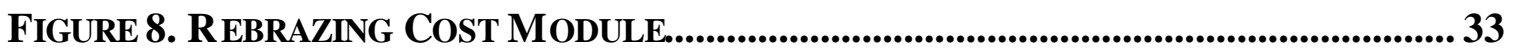

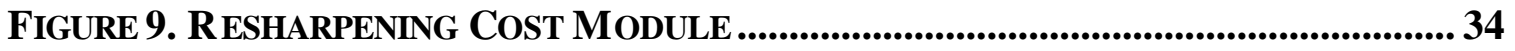

FIGURE 10. CARbide INSERT COST MOdULE ............................................................................ 35

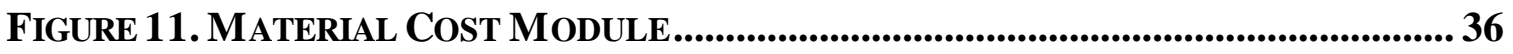

FIGURE 12. REWORK COST MODULE....................................................................... 37

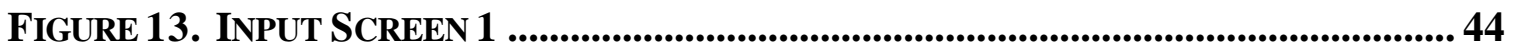

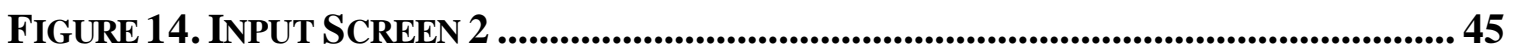

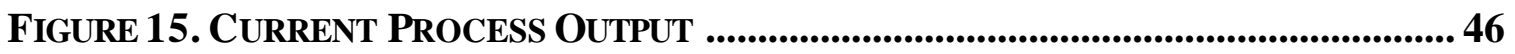

FIGURE 16. COST COMPONENT CONTRIBUTION ...................................................... 47

Figure 17. COST COMPONENTS BEFORE AND AFTER TARgET-COSTING.................... 48

FIGURE 18. VARIATION OF UNIT COST OVER FOUR ITERATIONS................................. 49

FIGURE 19. VALIDATION EXAMPLE 1 ..........................................................................63

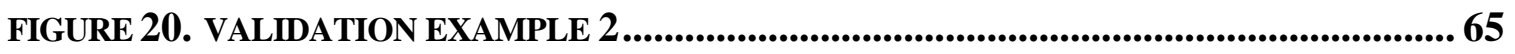




\section{LIST OF TABLES}

TABle 1: Database table for Cold Drawn Material Condition ...................... 39

TAble 2: Change in Data between Base CaSe AND ITERATiOn 1. ............................ 52

TABLE 3: COMPARISON OF R ESUltS BETWEen BASE CASE AND ITERATION 1............ 54

TABLE 4: COMPARISON OF RESUltS BETWEEN BASE CASE AND ITERATION 2............. 56

TABle 5: Comparison OF ReSults between BASE CASE AND ITERATION 3............ 58

TABLE 6. S YSTEM VALIDATION CASE 1: 2\% COST R EDUCTION.................................. 62

TABLE 7. S YSTEM VALIDATION CASE 2: 2.9\% COST R EdUCTION................................ 64 


\section{CHAPTER 1}

\section{INTRODUCTION}

\subsection{Need For Target-costing}

In an era of intensely competitive and ever changing business environment, consistent development of low cost and high quality products meeting the functionality requirements is a key to a company's survival. Companies continuously look forward to cut down costs while still producing quality products and stay ahead in the competition. Many companies have adopted a process known as target-costing for controlling both manufacturing and non-manufacturing costs. The following example illustrates the role played by target-costing in redesigning and reengineering the business process of one of the largest camera manufacturer.

In the 1980s, five Japanese companies dominated the world's $35 \mathrm{~mm}$ camera market: Asahi Pentax, Canon, Minolta, Nikon and Olympus. Olympus was the third major player with $10 \%$ market share. There were two major types of $35 \mathrm{~mm}$ cameras: Single Lens Reflex (SLR) and Lens Shutters (LS) or compact cameras. SLR cameras allowed the photographer to see exactly what a picture would look like before it was taken. Because of this feature SLR cameras rapidly gained a dominant share of the professional photographic market. Compact cameras, as suggested by their name, were smaller than SLR cameras. They were relatively unsophisticated and posed little challenge to the SLR market. However as advances in electronic control systems allowed auto-focus and automatic exposure features to be added at relatively low prices, the compact camera began to be viewed as a serious alternative to SLR cameras. Sales of SLR cameras 
plummeted. The shift in consumer preference to compact cameras adversely affected Olympus in particular, because the company historically had relied heavily on SLR sales and had failed to develop a leadership position in the compact camera arena. In the mid1980s, Olympus' camera business began to lose money and by 1987 Olympus suffered considerable losses. Top management reacted to the losses by introducing an ambitions three-year program to "reconstruct" the camera business. At the core of this program were three objectives: first, to recapture lost market share; second, to dramatically improve product quality; and third, to reduce production costs via an aggressive set of cost reduction programs. At the heart of the cost reduction program was the company's target-costing system (Cooper \& Slagmulder 1999).

\subsection{Target-costing Methodology}

The first step in determining the target cost of a product is to establish the selling price and the company's desired profit margin for a product. The desired profit is subtracted from the selling price to determine the product-level target cost. The product-level target cost is then decomposed to component-level so that the purchase price of the components can be determined. This also enables in making "make vs buy" decisions. The critical factor that distinguishes target-costing is the intensity with which the cardinal rule is

applied: the target cost can never be exceeded (Cooper \& Slagmulder 1999). By setting the target cost in this way, the company assures itself that when the product's target cost and the market price are realized, the product will generate its anticipated returns. If the actual cost exceeds its target cost, actions must be taken to reduce the product manufacturing cost. Manufacturing costs can be reduced by taking different actions. 
One option to achieve the target cost is to reengineer the manufacturing process. Manufacturing is a very broad term consisting of different processes like casting, forging, machining, bending, drawing, extrusion etc that strive to impart the desired shape to a work-piece. The next section gives an overview about machining operation.

\subsection{Target-costing In Machining}

Machining is one of the major manufacturing processes. It aims to generate the shape of a work-piece from a solid body or improve the tolerances and surface finish of a previously formed work-piece. A very high percentage of parts used in the automotive industry, aircraft industry, pumps, turbines etc have machined components forming a major part of the final product. Machining cost therefore forms a significant portion of the total cost of the final product. The machining cost depends upon the machining process, cutting tools, labor, type of machine, material and several other factors and hence significant cost reduction can be obtained by proper design and selection of these parameters. Different machining operations such as turning, milling, drilling, tapping and grinding are widely used, of which the turning operation and the cost of turning will be the focus of this research. Subsequent sections will be dedicated to an overview of the turning operation and its associated costs, and the application of target-costing in machining for the turning operation

\subsection{Turning}

Turning is probably the most widely used of all the machining processes. It is a continuous machining process governed by various parameters. The work-piece is held 
in the chuck that rotates and a single point cutting tool is used to remove the metal from the work-piece. Different parameters which govern the turning process are cutting speed, feed depth of cut, tool life, tool angles and so on. The cost per piece in turning can be divided into two components: machine time cost and tool cost. The total machine time cost can be subdivided into feeding cost, rapid traverse cost, tool-changing cost, loading/unloading cost and setup cost. The total tool cost is made up of tool depreciation cost, tool re-sharpening cost, re-brazing cost, carbide insert cost and grinding wheel cost. Some components of the total tool cost may be zero depending upon the type of tool selected.

\subsection{Primary Variables In Turning}

The primary variables in turning operation are cutting speed, the feed and the depth of cut. The product of these three variables results in the metal removal rate, and generally a high metal removal rate is desirable. However, the tool costs and tool changing costs increase as the three variables increase, so there is an optimal set of parameter levels for the three variables. The general situation is to first select the depth of cut, then the feed and finally the cutting speed [7]. The depth of cut is determined by the part dimensions, machine power and also the surface finish requirements. The feed is mainly controlled by surface finish requirements or machine power and the cutting speed is controlled by the economical or production requirements. 


\subsubsection{Cutting Speed}

The cutting speed is the rate at which the workpiece surface moves past the cutting edge of the tool. It is expressed in surface feet per minute or meters per second and denoted by "V" in various machining calculations.

\subsubsection{Feed}

The feed rate is defined as the displacement of the tool along the workpiece in the direction of the feed motion. It is expressed inches per minute denoted by "F" or inches per revolution denoted by " $\mathrm{f}_{\mathrm{r}}$ ".

\subsubsection{Depth Of Cut}

The depth of cut is defined as the undeformed chip thickness. It is the distance between the surface of material formed by the previous cut to the new workpiece surface. It is measured in inches or millimeters and is denoted by " $\mathrm{d}$ ".

All three variables depend upon the cutting tool material, workpiece material, cutting fluids if used, the machining capabilities and the surface finish desired. These variables are important for determining the machining times as well as for estimating the power requirements.

\subsection{Notations Used In The Target-costing Algorithm}

a

e

L approach of tool to work-piece; in

over-travel of tool past work-piece; in

length of work-piece; in 


\begin{tabular}{|c|c|}
\hline ID & initial diameter of work-piece; in \\
\hline $\mathrm{D}_{\text {fin }}$ & final diameter of workpiece; in \\
\hline $\mathrm{D}$ & Average diameter of workpiece; in \\
\hline $\mathrm{f}_{\mathrm{r}}$ & feed per revolution; in/rev \\
\hline $\mathrm{V}$ & cutting speed; sfpm \\
\hline $\mathrm{d}$ & depth of cut; in \\
\hline $\mathrm{N}_{1}$ & batch size \\
\hline $\mathrm{R}$ & rapid traverse rate of tool; in/min \\
\hline$t_{L}$ & time to load and unload work-piece; min \\
\hline$t_{c}$ & time to change tool; min \\
\hline$t_{0}$ & time to setup machine tool for operation; min \\
\hline$t_{s}$ & time to re-sharpen the tool; min \\
\hline$t_{b}$ & time to re-braze the carbide tip; min \\
\hline $\mathrm{C}_{\mathrm{p}}$ & purchase cost of tool shank; $\$$ \\
\hline $\mathrm{K}_{2}$ & number of parts machined after which the carbide tip is re-brazed. \\
\hline $\mathrm{C}_{\mathrm{w}}$ & cost of grinding wheel for re-sharpening the tool; $\$ /$ tool. \\
\hline G & labor + overhead on tool grinder; $\$ / \mathrm{min}$ \\
\hline$P$ & labor + overhead on brazing machine; $\$ / \mathrm{min}$ \\
\hline M & labor + overhead on lathe; $\$ / \mathrm{min}$ \\
\hline $\mathrm{C}_{\mathrm{c}}$ & purchase cost carbide insert; $\$$ \\
\hline $\mathrm{K}_{3}$ & $\begin{array}{l}\text { number of parts machined after which the carbide insert is } \\
\text { discarded. }\end{array}$ \\
\hline $\mathrm{T}$ & tool life in minutes \\
\hline
\end{tabular}




$\begin{array}{ll}\text { Mp } & \text { Material Price } \\ \text { Wt } & \text { Weight of material } \\ \text { Mc } & \text { Material cost } \\ \text { rwc } & \text { Rework cost } \\ \text { ubs } & \text { updated batch size } \\ \text { rew-rate } & \text { rework rate } \\ \text { no_parts_reworked } & \text { number of parts reworked. }\end{array}$

\subsection{Machining Cost}

The machining cost comprises of costs associated with the machine time, cutting tools, work-piece material and costs associated with rejection and rework. The total machine time cost and the total tool costs can be divided into their respective components.

\subsubsection{Feeding Cost}

Feeding time is the time during which the tool actually cuts the metal. The feeding cost is calculated as the feeding time multiplied by the labor and overhead cost.

Feeding Cost $=M\left[(D \times(L+a+e)) /\left(3.82 \times f_{r} \times V\right)\right]$

\subsubsection{Rapid Traverse cost}

When the tool finishes the cut and clears the work-piece, it comes back rapidly to the start point. The time taken for this motion is called rapid traverse time and the cost associated with this time is called rapid traverse cost. It is given as:

Rapid Traverse Cost $=\mathrm{M}[(\mathrm{a}+\mathrm{L}+\mathrm{e}) / \mathrm{R}]$ 


\subsubsection{Loading/Unloading Cost}

The time taken to load and unload the work-piece on the lathe is called loading/unloading time. The cost associated with this time is called loading/unloading cost, given as: Loading/Unloading Cost $=\mathrm{M} \mathrm{x}_{\mathrm{L}}$

\subsubsection{Setup Cost}

Before actually starting the machining operation, the machine has to be setup for the operation. Work-holding device like a chuck has to be loaded. The cutting tool has to be held in the tool holder and the line of cutting has to be adjusted. The time required for such activities is called setup time. The cost of setting up the machine is called setup cost. It is a one-time cost for a batch. It is given as :

Setup Cost $=M\left(t_{0} / N_{L}\right)$

\subsubsection{Tool Changing Cost}

Whenever the tool breaks during machining a part, it has to be replaced and the new tool has to be readjusted in the tool holder. The time required to change the tool and readjust it in the tool holder is called tool change time. The cost associated with the tool changing time is called tool change cost which is given as:

Tool Change Cost $=\mathrm{M}\left[\left(\mathrm{D} \times \mathrm{L} \times \mathrm{t}_{\mathrm{c}}\right) /\left(3.82 \times \mathrm{f}_{\mathrm{r}} \times \mathrm{V} \times \mathrm{T}\right)\right]$

\subsubsection{Re-Sharpening Cost}

This component of tool cost depends upon the number of times the tool fails. Every time a tool fails i.e. the cutting edge becomes blunt or the cutting edge breaks, it has to be re- 
sharpened. The cost associated with re-sharpening the tool is called the re-sharpening cost. If carbide inserts are used, this component is zero as carbide inserts are not resharpened. The re-sharpening cost is given as:

Re-sharpening Cost $=\left[(\mathrm{D} \times \mathrm{L}) /\left(3.82 \times \mathrm{f}_{\mathrm{r}} \times \mathrm{V} \times \mathrm{T}\right)\right] \times\left(\mathrm{G} \times \mathrm{t}_{\mathrm{s}}\right)$

\subsubsection{Re-Brazing Cost}

This cost is associated with tools wherein a carbide tip is brazed to a carbon steel shank. The shank can be any other low cost material with good toughness. This is the cost incurred in re-brazing the insert on to the shank. This component of cost does not depend upon the number of times the tool fails. It can be assumed that the carbide tip is rebrazed after a fixed number of parts are machined.

Re-brazing Cost $=\left(\mathrm{P} \times \mathrm{t}_{\mathrm{b}}\right) / \mathrm{K}_{2}$

\subsubsection{Carbide Insert Cost}

This is the cost of the carbide insert per part machined. It can be assumed that the insert is discarded after a certain number of parts are machined.

Carbide Insert Cost $=\mathrm{C}_{\mathrm{c}} / \mathrm{K}_{3}$

\subsubsection{Grinding Wheel Cost}

Whenever the edge of the cutting tool breaks or becomes blunt, it has to be re-sharpened to be used again. The cutting tools are re-sharpened on a tool and cutter grinder. Hence the cost of the grinding wheel for each tool re-sharpened has to be incorporated in the total tool cost. 
Grinding Wheel Cost $=\left[(\mathrm{D} \times \mathrm{L}) /\left(3.82 \times \mathrm{f}_{\mathrm{r}} \times \mathrm{V} \times \mathrm{T}\right)\right] \times \mathrm{C}_{\mathrm{w}}$

\subsubsection{Material Cost}

The amount of dollars spent on the material to make a part is the material cost per part. The material cost is given by the expression:

$\mathrm{Mc}=(\mathrm{Wt}) \mathrm{x}(\mathrm{Mp})$

\subsubsection{Rework Cost}

After machining, parts are subjected to a quality check where some parts may be rejected due to non-conformance of quality or design specifications. These parts are either rejected or reworked. The cost associated with reworking the parts to meet the specifications is called rework cost. This rework cost is spread over the entire batch.

Rework Cost $=($ Number of parts reworked $\mathrm{x}$ Rework rate $) /$ updated batch size .

\subsection{Need For Research}

Since the turning cost is comprised of many cost components, there is a huge opportunity for cost reduction through process improvement. Much of the research work done in machining economics area is based on forward approach wherein the process parameters are determined and cost is calculated for this set of parameters. This is the optimum cost. If there arises a situation where the machining cost of a product has to be cut down, to achieve a target cost so that the product realizes its desired profit, the machining process plan has to be changed or a new process plan has to be developed. The machining parameters, cutting tool, the raw material, labor or even the machine may have to be 
changed and all alternatives have to be assessed to obtain the target cost. Several trials have to be carried out with different combinations of tools, cutting parameters, labor and machine to achieve this objective. The general procedure is as shown in Figure 1.

On the other hand if there existed a structured approach to obtain a good set of feasible process parameters, which could satisfy the target cost, it could result in considerable saving of time and resources. This emphasizes the need to develop a structured targetcosting model to obtain a good process plan that realizes the target cost.

Many researchers have reported cases where target-costing has been applied during the early stages of product development. This concept has been seldom applied at later stages of product life cycle. According to Shank \& Fisher [21], target-costing seems to be applied mostly at the early stages of product development, but the target-costing principle can also be applied at a later stage of the product life cycle. They report a case, which shows how a paper mill reaped the benefits by applying target-costing in manufacturing and regained market share. Extensive literature review revealed that this concept has not been applied in the machining arena.

A need was felt to analyze the machining operations, and hence an attempt is made in this study to apply the concept of target-costing in machining in general and turning in particular. The study reveals a structured approach to achieve the target cost in turning. The turning operation was selected, as it is one of the most widely used machining operations.

\subsection{Research Objectives}

1. Apply the concept of target-costing in machining. 
2. Develop a target-costing model for turning operation to determine the machining process parameters and obtain the target cost.

3. Verify and validate the model over a range of cutting tools, labor and machines.

4. Develop a software program to handle the complexity of the iterative process.

5. Sensitivity Analysis of the system.

\subsection{Assumptions}

1. Taylor's extended tool life equation $\mathrm{VT}^{\mathrm{n}} \mathrm{f}^{\mathrm{m}} \mathrm{d}^{\mathrm{p}}=\mathrm{C}$ to determine the optimum cutting speed and feed rate for specific machining conditions.

2. Geometric programming model for determining optimum cutting speed and feed for a given depth of cut and cutting tool.

3. Availability of organizational databases of tools, labor and machines.

4. Tools database consists of tool life constant and exponents for different tools.

5. Machine database consists of rapid traverse rates for different machines.

6. Labor database consists of setup times, loading and unloading times and tool changing times for different categories of labor.

7. Carbide insert is discarded after a certain number of parts are machined.

8. The tool shank is discarded after a certain number of parts are machined.

\subsection{System Diagram}

The current and the proposed system diagrams are shown in Figure 1 and Figure 2 respectively. The current system diagram shows an unstructured approach to cost reduction. Several trials are conducted and various parameters are tweaked to reduce the 
machining cost, based on the experience and expertise of the person handling the problem. In such cases trade offs between two or more outcomes are often given more importance. Since the problem solving technique is based upon the "feel" of the person, the result obtained may not give the desired results or considerable efforts may be required to achieve the target cost. This type of approach is common on shop floor where the operator may increase or decrease the speed of the machine depending upon the workload.

Figure 2 shows a structured approach to cost reduction to meet the target cost. The user inputs the current process and the program calculates the unit cost for the process. The user then inputs the target cost in the form of percentage reduction in the unit cost required. The current process unit cost is compared to the target cost and if the target is reached, the program ends. If the target cost is not achieved, the target-costing algorithm examines different alternatives based upon their relative importance and their potential to achieve the target cost. The programs ends after achieving the target cost or after all alternatives are examined. 


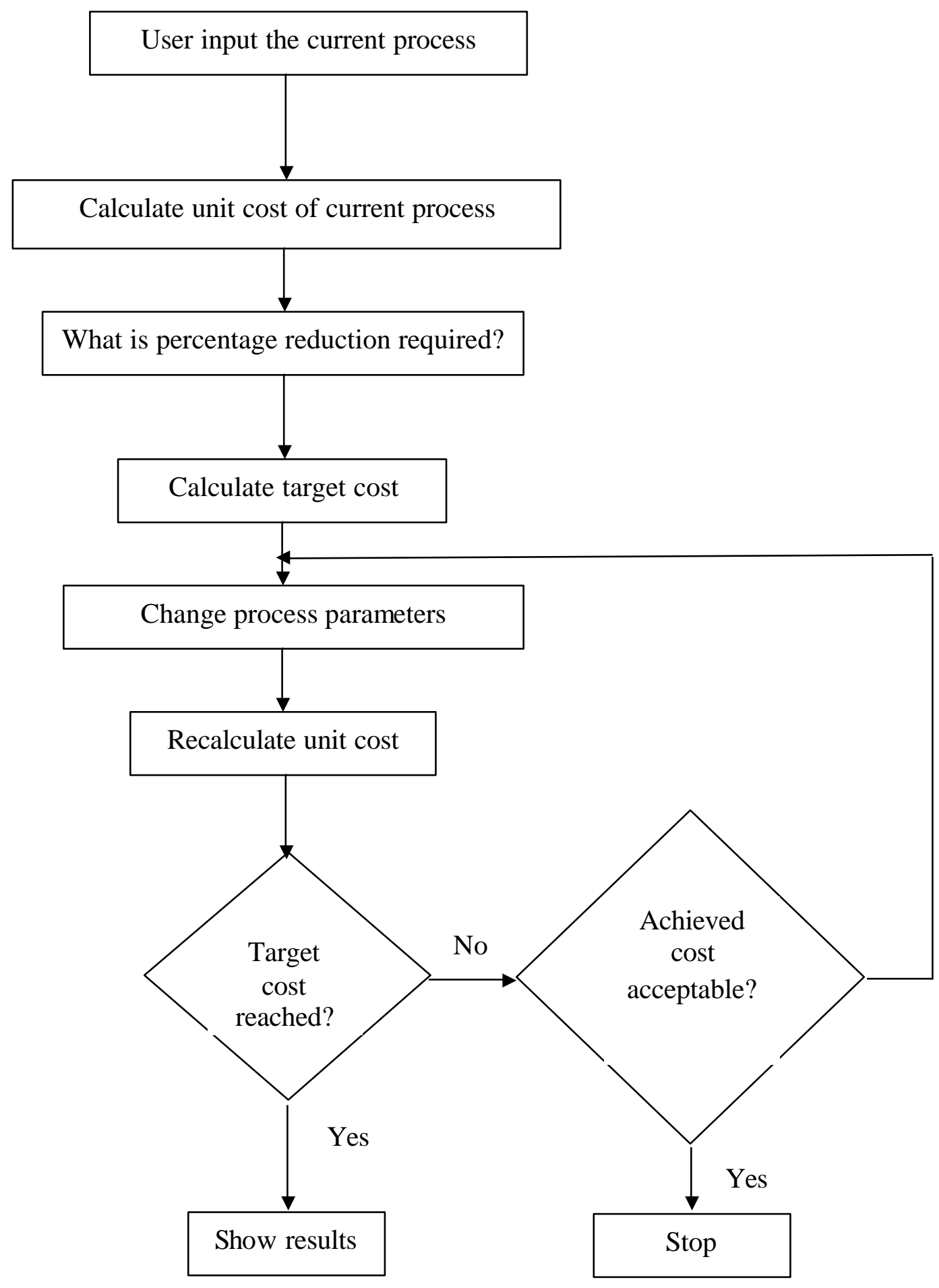

Figure 1. UnSTRUCTURED APPROACH TO ACHIEVE TARGET COST 


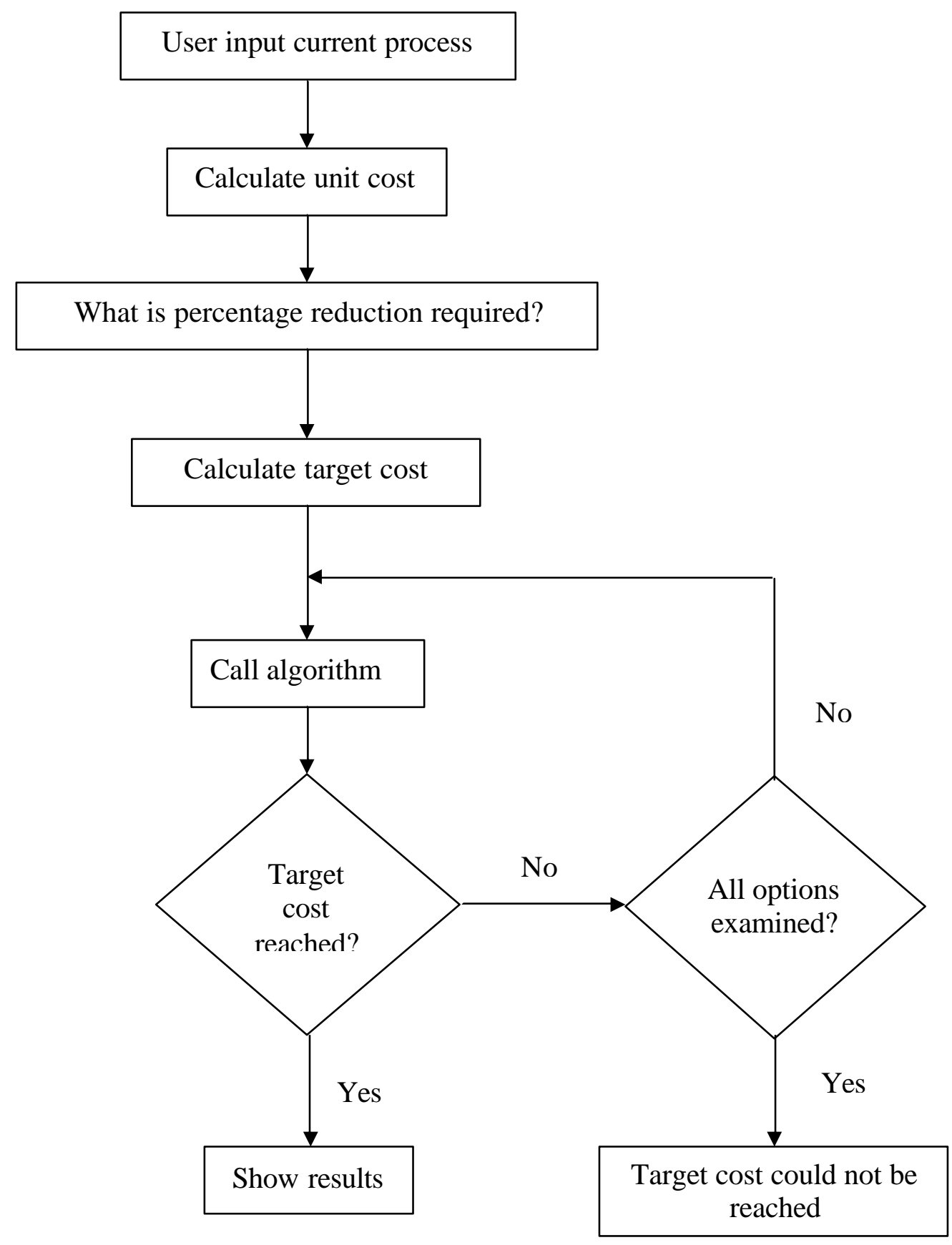

Figure 2. STRUCTURED APProACH To ACHIEVE TARget CoST 


\subsection{Conclusion}

Target-costing philosophy is widely used for achieving cost reduction during the design and development of a new product or the cost reduction of an existing product by combining various techniques like value engineering, quality function deployment or simple functionality analysis. This enables a company to generate more profits by reducing the manufacturing cost or reduce the product price to increase market share. This research aims at exploring the benefits of target-costing in turning operation. 


\section{CHAPTER 2}

\section{LITERATURE REVIEW}

In competitive markets, prices of the product are decided by the market. Large number of competitors can offer similar products at keen prices and consumers will expect greater value for their money. Hence it is the job of the producer to sell their products at a price that the market expects and is prepared to pay. To ensure the continuing survival and growth, the company needs to make a financial return on the products sold. They must be made at a cost that meets the market's expectations on price and make a profit. Many companies have turned to target-costing to achieve these objectives.

\subsection{Target-costing History}

Target-costing has a history of more than 40 years in Japanese industry. In 1959 Toyota invented target-costing as it has developed in Japan. Although many manufacturers in Japan use target-costing, the system used at Toyota Motor Corporation is the oldest and considered by many the most technically advanced. While the idea of systematic cost reduction had existed at Toyota since it was founded, the process was first codified in the mid-1960s, when the firm set itself the objective of producing a $\$ 1000$ car [5].

\subsection{Target-costing Definitions}

Target-costing (Genkakikaku in Japanese) is defined in many ways, but its goal is cost reduction. It is a system to support the cost reduction process in the development and 
designing phase of an entirely new model, a full model change or a minor model change [16]. Target-costing is not actually a form of costing. Rather it is a comprehensive program to reduce costs [12]. It is a process for ensuring that products and services are designed such that the company can sell them cheaply and still makes a fair profit [31]. Target-costing is a strategic cost management concept for reducing cost over the entire life cycle of a product [11]. Target-costing is a structured approach to determine the cost at which a proposed product with specified functionality and quality must be produced in order to generate the desired level of profitability over its life cycle at its anticipated selling price [5]. Accordingly target-costing has multiple objectives of cost reduction, quality assurance, timely introduction of new products into the market and product development to attract customers.

\subsection{Approach To Target-costing}

Different authors present varied ways to achieve the target cost. Target-costing can be achieved by taking various types of actions. The first category includes those actions that achieve target costs by increasing production. The second category of actions includes those that decrease the product's fixed or variable costs by increasing some other component of cost. Finally, the third category of actions includes those that reduce the

product's variable or fixed costs [31]. Target-costing projects can pursue the routes of total cost management, cost cutting and cost shifting to reach their goals [1]. 


\subsection{Target-costing In Industry}

Target-costing has been successfully applied in process industries as well as in assembly industries. It produces much better results when combined with simultaneous engineering. Target cost management together with simultaneous engineering helps generate unique ideas for product development and cost reduction [26]. Nissan Motor Corporation's approach to total cost control entails a strategic approach, utilizing targetcosting principles [3]. At Lucent Technologies, target-costing has been applied on both existing and new products ranging from business telephones, to wireless mini-cells and more. The phrase "Set the target; achieve the target; maintain the target" is used at Lucent Technologies to summarize target-costing [5]. Motor Division, Goldstar Company Ltd., in South Korea uses target-costing in conjunction with value engineering to obtain the target costs of the final products [24]. Target-costing has been adopted by many successful market leaders such as Mercedes, Kodak, Boeing, Chrysler and Goodyear [6], [18], [12] and [26].

\subsection{Machining Economics}

The machining economics problem, with respect to the turning operation has been investigated to no end. Considerable research has been done to determine the constrained machining parameters. Taylor [28] focused on investigating the efficient range of machining parameters through experimental studies; over a period of 26 years, he conducted numerous experiments at Midvale Steel Company to achieve metal cutting efficiency. Ever since, many mathematical models have been developed to determine the optimum cutting conditions for either single pass or multi-pass turning. Extensive 
literature review revealed that Geometric Programming [18], [29] and [30]; Lagrange multiplier [2]; a combination of linear and geometric programming [8]; and Goal programming [9] and [23] were some of the optimization techniques used by researchers in this area. An analytical approach to select machining parameters for turning with constraints was developed by Gopalakrishnan and AlKhayyal [10] based on geometric programming; F.P. Tan and R. C. Creese [25] developed a generalized multi-pass machining model based on sequential linearization optimization. Variable flow stress machining theory has been used to predict cutting forces and stress to check process constraints depending upon which, optimum cutting conditions have been determined [14]. A knowledge-based expert system has been developed to automate the process planning functions and determine the machining parameters by R. V. Narang and G. W. Fischer [17].

The main objective of these process planning systems has been either to minimize the cost or to maximize the production rate. Some authors have also considered a combination of three criteria simultaneously: minimum unit production cost, minimum unit production time and minimum number of passes [15]. The objective function to minimize the machining cost has traditionally consisted of cutting costs and tool costs. Some researchers have also considered including the "other" costs such as in-process inventory costs and penalty costs for not meeting the demand [21], non-productive costs of loading, unloading and inspection [20], and costs due to loss of quality when the quality characteristic of the part deviates from its target value [13], even though they may not be directly related to machining economics. All these models strive $\mathbf{b}$ select an optimum set of machining parameters, which are then utilized to obtain the machining 
cost. These models follow a forward approach; by first selecting a set of machining parameters, and then determining the machining cost.

\subsection{Conclusion}

In this chapter, the target-costing history and its development were discussed. Various definitions of target-costing as proposed by different authors and industry leaders and its applications in industry were cited. Some methods of achieving the target cost were stated. The later part of the chapter was dedicated to the machining economics problem. Various methods of achieving the optimum cutting conditions and machining cost as published by several authors were mentioned. 


\section{CHAPTER 3}

\section{SYSTEM DEVELOPMENT}

\subsection{Design And Development Of The Algorithm}

The algorithm developed in the present study was designed after reviewing the turning process and the associated costs. The machining cost comprises of costs pertaining to the machine time, cutting tools, work-piece material and costs associated with rejection and rework. The total machine time cost and the total tool costs can be divided into their respective components. Depending upon the cutting parameters selected, the percentage of each cost component in the unit cost changes. Hence the reduction in the highest cost component will have the largest effect in reducing the unit cost of the product. The algorithm was developed based on the "Pareto Principle" where the causes of a problem are arranged in descending order of severity and efforts are directed at resolving the cause with highest effect first. The cost components are arranged according to their percentages in the unit cost from highest to lowest and the cost component with highest percentage is targeted for reduction. The algorithm takes the current process and the current costs as a base case and then tries to make improvements in the process thereby reducing the cost components. It is shown graphically in Figures 3 to 12. A Geometric Programming model [9] was used to calculate optimum cutting speed, and feed for a given depth of cut and cutting tool, thus satisfying the surface finish, and machine power constraints.

The algorithm tries to minimize the cost components with maximum contribution to the unit cost in a sequential order after arranging the cost components in decreasing order and 
the component with maximum contribution is targeted for reduction. The parameters involved in the calculation of that cost component are replaced with values either from the database or from the user input. The unit cost is calculated and compared with the target cost. If the target cost is reached, the algorithm stops and shows the results. Otherwise, the process is repeated until all the combinations from the database are exhausted or there is no scope for any further improvements.

Different cutting tools are analyzed for reduction in feeding cost and different machines are examined to reduce the rapid traverse cost. If these combinations do not result in satisfying the target cost, the user is prompted to improve some other parameters based on which the unit cost is recalculated.

\subsection{Geometric Programming Model Background}

The geometric programming model developed by Gopalakrishnan and AlKhayyal was used in the development of this algorithm. The setting of the machine parameters in turning operation determines the cost of the machining process. The rate and cost of production depend on the cutting speed, feed and the depth of cut. The depth of cut is usually fixed for a particular pass in turning operation and in this case the cutting speed and the feed are the only variables in the minimization of the production cost or the maximization of production rate. The major constraints affecting the turning process are related to the required surface finish of the product being machined, and the maximum power, which the machine tool can provide for the operation. The geometric programming model developed by Gopalakrishnan and Al-Khayyal uses Taylor's 
extended tool life equation, $\mathrm{VT}^{\mathrm{n}} \mathrm{f}^{\mathrm{m}} \mathrm{d}^{\mathrm{p}}=\mathrm{C}$ to determine the costs due to losses in tool life, and due to the time incurred in removing a defective tool and replacing it.

In the above equation, $\mathrm{T}$ is the tool life in minutes, $\mathrm{V}$ is the cutting speed in inches/minute, $\mathrm{f}$ is the feed in inches/rev, and $\mathrm{m}, \mathrm{n}, \mathrm{p}, \mathrm{C}$ are constants based on the tool material and workpiece material.

\subsection{Geometric Programming Model Nomenclature}

$\begin{array}{ll}\text { HPmax } & \text { maximum horse power available } \\ \text { Sfmax } & \text { surface finish acceptable } \\ \mathrm{Cm} & \text { coefficient in machine power constraint } \\ \mathrm{Cs} & \text { coefficient in surface finish constraint } \\ \mathrm{n}, \mathrm{m}, \mathrm{p} & \text { coefficients in tool life equation } \\ \mathrm{b}, \mathrm{c}, \mathrm{e} & \text { exponents in machine power constraint } \\ \mathrm{g}, \mathrm{h}, \mathrm{i} & \text { exponents in surface finish constraint }\end{array}$

\subsection{The Algorithm}

The algorithm shown in a graphical format in figure 3 is described in the following seven steps.

1. Read the current process and calculate current unit cost.

2. Calculate the target cost based on the percentage reduction required.

3. Select the first cutting tool from the database and calculate the unit cost. If the target cost is reached, then go to step 6. If the target cost is not reached and the new unit cost is less than the current unit cost, then retain the new cutting tool, else reject it. 
Select the next cutting tool and repeat the process till target cost is reached or all cutting tools are explored.

4. Sort the cost components in descending order. If the highest cost component is rapid traverse cost, then chose the first machine from the database and calculate the new unit cost. If the target cost is reached, then go to step 6. If the target cost is not reached and the new unit cost is less than the current unit cost, then accept the new machine else reject it. Repeat the process till target cost is reached or all machines are explored.

5. If the highest cost component in step 4 is not rapid traverse cost, then prompt the user for improvements. If the target cost is reached, then go to step 6, else prompt user for further improvements till all options are explored.

6. If target cost is reached then print, " Target cost achieved" else print, "Target cost could not be achieved".

7. Show the details of the process.

Figure 3 shows the program logic, which epitomizes the algorithm. The program acquires the current process details from the user and calculates the unit cost of machining. The user is then prompted to enter a target percentage reduction based upon which the target cost is calculated. The program then selects the highest cost component for cost reduction and prompts the user to enter the percentage improvement that could be achieved in the factors affecting that cost component, so that the unit cost of the product can be reduced to meet the target cost. The user can enter " 0 " if improvements are practically infeasible. The unit machining cost is recalculated and compared to the target cost. The program stops further calculations if the target cost is reached; else the next highest cost 
component is selected for cost reduction and the process is repeated. After the targetcosting process is completed the program enables the user to view the information in graphical as well as tabular format. The graphical format shows the user, the number of iterations required to achieve the target cost and how the cost varied between iterations. The tabular format gives the details of the changes that occurred between iterations.

\subsection{Scope Of The Target-costing Program}

The program is interactive in nature and elicits responses from the user. It presumes that the user has knowledge about the process and knows the feasibility of performing the improvements suggested to achieve the target cost. The program arranges the cost components sequentially from highest to lowest and prompts the user to improve upon the factors affecting these cost components. If improvements cannot be made fr some factors, the user can enter " 0 " when prompted. The user also has to understand that the improvements suggested by the program involve implementation costs to bring about necessary process changes. Deciding whether the cost component can be reduced or not and its implementation cost depends upon the user and is out of scope of this program and this research work.

When the target-costing program prompts the user to enter percentage by which the setup time can be reduced, it assumes that the user knows if and how the reduction can be made, what changes are required in the process to bring about this improvement and has a fair idea about the cost involved in performing the improvement. The user has to perform a cost benefit analysis about the improvement in setup time and the monetary gain achieved. This program prioritizes the cost components and provides the user with 
opportunities to direct resources towards those cost components that have a high effect on the unit cost of the product. The program does not suggest what is required to implement the changes in the process parameters and their implementation costs as this is outside the scope of this research work.

The program comprises of a main program and consists of modules for each cost component, which will be discussed in the upcoming pages. 


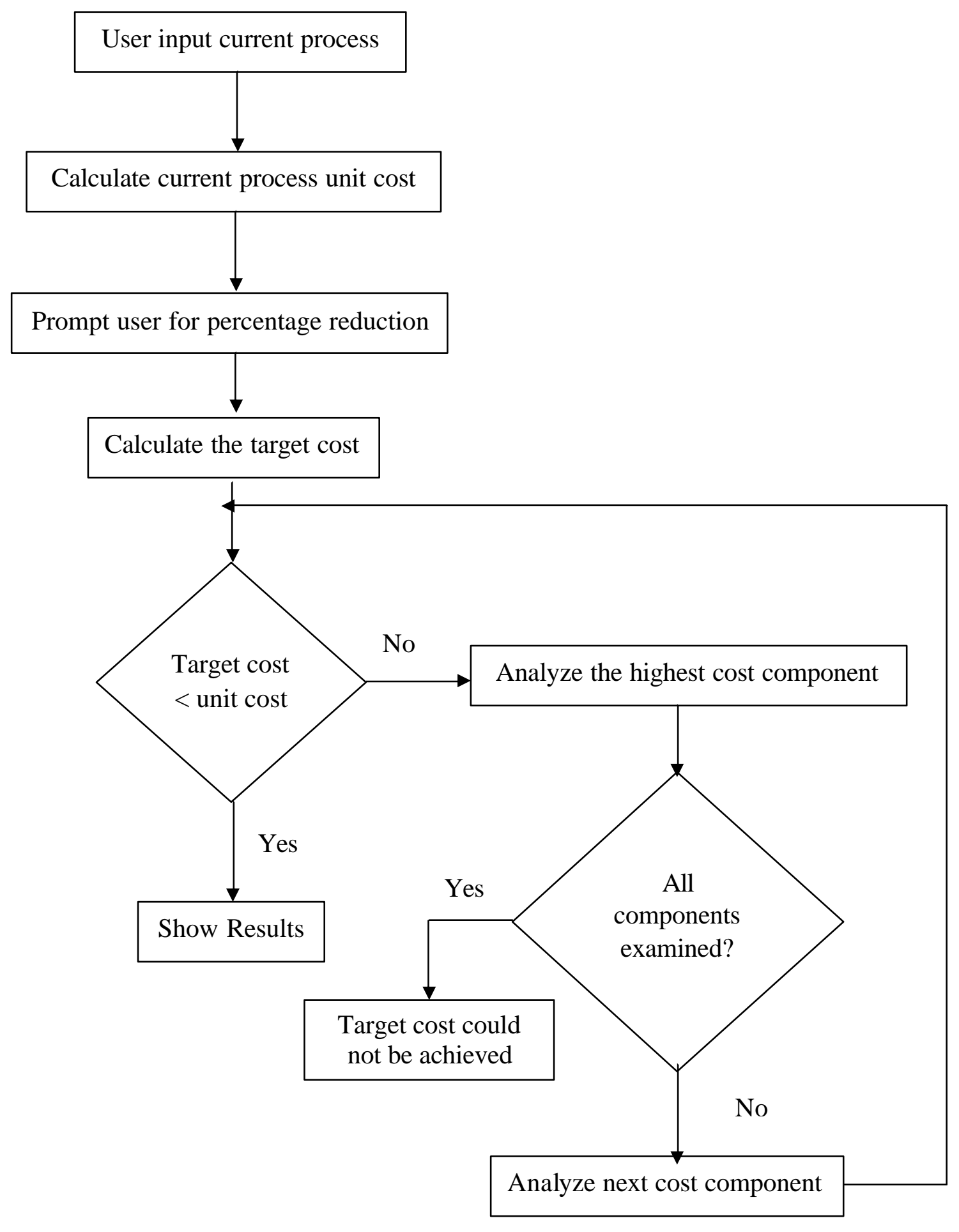

Figure 3. Program Logic 


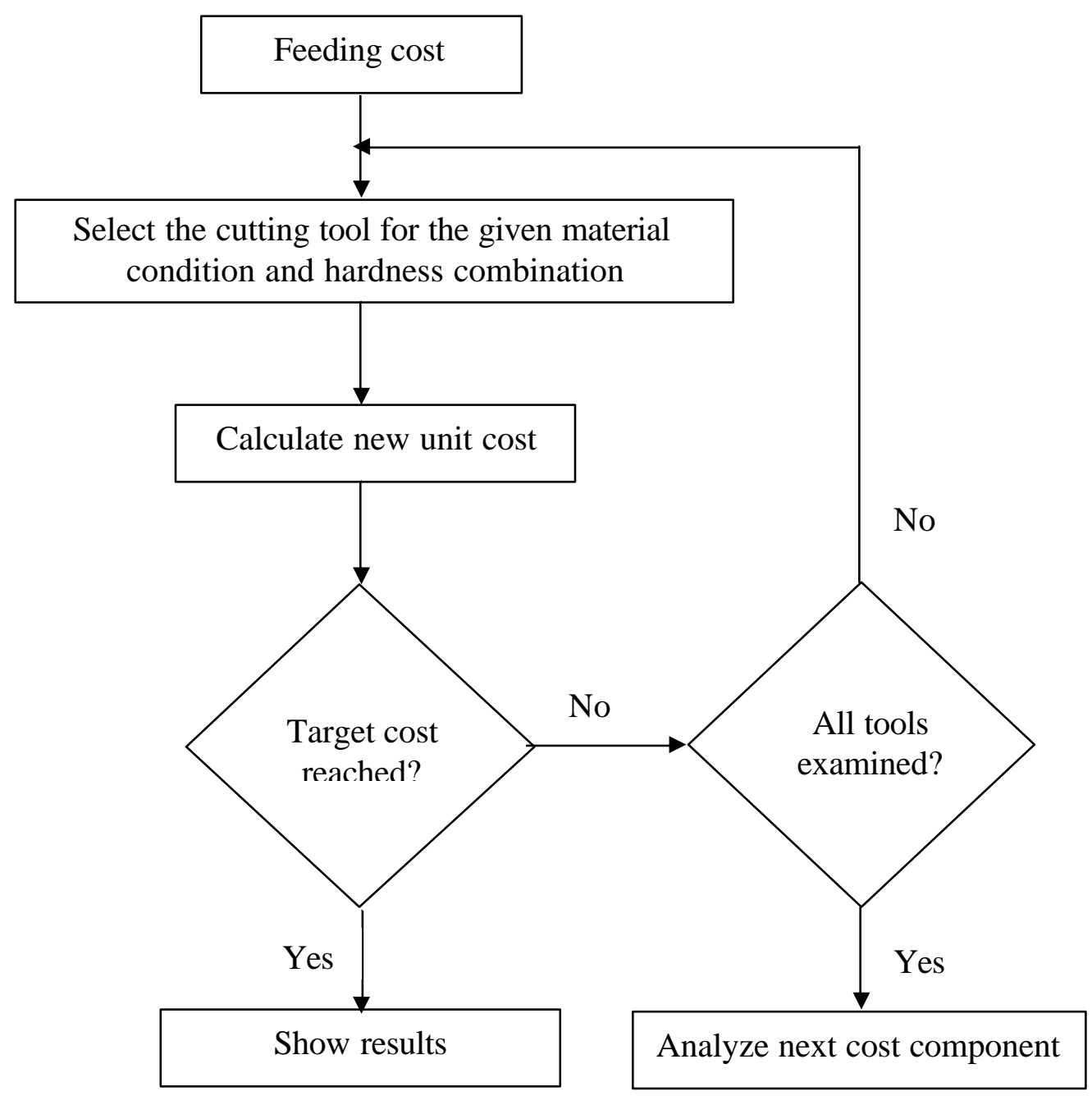

Figure 4. FeEding Cost Module

Figure 4 shows the feeding cost module. The feeding cost depends upon the cutting speed, feed rate, depth of cut and the tool life, which are dependent upon the selection of the cutting tool. Hence this module tries to reduce the feeding cost by examining different cutting tools and selecting the one that gives the minimum feeding cost. The unit cost is calculated and compared to the target cost after each cutting tool selection. If the target cost is not reached and all the tools are examined, the program retains the tool that gives the minimum cost and transfers the logic to the next module. 


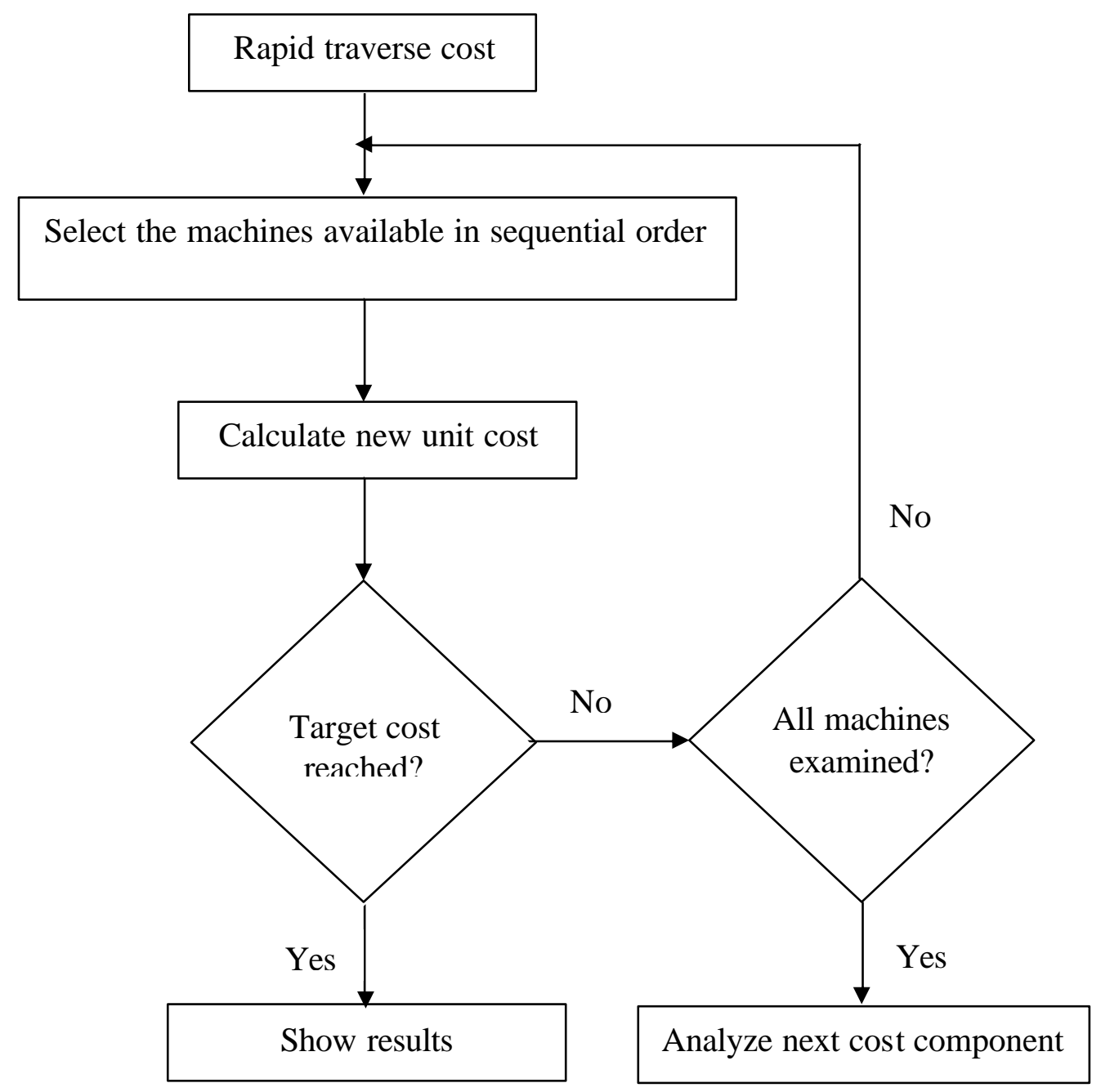

\section{Figure 5. RAPID TRAVERSE COST MODULE}

The rapid traverse cost module is shown in figure 5. The rapid traverse rate is dependent upon the machine and therefore this module tries to reduce the rapid traverse cost by examining different machines and selecting the one that gives the minimum rapid traverse cost. The unit cost is calculated and compared to the target cost after each iteration till the target cost is reached or till all machines are examined. If the target cost is not reached and all the machines are examined, the program retains the machine that gives the minimum cost and transfers the logic to the next module. 


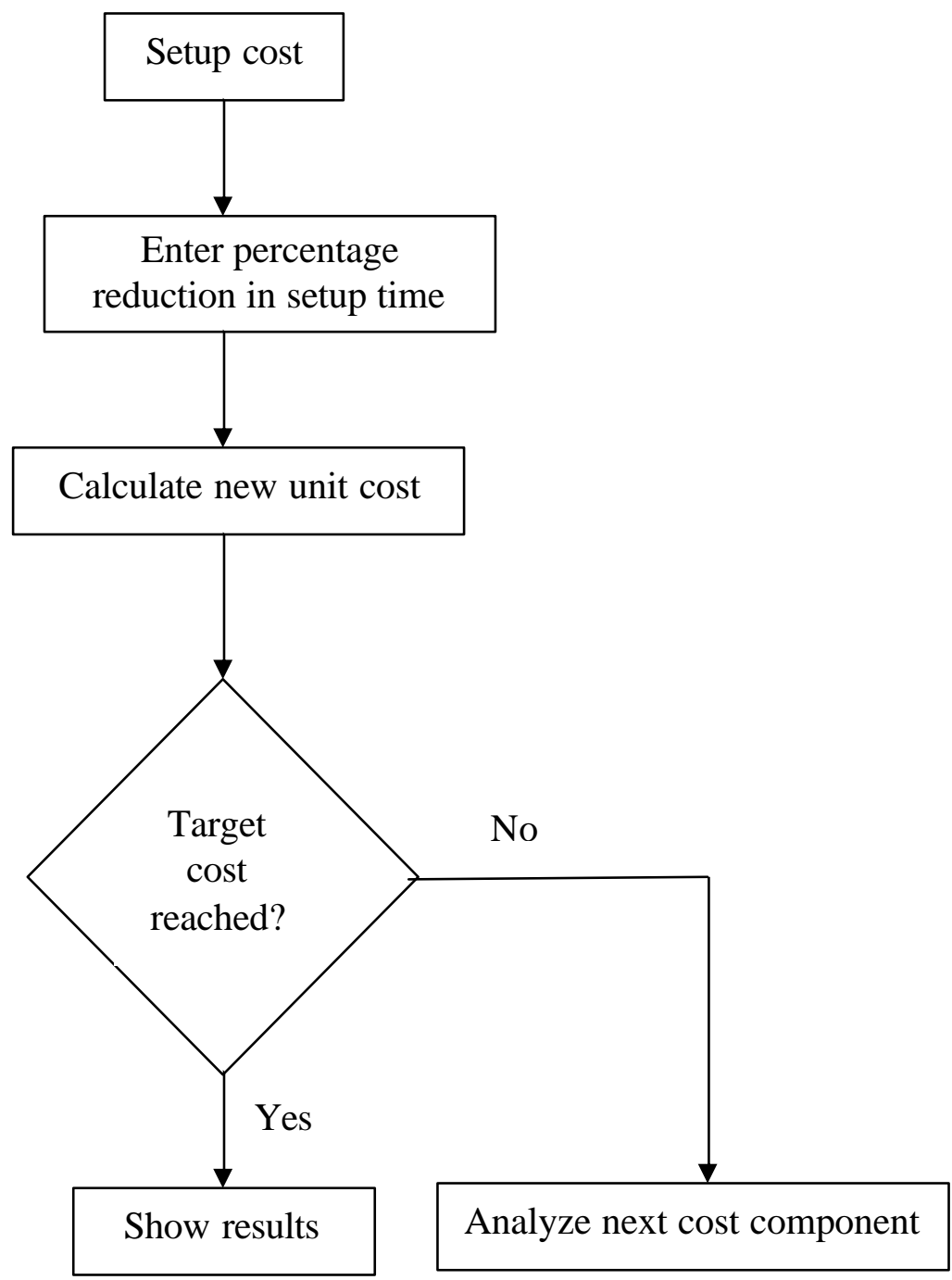

Figure 6. Setup CoSt Module 


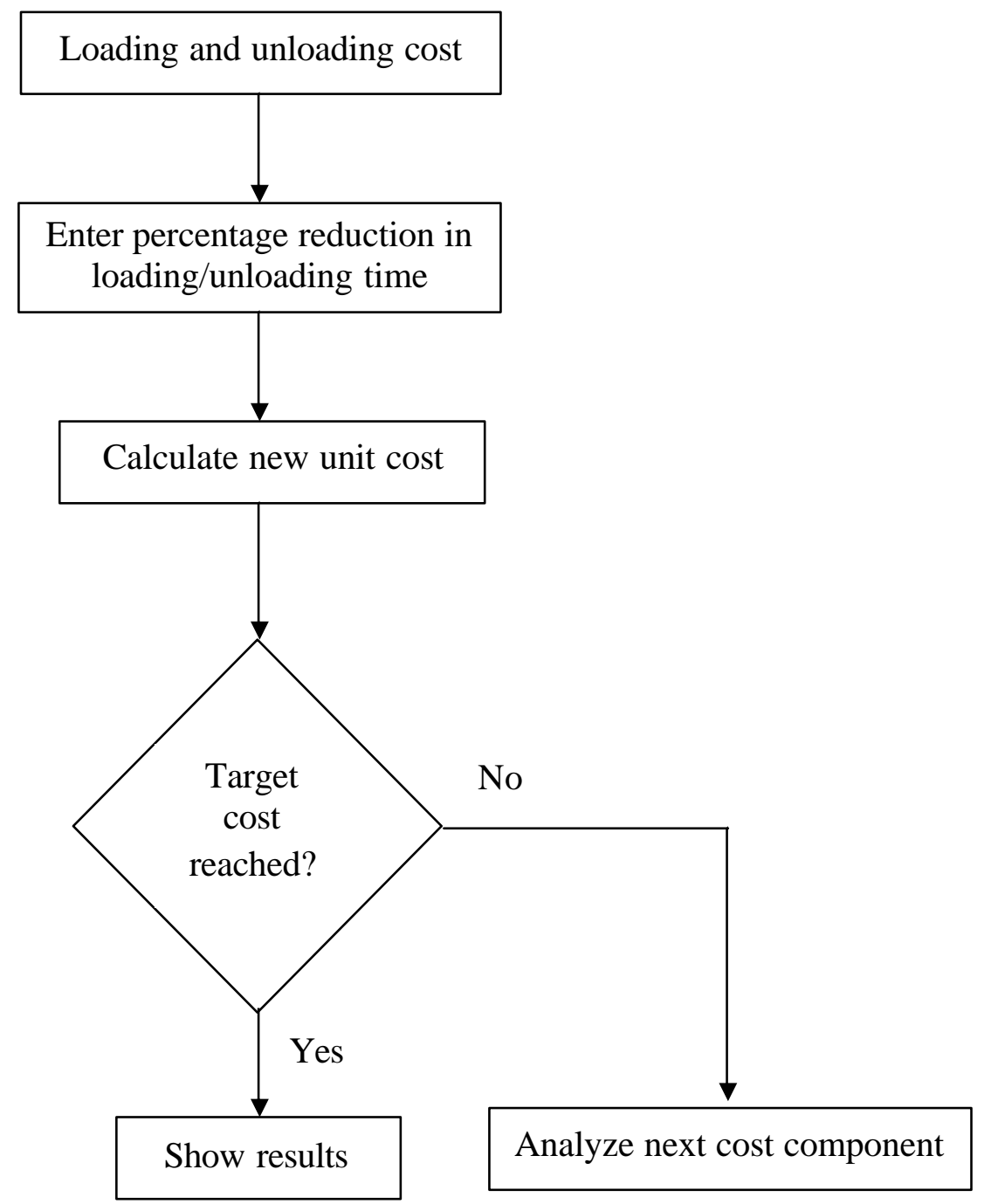

Figure 7. LOADING AND UNLOADING COST MODULE 


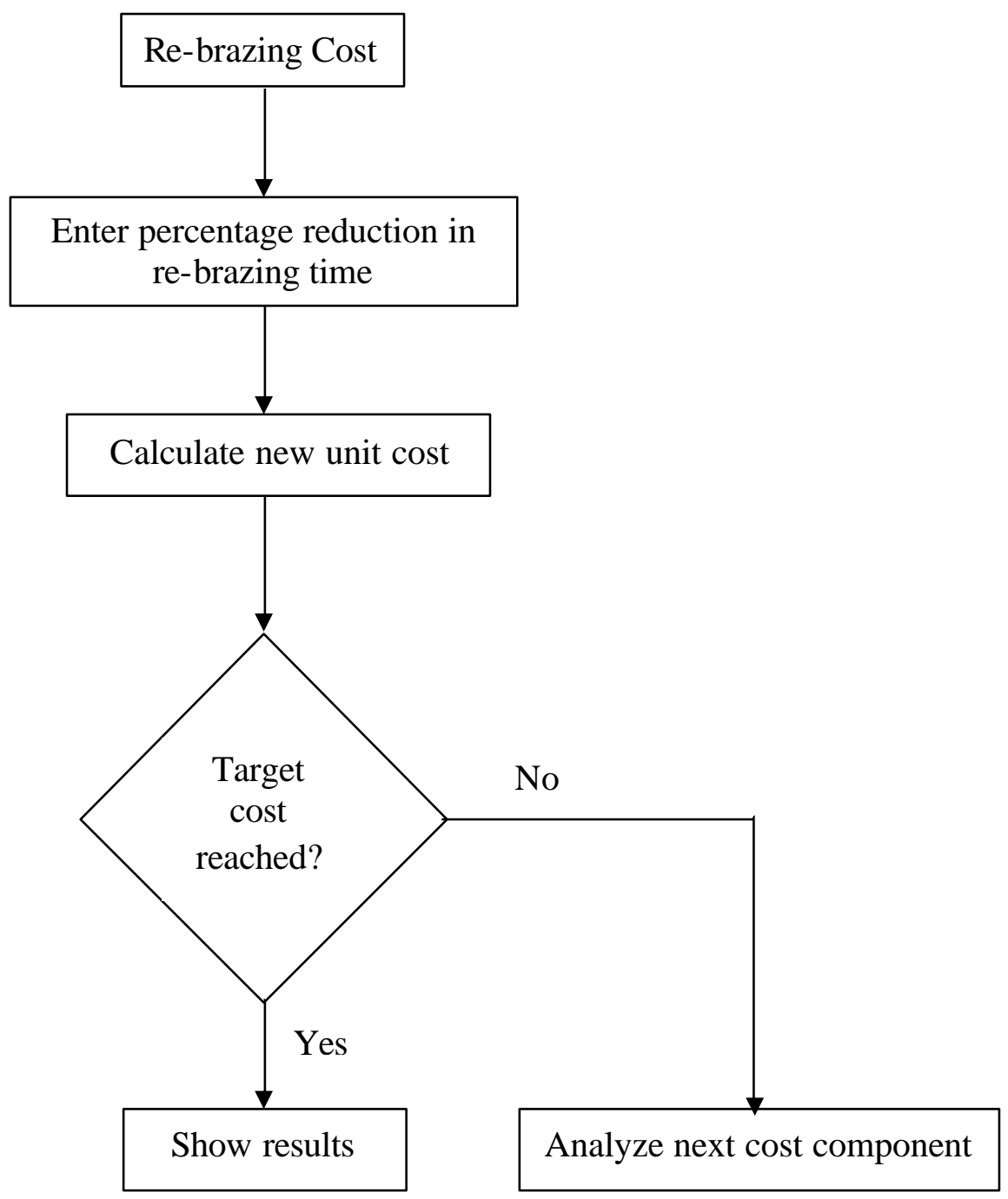

Figure 8. Rebrazing Cost Module 


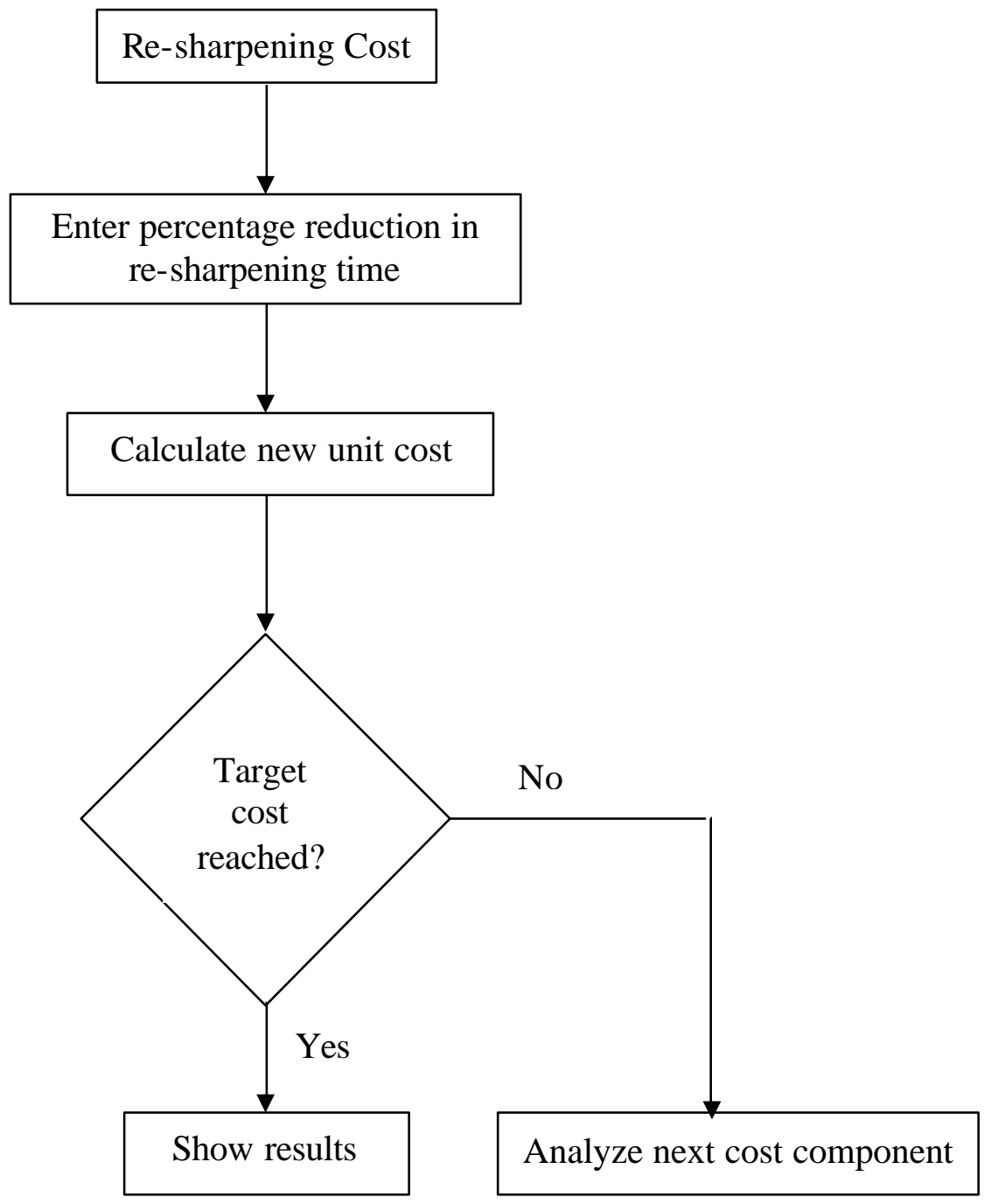

FiguRE 9. RESHARPENING COST MODULE 


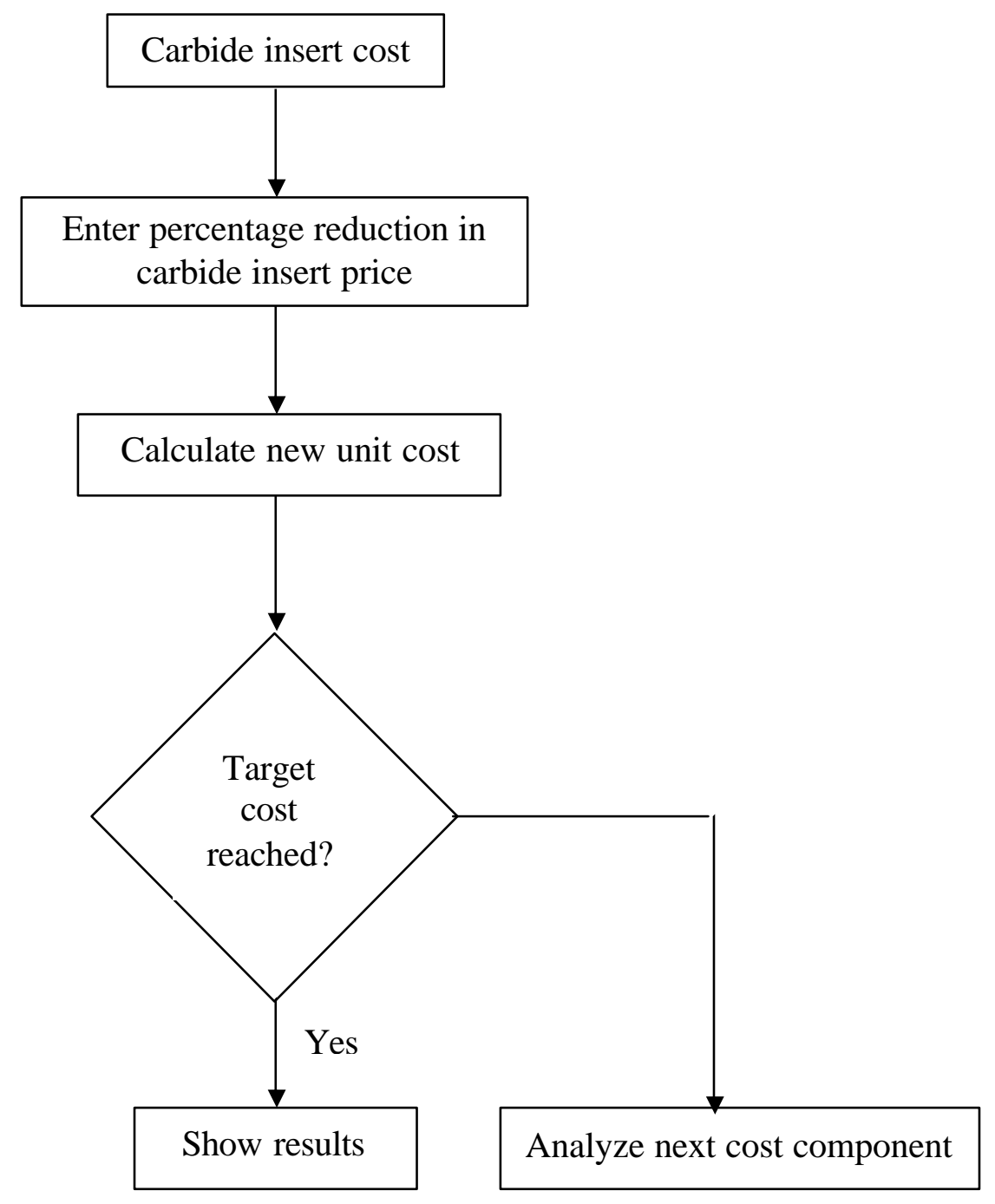

Figure 10. CARbide InSERT CoST MOdule 


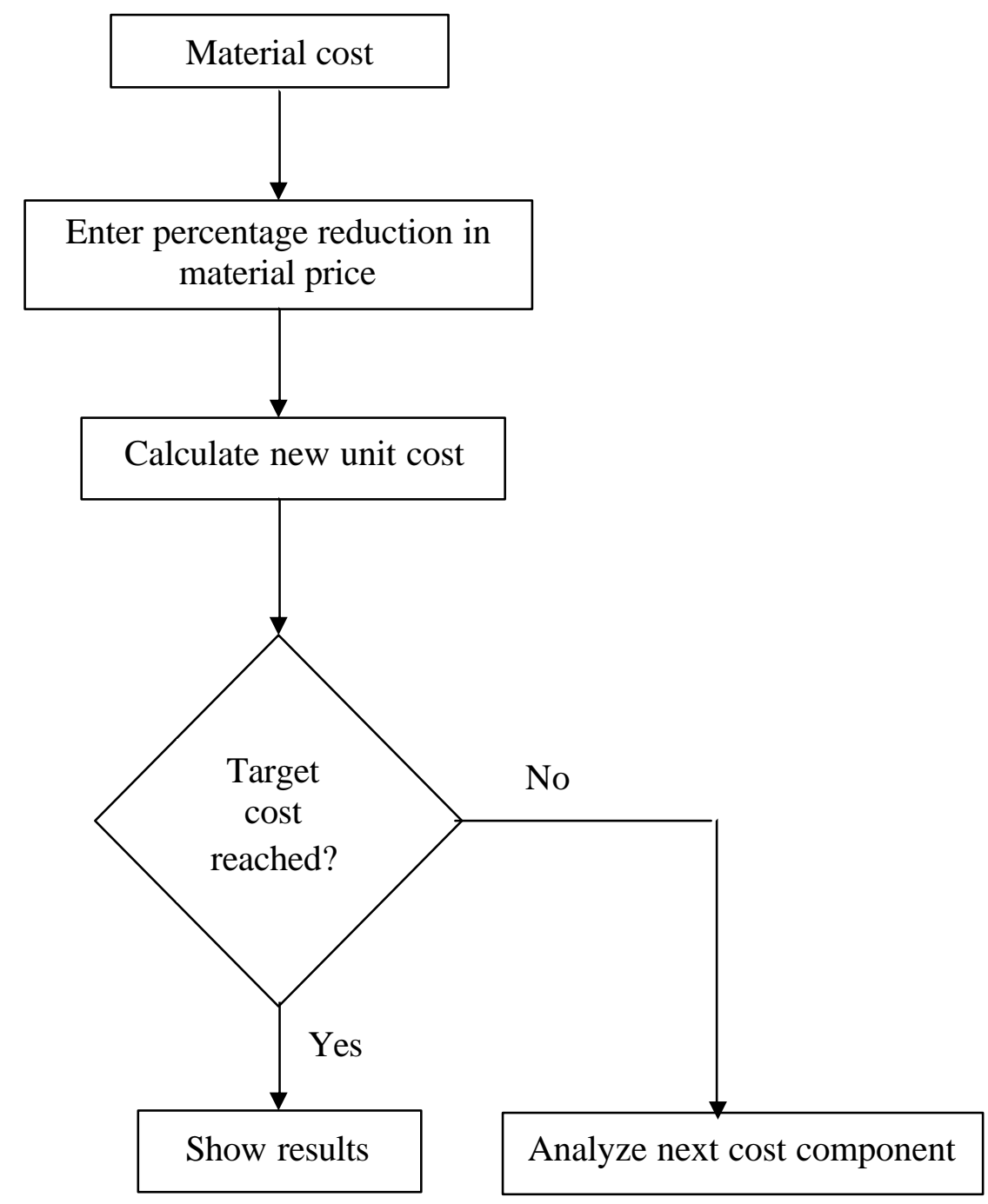

Figure 11. MATERIAL CoST Module 


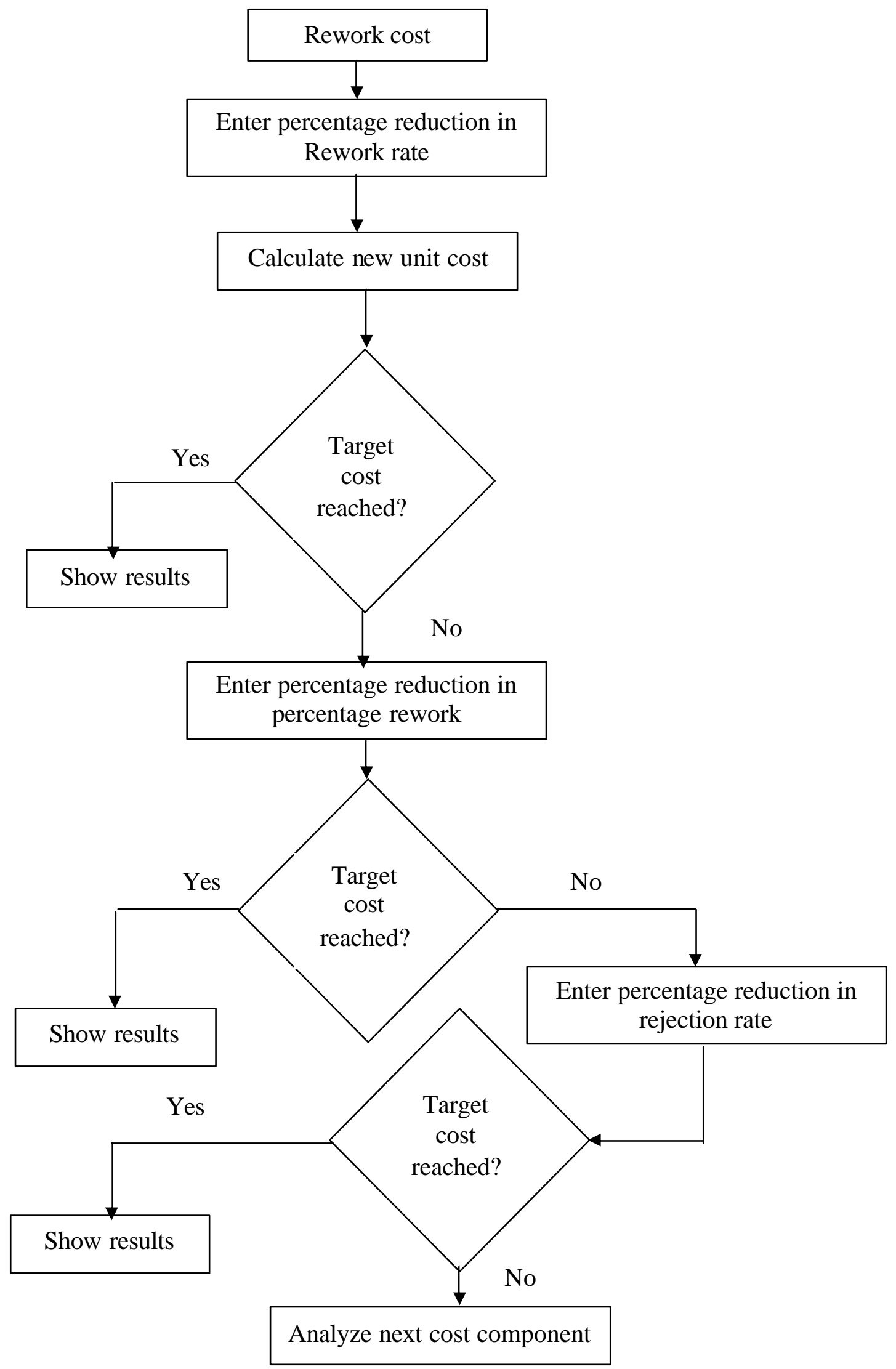

FiguRE 12. R EWORK COST MODULE 


\subsection{Code Development}

The user interface was developed using Microsoft Visual Basic version 6.0. Visual Basic is an object oriented programming language, which is used to design the user interface. The various objects are forms, textboxes, list-boxes, labels, grids and many others. Forms are the basic objects or the background on which various controls such as text boxes, buttons, list-boxes, labels etc are arranged. A source code or a program to perform specific tasks then ties up these controls. The tasks may be simply reading an input or performing a calculation or showing an output. The user interface consists 7 forms and a module. A module is a program space consisting of subprograms, subroutines and variable declarations that are called by the main programs repeatedly. The input screen shown in figure 13 allows the user to enter the data for the current process. This data consists of the design requirements for the product, the machining parameters and constraints on machine power and surface finish. The program checks if all the data was entered and prompts the user if any data fields are left blank. The second input screen shown in figure 14 prompts the user to select the cutting tool and its related parameters for the current process. The program then calculates the unit cost and the current process output screen in figure 15 details the cost components. It also provides the user with an option to enter the percentage reduction required in the unit cost. This percentage reduction is required to calculate the target cost. After determining the target cost, the cost component contribution screen in Figure 16 arranges the cost components of the current process according to their contribution to the unit cost starting from highest to lowest. It also shows the percentage contribution of each cost component. After clicking on the "Achieve Target Cost" button, the algorithm is called which prompts the user for 
improvements in the current process. A note is displayed suggesting the user if the target cost was achieved or not. Figure 17 shows a comparison between the cost components before and after the target-costing process. The program also allows the user to see the variation of the unit cost for different iterations in a graphical format as shown in figure 18.

\subsection{Database Design}

The information pertaining to different work materials, cutting tools, machines and labor are stored in a database. The database, which is designed in Microsoft Access, forms the back end and the user interface forms the front end. The database is in the form of tables and the tables consist of several fields and records. The columns are called fields and the rows are referred to as records. A table consisting of several machines will have a record for each machine and each record will have several fields. Each field may represent a particular characteristic for a machine.

The database in this model consists of several tables for different material conditions. Table 1shows data for a cold drawn material condition.

Table 1: Database table for Cold Drawn Material Condition

\begin{tabular}{|l|l|l|l|l|l|l|l|l|l|l|l|l|l|l|l|l|}
\hline ID & Condition & Hardness & $\mathrm{C}$ & $\mathrm{m}$ & $\mathrm{n}$ & $\mathrm{p}$ & Type & Cost & $\mathrm{dmax}$ & $\mathrm{G}$ & $\mathrm{Cw}$ & $\mathrm{ts}$ & $\mathrm{Lrb}$ & $\mathrm{tb}$ & $\mathrm{k} 2$ & $\mathrm{k} 3$ \\
\hline 11 & $\begin{array}{l}\text { Cold } \\
\text { Drawn }\end{array}$ & $175-200$ & 120 & 0.25 & 0.29 & 0.35 & HSS & 2 & 0.1 & 30 & 0.5 & 15 & 0 & 0 & 0 & 0 \\
\hline 12 & $\begin{array}{l}\text { Cold } \\
\text { Drawn }\end{array}$ & $175-200$ & 140 & 0.27 & 0.31 & 0.4 & $\begin{array}{l}\text { Carbide } \\
\text { tip }\end{array}$ & 3 & 0.3 & 30 & 0.5 & 15 & 30 & 15 & 50 & 0 \\
\hline 13 & $\begin{array}{l}\text { Cold } \\
\text { Drawn }\end{array}$ & $175-200$ & 160 & 0.29 & 0.35 & 0.43 & $\begin{array}{l}\text { Carbide } \\
\text { insert }\end{array}$ & 4 & 0.5 & 0 & 0 & 0 & 0 & 0 & 0 & 4 \\
\hline
\end{tabular}


The table consists the hardness of the material, different tools that can be used for machining this material, tool life coefficient and the tool life exponents for each tool and material combination. The table consists of other data like cost of the tool, labor and overhead on the tool grinder, cost of grinding wheel for re-sharpening the tool, tool resharpening time. A brazed tip carbide tool also has other data like re-brazing time and labor and overhead for brazing the carbide tip. The database consists of similar tables for different material conditions.

The database also consists of a machine table which contains the type of machine, the labor and overhead for each machine, the rapid traverse rate, maximum horse power available, exponents and coefficients in machine power and surface finish constraint and the tool handling times for each machine.

The database can be easily updated by inserting new information in the tables. The information entered in the database will have a significant effect on the results. Hence the database should be updated with realistic values in order to prevent inaccurate results.

\subsection{Conclusion}

The design and development of the target-costing algorithm was presented in this chapter. The steps involved in developing the algorithm were discussed and an analogy was made to the Pareto principle. The algorithm and the programming logic were elucidated in detail with the help of flowcharts. The later part of the chapter was dedicated to the development of the user interface using Microsoft Visual Basic programming language and the database design in Microsoft Access. 


\section{CHAPTER 4}

\section{SYSTEM BEHAVIOR ANALYSIS}

This chapter analyses the dynamics of the target-costing model and its application to turning process. The turning process consists of numerous parameters that are interrelated and the turning cost depends upon the selection of these parameters. The turning cost is made up of components like machine time cost, tool cost and material cost. The selection of process parameters affects the cost components and hence the turning cost. Since the process parameters are interdependent and their selection is a complex process, they have to be selected such that they meet the target cost. The target-costing model uses a structured approach to select these process parameters to comply with the target cost. The program is very interactive and elicits responses from the user. The path taken to achieve the target cost depends upon the behavior of all the parameters involved in the machining process. The system behavior will be explained with the help of an example.

The values of the tool life exponents, exponents in surface finish and horsepower constraint, and other coefficients used to verify the model were taken from the examples published by Gopalakrishnan et al.

The target-costing program starts with an input screen. The input parameters are categorized into four types. The first category is design parameters, which consist data like initial diameter, final diameter, work material, batch size, material condition and hardness, acceptable surface finish and the material price. These parameters are design requirements except the batch size and the material price, and hence cannot be changed. The batch size and the material price though are not design requirements and hence can be varied to achieve cost improvements. The second type of input requirement is 
machining parameters. This consists of machine related data like labor and overhead rate, tool-handling times, rejection rate and rapid traverse rate of the machine. These parameters are machine dependent and hence vary with the type of machine. The third category of input data consists of exponents and coefficients of the geometric programming model. Since the geometric programming model forms the part of the target-costing model, these parameters are required to be furnished by the user. The last category of input data is related to the cutting tools. The target-costing program consists of a tools base, which has three different types of cutting tools: high speed steel (HSS), brazed carbide tip and carbide insert. HSS is the lowest quality cutting tool in comparison to the other two. The cutting speeds at which it can be used are lower than the tools with carbide tip or carbide insert. It possesses lower hot hardness and hence cannot be used for machining applications where very high heat is generated. But its main advantage is low cost and hence can be used for low cost machining applications. The cutting edge can be ground repeatedly and hence it may prove economical in some cases. The brazed carbide tip cutting tool consists of a carbide tip that is brazed to a mild steel shank. This type of tool can achieve higher cutting speeds and the cutting edge can be machined to regain its sharpness. The carbide insert cutting tool consists of a carbide insert that is screwed in place on a tool holder. The carbide insert has more than one cutting edge and generally has a higher tool life compared to HSS or a brazed tip tool. When one edge breaks, the orientation of the insert is changed to expose a fresh cutting edge. It can be used at very high cutting speeds and possesses good hot hardness.

The first input screen is shown in Figure 13. This is the first step in the target-costing model. The input data is as shown. 


\begin{tabular}{|c|c|}
\hline \multicolumn{2}{|c|}{ Work-piece Parameters: } \\
\hline Initial Diameter & 6 inches \\
\hline Final Diameter & 5 inches \\
\hline Batch Size & 250 \\
\hline Material Condition & Hot Rolled or Annealed \\
\hline Hardness & $100-125 \mathrm{BHn}$ \\
\hline \multicolumn{2}{|c|}{ Machining Parameters: } \\
\hline $\mathrm{d}$ & 0.1 inches \\
\hline $\mathrm{M}$ & $60 \$ / h r$ \\
\hline $\mathfrak{t}_{0}$ & 25 minutes \\
\hline $\mathrm{t}_{\mathrm{ch}}$ & 5 minutes \\
\hline $\mathrm{t}_{1}$ & 1 minute \\
\hline $\mathrm{R}$ & 60 inches/min \\
\hline Rejection & $10 \%$ \\
\hline Rework & $10 \%$ \\
\hline Rework Rate & $30 \$ / \mathrm{hr}$ \\
\hline
\end{tabular}




\section{Current Process}
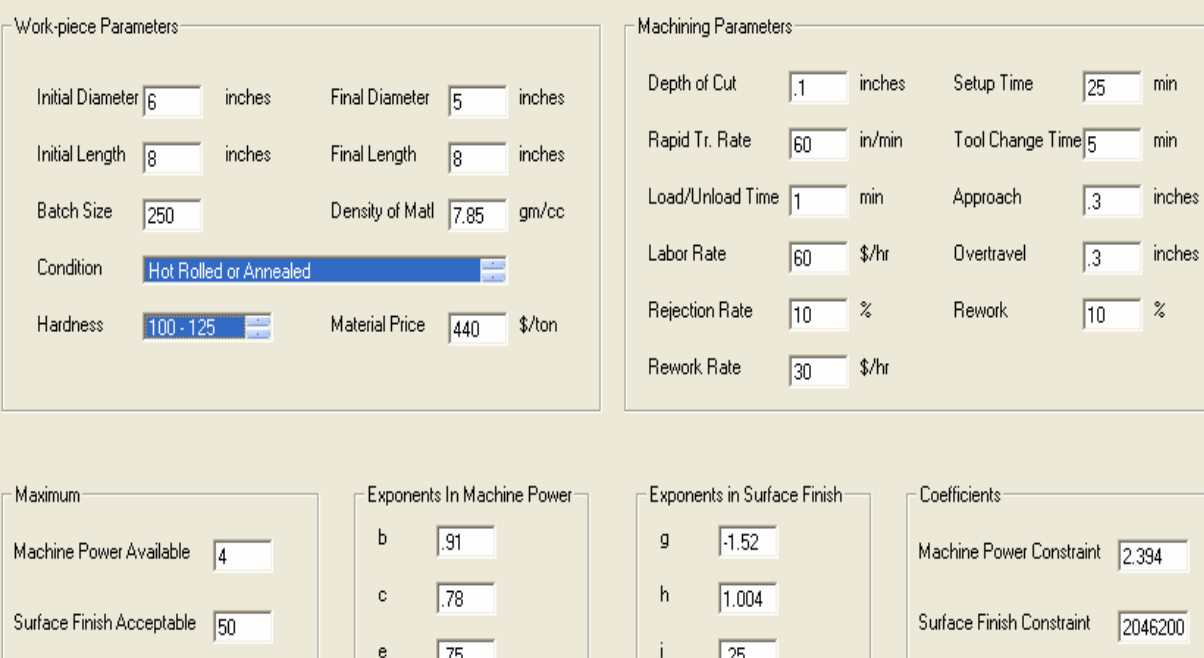

\section{FIGURE 13. INPUT SCREEN 1}

As described in the previous section, this screen has three parts. The user is required to enter all the information in the text boxes. The material condition and hardness can be selected from the drop down list. The user is also required to enter information related to the maximum horsepower available and the exponents and coefficients in the machine power and surface finish constraint. If the information is incomplete, the program gives a message on the screen that a particular data point is missing and instructs the user to enter data in that particular text box. Once all the information is complete, the user clicks on the "next" button to invoke the second input screen, which is shown in Figure 14. 


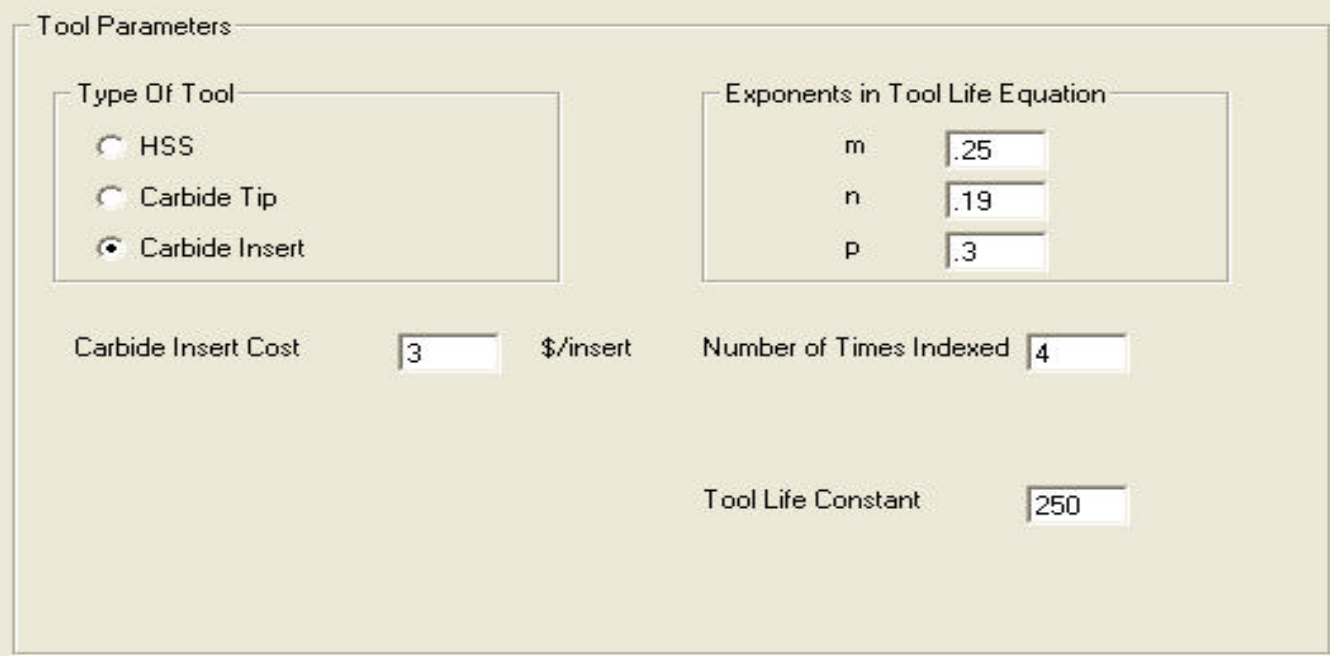

Back

Calculate

Fiesults

\section{FIGURE 14. INPUT SCREEN 2}

The second step in the target-costing process is tool selection. The second input screen allows the user to enter information about the cutting tool being used for the current process. The user selects a cutting tool from the three options and enters values for exponents in tool life equation, cost of the cutting tool and tool life constant. If the selected cutting tool is HSS then the user is prompted for labor and overhead on the tool grinder. The user also has to enter the labor and overhead for brazing if the cutting tool selected is a brazed carbide tip.

The tool data is as shown.

Cutting Tool Carbide Insert 
Cost of Tool $\quad 3$ \$insert

Number of edges $\quad 4$

C (Tool life constant) 250

After entering all the information the user then clicks on "calculate" button. This screen invokes the third screen, which is shown in Figure 15. This screen details the cost components in turning operation. All the cost components discussed in chapter 1 are displayed on the screen, which enables the user to see the breakdown of the total cost of turning operation. The screen also shows the unit cost for turning that product. The model uses the equations shown in chapter 1 to calculate the cost components and the unit cost. At the bottom of the screen the program asks the user to enter the target cost in the form of percentage reduction in the unit cost. This percentage has to be realistic and the user has to have fair knowledge of the amount of cost reduction that is feasible with the available machines, labor and tools.

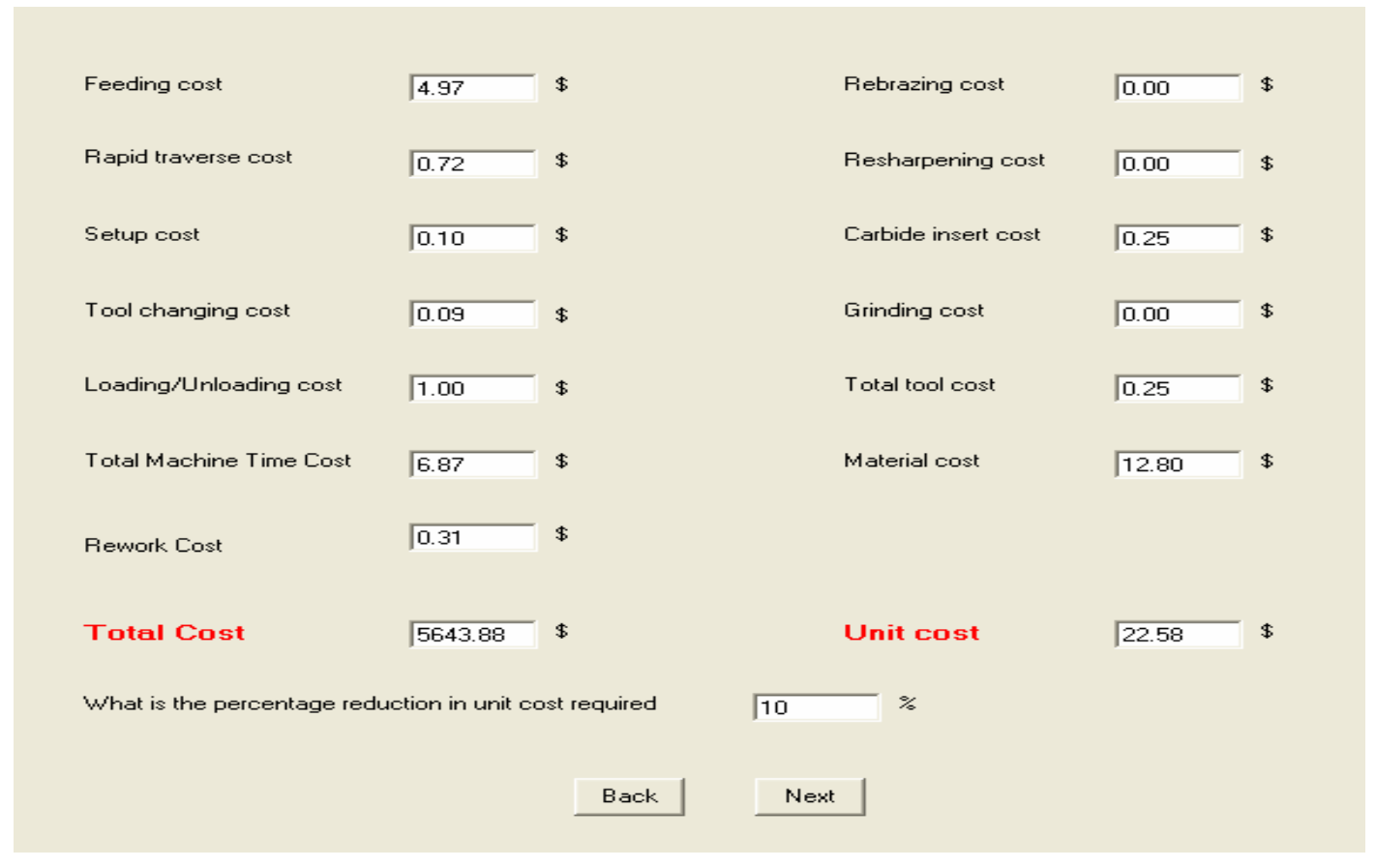

Figure 15. Current Process OutPut 
After entering the percentage reduction required, the user then clicks on the "Next" button to bring up the screen shown in Figure 16. This screen shows the contribution of different cost components towards the unit cost and also the target cost. This user can recognize those cost components that have a major effect on the unit cost and hence identify those process parameters that are critical. The target-costing algorithm is designed in such a way that cost components with higher contributions are targeted first for improvement. The user clicks on "Achieve Target Cost" button to invoke the targetcosting algorithm, which tries to achieve a unit cost that is less than or equal to this target cost. The program identifies the critical parameters for improvement and prompts the user to enter a percentage by which that particular parameter can be improved. The program continues till the target cost is reached or all selected parameters are examined.

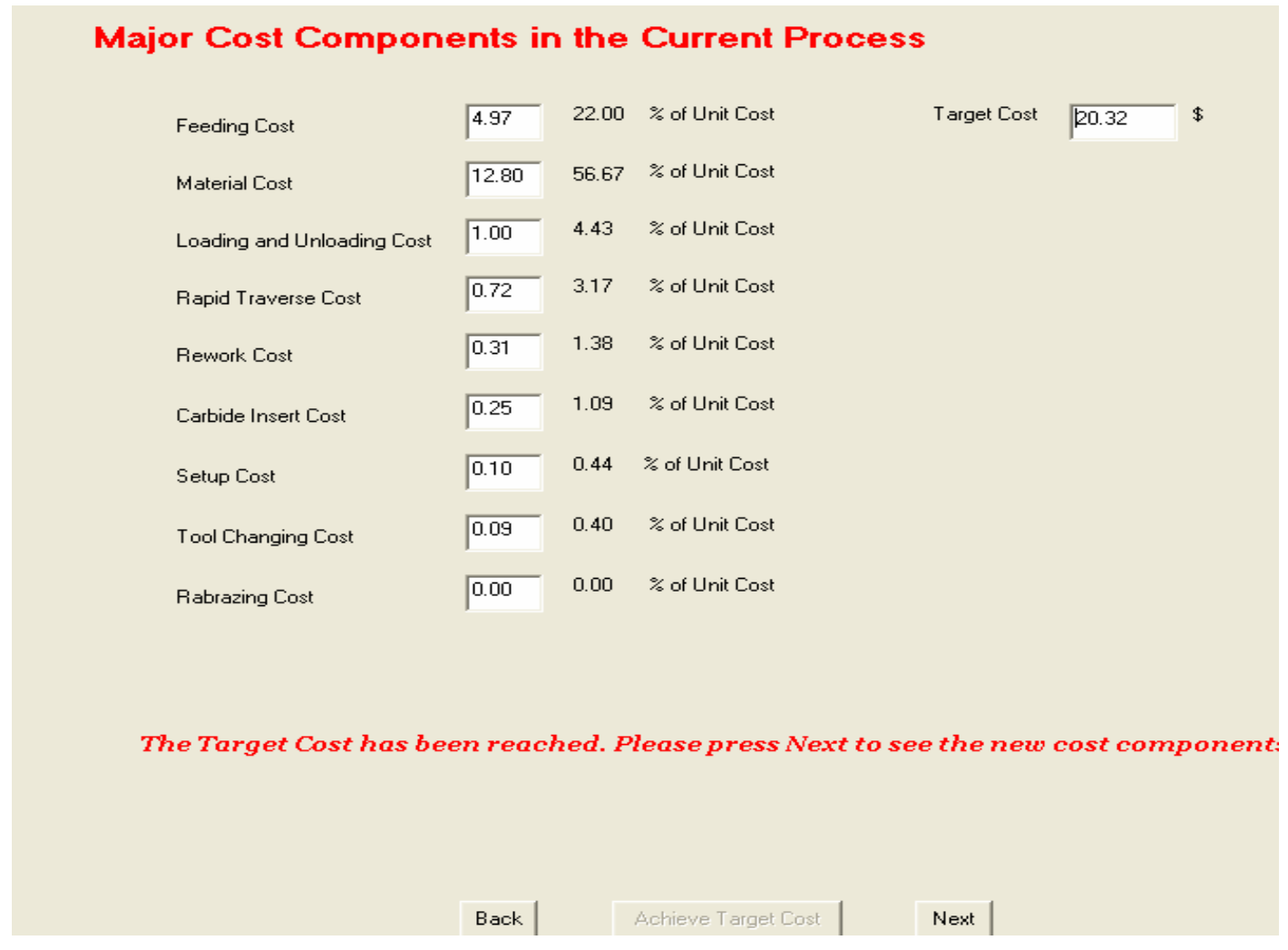

FiguRE 16. COST COMPONENT CONTRIBUTION 
A message is displayed on the screen informing the user if the algorithm was successful in achieving the target cost. The user then clicks the "Next" button to invoke the screen shown in Figure 17. This screen shows a comparison between the cost components, the unit cost and the total cost, before and after the target costing process. The unit turning cost for the base case was $\$ 22.58$ and a cost reduction of $10 \%$ was desired in this unit cost. Based upon this reduction the target cost was calculated to be $\$ 20.32$.

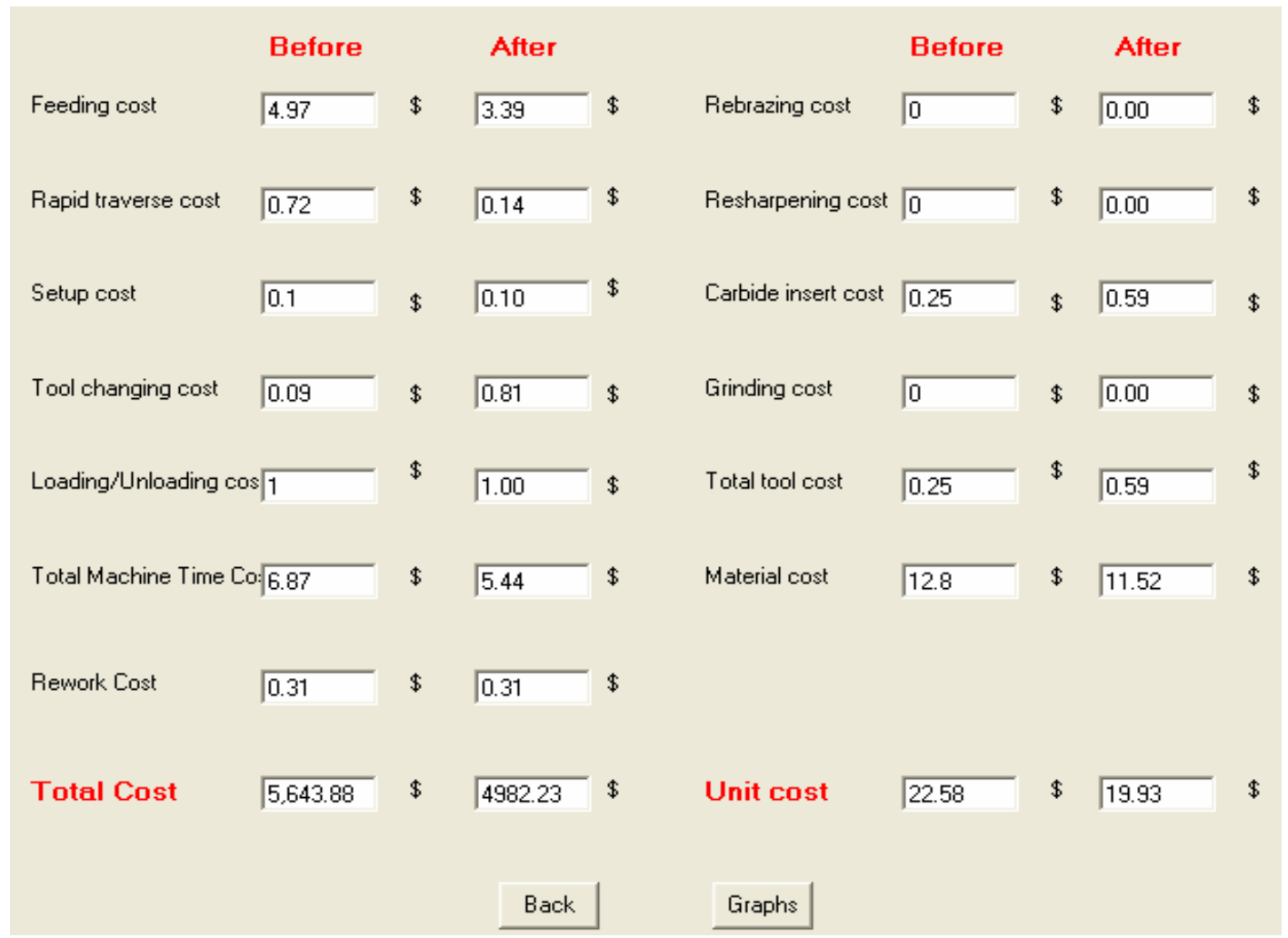

Figure 17. Cost COMPONENTS BEFORE AND AFTER TARgET-COSTING

The unit cost after the target-costing process was $\$ 19.93$, which was less than the target cost of $\$ 20.32$. This cost reduction was achieved after four iterations as shown in Figure 
18. The steps described in section 3.1 are applied sequentially to achieve the target cost. The following section shows the calculations for each iteration.

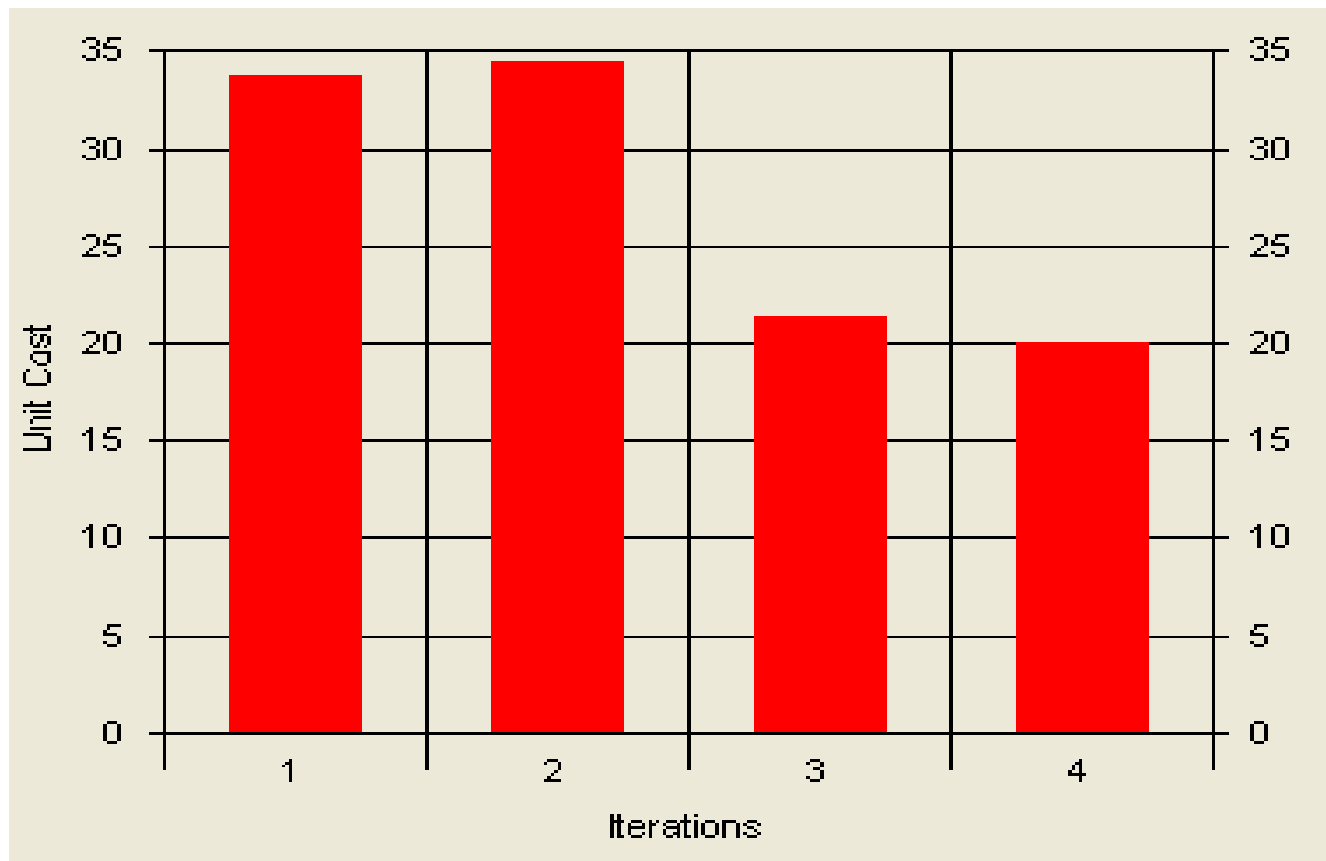

FigURE 18. VARIATION OF Unit COST OVER FOUR ITERATIONS

\subsection{Base Case}

The cutting speed and the feed per revolution were calculated to be

$\mathrm{V}=878.97$ feet per minute

$\mathrm{f}_{\mathrm{r}}=0.0014$ inches per revolution

Tool Life $\mathrm{T} \quad=\mathrm{C} /\left(\mathrm{f}_{\mathrm{r}}^{\mathrm{m}} \mathrm{d}^{\mathrm{p}} \mathrm{v}\right)^{1 / \mathrm{n}}$

$$
\begin{aligned}
& =250 /\left(0.0014^{0.25} 0.1^{0.3} 878.87\right)^{1 / 0.19} \\
& =60.35 \text { minutes. }
\end{aligned}
$$

Number of passes

$$
\begin{aligned}
& =\left(\left(\mathrm{ID}-\mathrm{D}_{\mathrm{fin}}\right) / 2\right) / \text { depth of cut } \\
& =((6-5) / 2) / 0.1
\end{aligned}
$$




$$
=5 \text {. }
$$

Rapid Traverse Cost $\quad=\mathrm{M}[(\mathrm{a}+\mathrm{L}+\mathrm{e}) / \mathrm{R}]$

$$
\begin{aligned}
& =60[(0.3+8+0.3) / 60] \\
& =\$ 0.72
\end{aligned}
$$

Feeding Cost

$$
\begin{aligned}
& =M\left[(D \times(L+a+e)) /\left(3.82 \times f_{r} \times V\right)\right] \\
& =60[(D \times(8+0.3+0.3)) / 3.82 \times 0.0014 \times 878.87)]
\end{aligned}
$$

Since D is average diameter, its value changes after every pass. The feeding cost was calculated for each pass and the total feeding cost was $\$ 4.97$.

Loading/Unloading Cost $\quad=\mathrm{M} \times \mathrm{t}_{\mathrm{L}}$

$$
\begin{aligned}
& =(60 \mathrm{x} 1) / 60 \\
& =\$ 1 \\
& =\mathrm{M}\left(\mathrm{t}_{0} / \mathrm{N}_{\mathrm{L}}\right) \\
& =60(25 / 60) / 250 \\
& =\$ 0.1
\end{aligned}
$$

Setup Cost

Tool Change Cost

$$
\begin{aligned}
& =\mathrm{M}\left[\left(\mathrm{ID} \times \mathrm{L} \times \mathrm{t}_{\mathrm{c}}\right) /\left(3.82 \times \mathrm{f}_{\mathrm{r}} \times \mathrm{V} \times \mathrm{T} / 60\right)\right] \\
& =60[(6 \times 8 \times 5) /(3.82 \times 0.0014 \times 878.87 \times 60.35 / 60)] \\
& =\$ 0.009
\end{aligned}
$$

Re-sharpening Cost

$$
=\left[(\mathrm{ID} \times \mathrm{L}) /\left(3.82 \times \mathrm{f}_{\mathrm{r}} \times \mathrm{V} \times \mathrm{T}\right)\right] \times\left(\mathrm{G} \times \mathrm{t}_{\mathrm{s}}\right)
$$

As the cutting tool was carbide insert, there was no re-sharpening cost as the carbide insert cannot be re-sharpened. The insert has to be indexed if it breaks.

Re-brazing Cost $\quad=\left(\mathrm{P}_{\mathrm{x}} \mathrm{t}_{\mathrm{b}}\right) / \mathrm{K}_{2}$

Since the cutting tool for the base case was a carbide insert, there was no re-brazing cost, as a carbide insert cutting tool cannot be brazed. 
Carbide Insert Cost

$=\left(\mathrm{C}_{\mathrm{c}} / \mathrm{T}\right) \times$ total cutting time

$=(3 / 60.35) \times 4.97$

$=\$ 0.25$

Grinding Wheel Cost

$$
=\left[(\mathrm{D} \times \mathrm{L}) /\left(3.82 \times \mathrm{f}_{\mathrm{r}} \times \mathrm{V} \times \mathrm{T}\right)\right] \times \mathrm{C}_{\mathrm{w}}
$$

The grinding wheel cost was zero as the tool was carbide insert.

Material Cost

$$
\begin{aligned}
& =(\mathrm{Wt}) \times(\mathrm{Mp}) \\
& =0.029 \times 440 \\
& =\$ 12.80
\end{aligned}
$$

Rework Cost $=($ Number of parts reworked $\mathrm{x}$ Rework rate $) /$ updated batch size

$$
\begin{aligned}
& =(2.9 \times 30) / 279 \\
& =\$ 0.31
\end{aligned}
$$

Total Machine Time Cost $=$ Feeding Cost + Rapid Traverse Cost + Setup Cost + Loading/Unloading Cost + Tool Changing Cost

$$
\begin{aligned}
& =4.97+0.72+0.1+1+0.009 \\
& =\$ 6.87
\end{aligned}
$$

Total Tool Cost $=$ Carbide Insert Cost + Re-brazing Cost + Re-sharpening

$$
\text { Cost + Grinding Wheel Cost }
$$$$
=0.25+0.00+0.00+0.00
$$$$
=\$ 0.25
$$

Total Cost

$$
\begin{aligned}
= & \text { ubs } x(\text { Total Machine Time Cost }+ \text { Total Tool Cost }+ \\
& \text { Material Cost }+ \text { Rework Cost }) \\
= & 279 \times(6.87+0.25+12.80+0.31) \\
= & \$ 5643.88
\end{aligned}
$$


Unit Cost

$$
\begin{aligned}
& =\text { Total Cost } / \mathrm{N}_{1} \\
& =5643 / 250 \\
& =\$ 22.58
\end{aligned}
$$

A $10 \%$ reduction was desired in the unit cost based upon which the target cost was calculated to be $\$ 20.32$.

\subsection{Iteration 1: HSS Cutting Tool}

The cutting tool was changed from carbide insert to HSS. The notion behind this change is that the cost of HSS cutting tool is less than carbide insert. The following parameters changed from the base case.

Table 2: Change in Data between Base Case and Iteration 1.

\begin{tabular}{|c|c|c|}
\hline Parameter & Base Case & Iteration 1 \\
\hline Cutting Tool & Carbide Insert & HSS \\
\hline Cost Of Cutting Tool & $\$ 3.00$ & 150 \\
\hline $\mathrm{C}$ & 250 & 0.29 \\
\hline $\mathrm{N}$ & 0.19 & 0.35 \\
\hline $\mathrm{P}$ & 0.30 & \\
\hline
\end{tabular}

As seen from the table above the cost of HSS cutting tool was less than carbide insert cutting tool. Also the tool life coefficient was significantly lower than that of the carbide insert. The results obtained after the cutting tool was changed from carbide insert to HSS are shown in Table 3 and are compared to the results of the base case. The unit cost increased by $49 \%$ from $\$ 22.58$ to $\$ 33.71$. The increase in unit cost was due to the 
increased machine time cost and tool cost. The rework cost did not change because the rework rate and the rejection rate remained constant. The number of parts rejected and the number of parts reworked also did not change resulting in the updated batch size of 279 , which was equal to the updated batch size in the base case.

The amount of material required is influenced by the updated batch size. The updated batch size depends upon the rework and rejection rate and hence 279 parts have to be machined in order to produce 250 acceptable parts. Since the updated batch size did not change the material cost remained constant at $\$ 12.80$.

The unit cost increased by $49 \%$ even though the cost of cutting tool decreased by $33.33 \%$. This signifies that by reducing only the cost of the cutting tool, the unit cost of machining cannot be reduced. There are other parameters involved in the process that have to be analyzed. Nevertheless the selection of the right cutting tool is still an important step in obtaining the desired machining cost. HSS was rejected and the next cutting tool, brazed carbide tip was selected for analysis in the second iteration, the results of which are shown in the next section. 
Table 3: Comparison of Results between Base Case and Iteration 1.

\begin{tabular}{|c|c|c|}
\hline Parameter & Base: Carbide Insert & Iteration 1: HSS Cutting Tool \\
\hline $\mathrm{D}$ & 0.1 inches & 0.1 inches \\
\hline $\mathrm{V}$ & 878.97 feet per minute & 652.36 feet per minute \\
\hline $\mathrm{fr}$ & 0.0014 inches per rev. & 0.0084 inches per rev. \\
\hline Number Of Passes & 5 & 5 \\
\hline Updated Batch Size & 279 & 279 \\
\hline Feeding Time & 4.97 minutes & 10.51 minutes \\
\hline Feeding Cost & $\$ 4.97$ & $\$ 10.51$ \\
\hline Rapid Traverse Cost & $\$ 0.72$ & $\$ 0.72$ \\
\hline Setup Cost & $\$ 0.10$ & $\$ 0.10$ \\
\hline Load/Unload Cost & $\$ 1.00$ & $\$ 1.00$ \\
\hline Tool Changing Cost & $\$ 0.009$ & $\$ 1.84$ \\
\hline Total Machine Time Cost & $\$ 6.87$ & $\$ 14.16$ \\
\hline Re-sharpening Cost & $\$ 0.00$ & $\$ 2.76$ \\
\hline Re-brazing Cost & $\$ 0.00$ & $\$ 0.00$ \\
\hline Carbide Insert Cost & $\$ 0.25$ & $\$ 0.00$ \\
\hline Grinding Wheel Cost & $\$ 0.00$ & $\$ 0.18$ \\
\hline Total Tool Cost & $\$ 0.25$ & $\$ 2.94$ \\
\hline Material Cost & $\$ 12.80$ & $\$ 12.80$ \\
\hline Rework Cost & $\$ 0.31$ & $\$ 0.31$ \\
\hline Total Cost & $\$ 5643.88$ & $\$ 8428.59$ \\
\hline Unit Cost & $\$ 22.58$ & $\$ 33.71$ \\
\hline
\end{tabular}




\subsection{Iteration 2: Brazed Carbide Tip Cutting Tool}

The target-costing algorithm was not able to achieve the target cost of $\$ 20.32$ by changing the cutting tool from carbide insert to HSS. Instead the unit cost increased by $49 \%$ from $\$ 22.58$ to $\$ 33.71$ due to which HSS was rejected and the original carbide insert was retained. The algorithm is designed such that it analyzes all the available cutting tools sequentially. Hence the next cutting tool examined was a brazed carbide tip tool. The results obtained with brazed carbide tip cutting tool are shown in Table 4 and are compared to the initial carbide insert.

As can be seen from Table 4, the brazed carbide tip cutting tool yielded a unit turning cost of $\$ 34.42$, which was $52.4 \%$ more than the unit cost of current process using a carbide insert cutting tool. This increase was more than the increase in unit cost using HSS cutting tool. By comparing to iteration 1 where HSS cutting tool was used, it can be seen that the total machine time cost decreased by $\$ 0.78$ but the total tool cost increased by $\$ 1.41$ resulting in a net increase of $\$ 0.63$. This increase in cost applies to 279 parts. Hence the effective unit cost for a batch size of 250 increased by $\$ 0.71$ when the cutting tool was changed from HSS to brazed carbide tip. The brazed carbide tip cutting tool was rejected, as it was not successful in lowering the unit cost below $\$ 22.58$. The algorithm then analyzes the next cutting tool in the database. 
Table 4: Comparison of Results between Base Case and Iteration 2.

\begin{tabular}{|c|c|c|}
\hline Parameter & Base: Carbide Insert & Iteration 2: Brazed Carbide Tip \\
\hline $\mathrm{D}$ & 0.1 inches & 0.3 inches \\
\hline $\mathrm{V}$ & 878.97 feet per minute & 617.51 feet per minute \\
\hline $\mathrm{fr}$ & 0.0014 inches per rev. & 0.0059 inches per rev. \\
\hline Number Of Passes & 5 & 3 \\
\hline Updated Batch Size & 279 & 279 \\
\hline Feeding Time & 4.97 minutes & 9.17 minutes \\
\hline Feeding Cost & $\$ 4.97$ & $\$ 9.17$ \\
\hline Rapid Traverse Cost & $\$ 0.72$ & $\$ 0.43$ \\
\hline Setup Cost & $\$ 0.10$ & $\$ 0.10$ \\
\hline Load/Unload Cost & $\$ 1.00$ & $\$ 1.00$ \\
\hline Tool Changing Cost & $\$ 0.009$ & $\$ 2.68$ \\
\hline Total Machine Time Cost & $\$ 6.87$ & $\$ 13.38$ \\
\hline Re-sharpening Cost & $\$ 0.00$ & $\$ 4.02$ \\
\hline Re-brazing Cost & $\$ 0.00$ & $\$ 0.08$ \\
\hline Carbide Insert Cost & $\$ 0.25$ & $\$ 0.00$ \\
\hline Grinding Wheel Cost & $\$ 0.00$ & $\$ 0.27$ \\
\hline Total Tool Cost & $\$ 0.25$ & $\$ 4.35$ \\
\hline Material Cost & $\$ 12.80$ & $\$ 12.80$ \\
\hline Rework Cost & $\$ 0.31$ & $\$ 0.31$ \\
\hline Total Cost & $\$ 5643.88$ & $\$ 8605.39$ \\
\hline Unit Cost & $\$ 22.58$ & $\$ 34.42$ \\
\hline
\end{tabular}




\subsection{Iteration 3: Carbide Insert II}

The database consists of three types of cutting tools with different characteristics and costs. The target-costing algorithm analyzed the first two cutting tools and rejected them, as they were not successful in achieving the target cost. The current process unit cost was $\$ 22.58$ and the target cost was $\$ 20.32$. After rejecting HSS and brazed carbide tip cutting tools, the target-costing algorithm selected carbide insert type cutting tool. The carbide insert cutting tool selected was different from the original carbide insert and hence it is referred as carbide insert II. The results of this iteration are shown in Table 5.

The application of carbide insert II cutting tool resulted in unit turning cost of $\$ 21.36$, which was lower than the current process unit cost by $\$ 1.22$. This reduction in the unit cost was mainly due to the decrease in feeding cost by $32 \%$ over the current process feeding cost even though the tool changing cost increased. It can be seen from the Table 5 that the cutting speed decreased and the feed per revolution increased. Hence each pass is completed at a faster rate. The number of passes were reduced from 5 to 1 because carbide insert II achieved a higher depth of cut of 0.5 inches compared to 0.1 inches that the original carbide insert achieved. The number of passes also influences the rapid traverse cost as the machine had to travel rapidly only once compared to 5 times in the current process. Since the unit cost was less than the current process unit cost, the targetcosting algorithm replaced the original carbide insert cutting tool by the carbide insert II cutting tool. But the target cost o $\$ 20.32$ or less was still not achieved. Since all the cutting tools were examined, the target-costing algorithm focused on the parameters influencing the highest cost component. 
Table 5: Comparison of Results between Base Case and Iteration 3.

\begin{tabular}{|c|c|c|}
\hline Parameter & Base: Carbide Insert & Iteration 2: Carbide Insert II \\
\hline $\mathrm{D}$ & 0.1 inches & 0.5 inches \\
\hline $\mathrm{V}$ & 878.97 feet per minute & 632.87 feet per minute \\
\hline Fr & 0.0014 inches per rev. & 0.0054 inches per rev. \\
\hline Number Of Passes & 5 & 1 \\
\hline Updated Batch Size & 279 & 279 \\
\hline Feeding Time & 4.97 minutes & 3.38 minutes \\
\hline Feeding Cost & $\$ 4.97$ & $\$ 3.38$ \\
\hline Rapid Traverse Cost & $\$ 0.72$ & $\$ 0.14$ \\
\hline Setup Cost & $\$ 0.10$ & $\$ 0.10$ \\
\hline Load/Unload Cost & $\$ 1.00$ & $\$ 1.00$ \\
\hline Tool Changing Cost & $\$ 0.009$ & $\$ 0.8$ \\
\hline Total Machine Time Cost & $\$ 6.87$ & $\$ 5.44$ \\
\hline Re-sharpening Cost & $\$ 0.00$ & $\$ 0.00$ \\
\hline Re-brazing Cost & $\$ 0.00$ & $\$ 0.00$ \\
\hline Carbide Insert Cost & $\$ 0.25$ & $\$ 0.60$ \\
\hline Grinding Wheel Cost & $\$ 0.00$ & $\$ 0.00$ \\
\hline Total Tool Cost & $\$ 0.25$ & $\$ 0.60$ \\
\hline Material Cost & $\$ 12.80$ & $\$ 12.80$ \\
\hline Rework Cost & $\$ 0.31$ & $\$ 0.31$ \\
\hline Total Cost & $\$ 5643.88$ & $\$ 5339.24$ \\
\hline Unit Cost & $\$ 22.58$ & $\$ 21.36$ \\
\hline
\end{tabular}




\subsection{Iteration 4: Material Cost Reduction}

The material cost of $\$ 12.80$ was $56.67 \%$ of the current process unit cost and was the highest cost component in the unit cost. The basis of the target-costing algorithm is to focus on the cost components that have high contribution towards the unit cost starting from highest to lowest. The parameters that affect the material cost are material price and weight of material. The rework and rejection rate were not changed and hence 279 parts were required to be machined to achieve a batch of 250 acceptable parts. As a result the weight of material remained constant. The only parameter affecting the material cost was material price. The material price was reduced by $10 \%$. The total machine time cost and the tool cost did not change, as the material price did not affect those cost components. The material cost decreased by $10 \%$ from $\$ 12.80$ to $\$ 11.52$ resulting in a unit cost of $\$ 19.93$ which was lower than the target cost of $\$ 20.32$. Since the target cost was reached, the algorithm did not resume any further iterations.

\subsection{Conclusion}

The target-costing program is very interactive and depends upon the type of response given by the user. All cost components are sequentially analyzed for reduction from highest to lowest after all cutting tools in the database are examined. When the program prompts the user to enter a percentage by which a certain factor can be reduced, the user should enter a percentage that could be achieved practically. The algorithm is based on the assumption that the user has good knowledge of the turning process. The information provided to the program influences its behavior. A sensitivity analysis was performed over five parameters and the results are shown in the appendix A. 


\section{CHAPTER 5}

\section{SYSTEM VALIDATION}

The system validation forms the final part of this research work. It was deemed necessary to validate the model to test its suitability to practical conditions. The data was obtained from De Vall Brothers Inc. in Morgantown, WV. The results are discussed in the upcoming sections.

\subsection{Data}

\section{Work-piece Parameters:}

$\begin{array}{ll}\text { Part } & \text { Thermowell Pin } \\ \text { Initial Diameter } & 2 \text { inches } \\ \text { Final Diameter } & 1.5 \text { inches } \\ \text { Length } & 8 \text { inches } \\ \text { Batch Size } & 4 \\ \text { Material } & 4140 \text { Heat Treated } \\ \text { Hardness } & 25-250 \text { BHn } \\ \text { Material Price } & \$ 1800 / \text { ton } \\ \text { Machining Parameters: } & 0.12 \text { inches } \\ d & 60 \$ / h r \\ \text { M } & 15 \text { minutes } \\ t_{0} & 0.11 \text { minutes } \\ t_{c h} & 0.25 \text { minute } \\ \end{array}$


$\mathrm{R}$

Rejection $\quad 0 \%$

Rework $\quad 0 \%$

Rework Rate $\quad 0 \$ / \mathrm{hr}$

Cutting Tool Carbide Insert

Cost of Tool $\quad 9$ \$/insert

Number of edges 6

C (Tool life constant) 250

\section{Machine Parameters:}

Machine Capacity $20 \mathrm{HP}$

Surface Finish $\quad 32$ micro inches

The manufacturing cost per part determined by the target-costing model was $\$ 14.40$, which was very close to the actual manufacturing cost of $\$ 15$ per part. The higher actual manufacturing cost is due to the chamfering operation performed on the ends of the pin, which is not considered in the model. The tool life data and the different exponents in the horsepower and surface finish constraint were not available and hence the data discussed in the previous sections was used. Several trials were conducted to determine the percentage cost reduction that could be achieved by the model. The model successfully achieved a target cost of $\$ 14.11$, which was a cost reduction of $2 \%$ and $\$ 13.98$ or a cost reduction of $2.9 \%$. 


\subsection{Case 1: 2\% Cost Reduction}

The details for this case are as follows:

Current Process Unit Cost $\$ 14.40$

Desired Cost Reduction $\quad 2 \%$

Target Cost

$\$ 14.11$

Achieved Cost

$\$ 14.04$

Iterations

5

The iterations are explained in table 43.

Table 6. System Validation Case 1: 2\% Cost Reduction

\begin{tabular}{|l|l|l|l|}
\hline It. No. & Unit Cost & Achieved & Description \\
\hline 1 & 14.40 & 21.85 & Cutting tool was changed from carbide insert to hss. \\
\hline 2 & 14.40 & 22.46 & Hss was replaced by carbide tip cutting tool. \\
\hline 3 & 14.40 & 14.48 & Carbide tip was replaced by carbide insert. \\
\hline 4 & 14.40 & 14.19 & Purchase price of material was reduced by $3 \%$. \\
\hline 5 & 14.19 & 14.04 & Setup time was reduced by 3\%. \\
\hline
\end{tabular}

The material cost contributed $40 \%$ towards the unit cost and the setup cost was the second highest with $26 \%$ contribution. The material price was $\$ 1800 /$ ton and hence was the highest cost component. The setup time was 15 minutes, which was low, compared to the hypothetical examples, but was absorbed by a very small batch size compared to the batch size of 250 in the previous examples. This emphasizes the necessity of having a large batch size to offset the effect of high setup time. The target-costing process is shown in Figure 28. All the tools were examined and carbide insert was finally selected. 
A further reduction in material price and setup time by $3 \%$ each was required to achieve the required target cost.

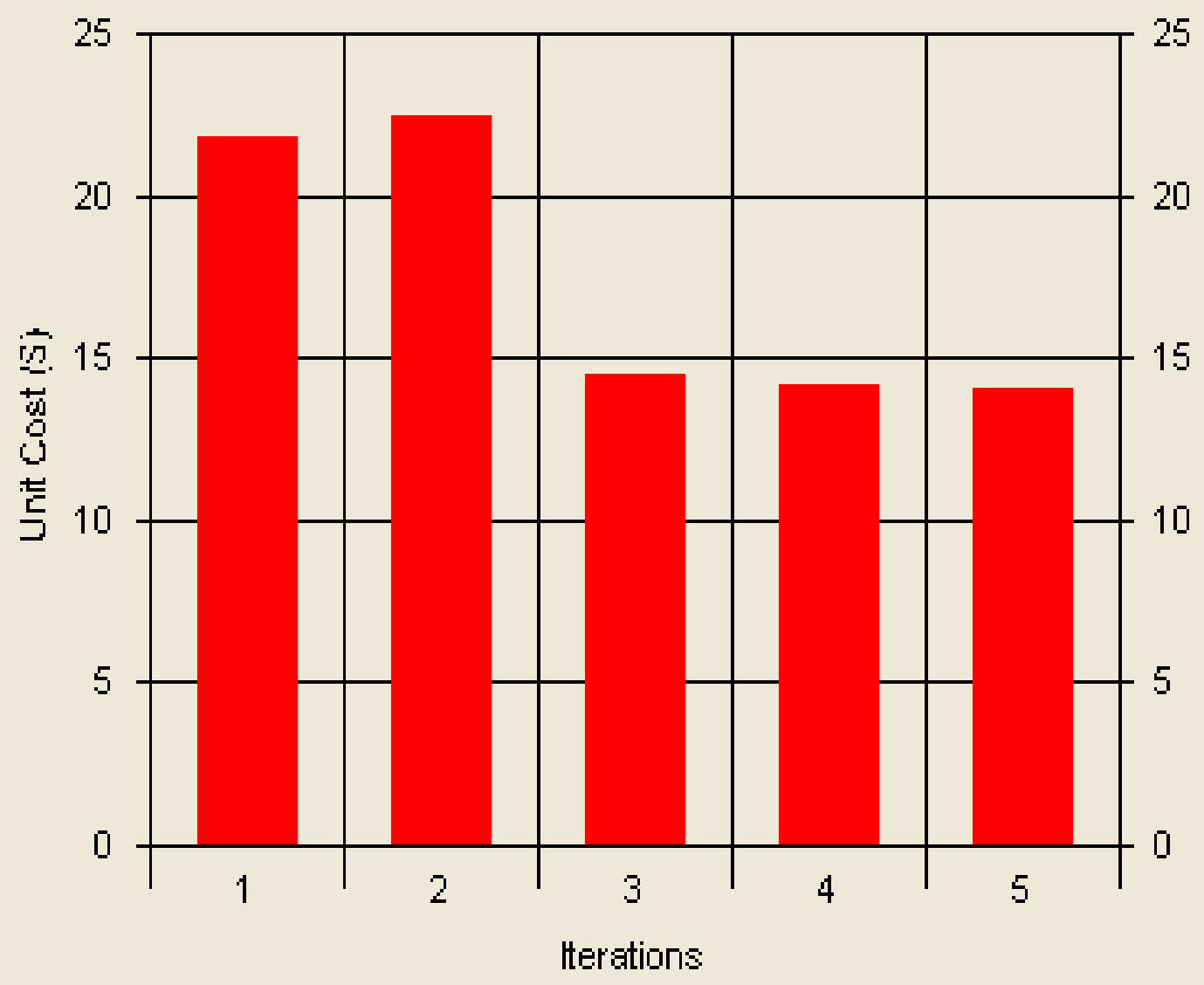

FIGURE 19. VALIDATION EXAMPLE 1 


\subsection{Case 2: 2.9\% Cost Reduction}

The details for this case are as follows:

Current Process Unit Cost $\$ 14.40$

Desired Cost Reduction $\quad 2.9 \%$

Target Cost $\$ 13.98$

Achieved Cost $\$ 13.98$

Iterations 10

The iterations are explained in table 44 .

Table 7. System Validation Case 2: 2.9\% Cost Reduction

\begin{tabular}{|l|l|l|l|}
\hline It. No. & Unit Cost & Achieved & Description \\
\hline 1 & 14.40 & 21.85 & Cutting tool was changed from carbide insert to hss. \\
\hline 2 & 14.40 & 22.46 & Hss was replaced by carbide tip cutting tool. \\
\hline 3 & 14.40 & 14.48 & Carbide tip was replaced by carbide insert. \\
\hline 4 & 14.40 & 14.19 & Purchase price of material was reduced by 3\%. \\
\hline 5 & 14.19 & 14.04 & Setup time was reduced by 3\%. \\
\hline 6 & 14.04 & 14.01 & Machine with rapid traverse rate 40 inches/min selected. \\
\hline 7 & 14.01 & 20.69 & Machine with rapid traverse rate 50 inches/min selected. \\
\hline 8 & 14.01 & 20.28 & Machine with rapid traverse rate 60 inches/min selected. \\
\hline 9 & 14.01 & 18.55 & Loading and Unloading time was reduced by $10 \%$. \\
\hline 10 & 14.01 & 13.98 & Cost of carbide insert was reduced by $5 \%$. \\
\hline
\end{tabular}

Since the target cost was lower compared to the previous case, more improvements were necessary. The percentage reduction in material price, setup time and the carbide insert 
cost show more realistic values, which can be achieved in the real world. The results are shown in table 44 and Figure 29.

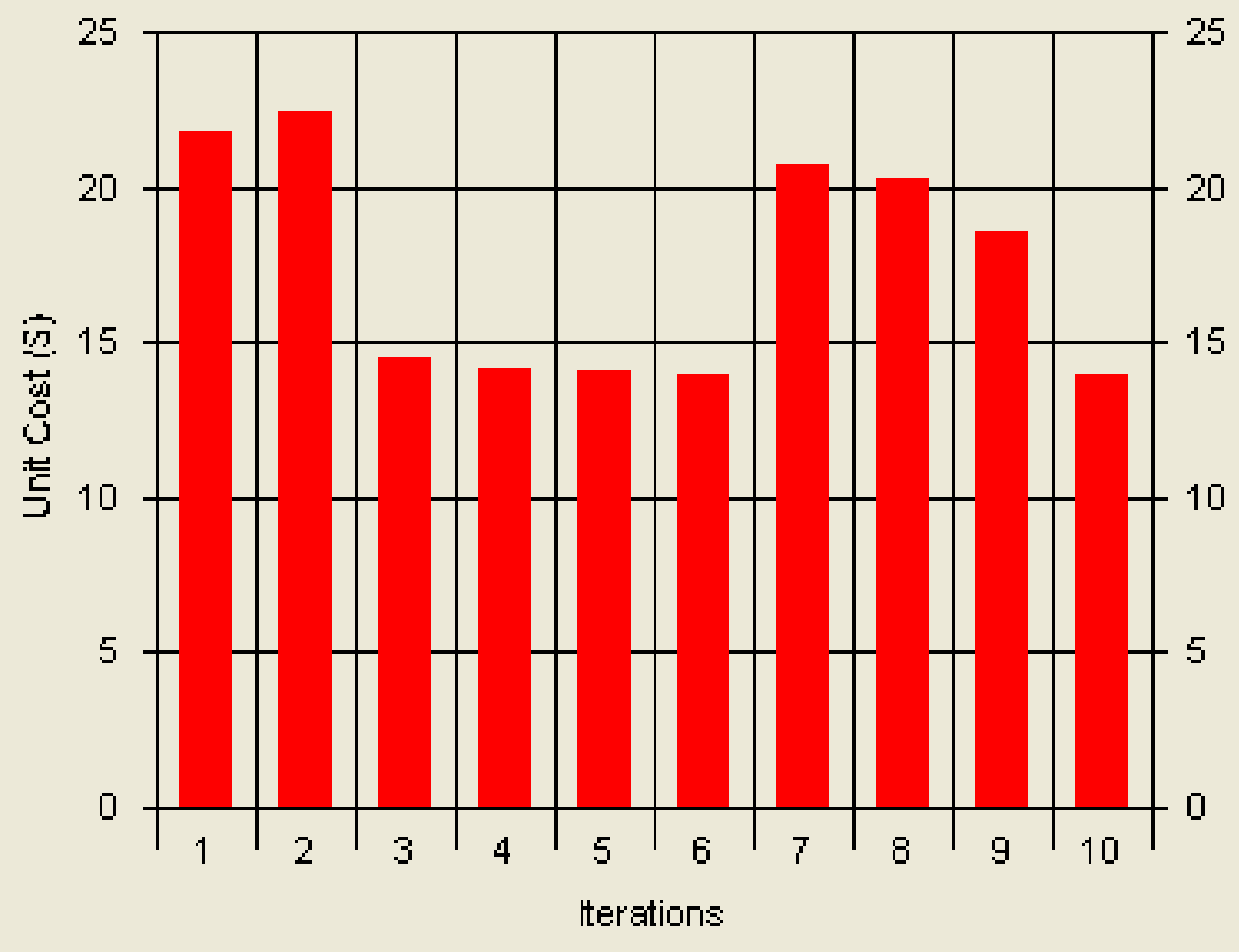

FIGURE 20. VALID ATION EXAMPLE 2

During iterations 7,8 and nine, different machines were evaluated to reduce the rapid traverse cost. The machines with lower rapid traverse rate had lower labor, but the higher unit cost is justified by higher handling times. 


\subsection{Conclusion}

The system validation formed the most important part of this research work. Two real life examples were solved using the target-costing model, the process and results of which were presented in this chapter. The model provided good results as illustrated by the examples and the accuracy of the results could be improved by populating the databases with more realistic and practical data. The examples also demonstrated that the material cost and the setup time constituted the major portion of the unit cost, which is consistent with real life applications. The examples provided in this chapter and the earlier chapters suggest that the effect of high setup time can be offset by larger batch sizes. 


\section{CHAPTER 6}

\section{CONCLUSION AND FUTURE WORK}

\subsection{Conclusion}

The field of target-costing is emerging fast as the solution to future product development and cost reduction. Target-Costing, Value Chain Analysis, Value Chain Improvement, Quality Function Deployment etc are different names which try to achieve the same objective: to produce a product at the lowest cost with all the required features with adherence to quality conformance and aesthetics. All the above mentioned are different techniques of process improvement but try to achieve the same objective. Target-costing has been widely applied in product development and process improvement by companies such as Toyota Motor Corporation, Nissan Motor Corporation, Boeing, Chrysler, Kodak, Lucent Technologies, Sony Corporation, and many others. Target-costing can be applied in the design of a new product as well as improvement of an existing process.

Machining is one of the most widely used manufacturing operations and hence there is a huge potential for cost reduction using the target-costing technique. In this research, a target-costing model was developed for turning operation, which uses a structured approach to reduce the machining costs. The user interface was designed in Microsoft Visual Basic and the database was developed using Microsoft Access. The model was tested using real time data and the results obtained were comparable to the actual values. This model can be utilized as a starting point in the development of an integrated targetcosting system for all machining operations. 


\subsection{Future Work}

The target-costing model was developed for the turning operation to evaluate its feasibility. Since the tests produced good results, this model can be further enhanced to incorporate more machining operations like milling, drilling, grinding, tapping and other finishing operations. The user can be given more choices regarding the materials and their respective hardness. By incorporating all machining operations, a good process planning system can be developed which can be used very well for instructional purposes. The program can also be made smart by incorporating user input data analysis feature, which screens the user input data before using it in the program.

Features such as implementation costs and opportunity costs can be incorporated to enhance the model and its us efulness. 


\section{REFERENCES}

1. Bayou, M., and Reinstein, A., 1998, Three routes for target-costing. Managerial Finance, 24, 28-45.

2. Bhattacharyya, A., Faria-Gonzalez, R., and Ham, I., 1970, Regression analysis for predicting surface finish and its application in the determination of optimum machining conditions. Transactions of ASME, Journal of Engineering for Industry, 92, 711-714.

3. Carr, C., and Ng, J., 1995, Total cost control: Nissan and its U.K. supplier partnerships. Management Accounting Research, 6, 347-365.

4. Clifton, B., and Townsend, W., 1998, Inputs for successful target-costing. Applications of Design for Manufacturing ASME, DE-Vol. 99/MED-Vol. 7, 2127.

5. Cooper, R., 2002, Target-costing for new-product development. Journal of Cost Management, May-June, 5-12.

6. Cooper, R., and Slagmulder, R., 1999, Target-costing and value engineering. Productivity Press, Portland, UK.

7. Creese. R, Adithan, M, and Pabla, B. S., 1992, Estimating and costing for metal manufacturing industries. Marcel Dekker, New York, USA.

8. Ermer, D. S., and Kromodihardjo, S., 1981, Optimization of multipass turning with constraints. Transactions of ASME, Journal of Engineering for Industry, 103, 462-469. 
9. Fischer, G. W., Wei, Y., and Dontamsetti, S., 1989, Process-controlled machining of gray cast iron. Journal of Mechanical Working Technology, 20, 47-57.

10. Gopalakrishnan, B., and AlKhayyal, F., 1991, Machine parameter selection for turning with constraints: an analytical approach based on geometric programming. International Journal of Production Research, 29, 9, 1897-1908.

11. Horvath, P., Gleich, R., and Schmidt, S., 1998, Linking target-costing to ABC at a US automotive supplier. Journal of Cost Management, Mar-Apr, 16-24.

12. Kato, Y., 1993, Target-costing support systems: lessons fom leading Japanese companies. Management Accounting Research, 4, 33-47.

13. Liang, M., Mgwatu, M., and Zuo, M., 2001, Integration of cutting parameter selection and tool adjustment decisions for multipass turning. International Journal of Manufacturing Technology, 17, 861-869.

14. Meng, Q., Arsecularatne, J., and Mathew, P., 2000, Calculation of optimum cutting conditions for turning operations using a machining theory. International Journal of Machine Tools and Manufacture, 40, 1709-1733.

15. Mesquita, R., Krasteva, E., and Doytchinov, S., 1995, Computer-aided selection of optimum machining parameters in multipass turning. International Journal of Advanced Manufacturing Technology, 10, 19-26.

16. Monden, Y., and Hamada, K., 1991, Target-costing and kaizen costing in Japanese automobile companies. Journal of Management Accounting Research, 3, Fall, 16-34. 
17. Narang, R.V., and Fischer, G.W., 1993, Development of a framework to automate process-planning functions and to determine machining parameters. International Journal of Production Research, 31, 1921-1942.

18. Nicolini, D., Tomkins, C., Holti, R., Oldman, A., and Smalley, M., 2000, Can target-costing and whole life costing be applied in the construction industry?: Evidence from two case studies. British Journal of Management, 11, 303-324.

19. Philips, D. T., and Beightler, C. S., 1970, Optimization in tool engineering using geometric programming. AIIE Transactions, 2, 355-360.

20. Philipson, R. H., and Ravindran, A., 1979 Application of mathematical programming to metal cutting. Mathematical Programming Study, 11, 116-134.

21. Ramaswamy, K. V., and Lambert, B. K., 1974, Cost optimization for a single pass turning operation including inventory and penalty costs. International Journal of Production Research, 12, 331-334.

22. Shank, J.K, and Fisher, J., 1999, Case study-target-costing as a strategic tool. Sloan Management Review, Fall, 73-82.

23. Sundaram, R. M., 1978, An application of goal programming technique in metal cutting. International Journal of Production Research, 16, 375-382.

24. Sung, N., 1991, Target cost allocation technique in development designing. SAVE Proceedings, 204-205.

25. Tan, F.P., and Creese, R.C., 1995, A generalized multi-pass machining model for machining parameter selection in turning. International Journal of Production Research, 33, 1467-1487. 
26. Tani, T., 1995, Interactive control in target cost management. Management Accounting Research, 6, 399-414.

27. Tani, T., Okano, H., Shimizu, N., Iwabuchi, Y., Fukuda, J., and Cooray, S., 1994, Target cost management in Japanese companies: current state of art. Management Accounting Research, 5, 67-81.

28. Taylor, F. W., 1907, On the art of cutting metals. ASME transactions, 29, 31-279.

29. Tsai, P., 1986, An optimization algorithm and economic analysis for a constrained machining model. Ph.D dissertation, West Virginia University.

30. Walvekar, A. G., and Lambert, B. K., 1970, An application of geometric programming to machining variable selection. International Journal of Production Research, 8, 241-245.

31. Williamson, A., 1997, Target and kaizen costing. Manufacturing Engineer, Feb, 22-24. 
APPENDIX 


\section{APPENDIX A}

\section{Sensitivity Analysis Tables}

Table A1. Labor rates and associated non-productive times.

\begin{tabular}{|c|c|c|c|c|}
\hline Case & Labor Rate & Setup Time & Tool Changing Time & Load/Unload Time \\
\hline 1 & 60 & 25 & 5 & 1 \\
\hline 2 & 50 & 30 & 8 & 3 \\
\hline 3 & 40 & 35 & 12 & 5 \\
\hline
\end{tabular}

Table A2. Target Costing Summary for Labor and Overhead Rate $\$ 60 / \mathrm{hr}$.

\begin{tabular}{|c|c|c|c|c|c|}
\hline Trial & $\begin{array}{c}\text { CPUC } \\
\$\end{array}$ & $\begin{array}{c}\text { Reduction } \\
\%\end{array}$ & $\begin{array}{c}\text { Target } \\
\$\end{array}$ & $\begin{array}{c}\text { Achieved } \\
\$\end{array}$ & Iterations \\
\hline 1 & 22.58 & 10 & 20.32 & 19.93 & 4 \\
\hline 2 & 22.58 & 12 & 19.87 & 19.82 & 5 \\
\hline 3 & 22.58 & 13 & 19.64 & 19.55 & 12 \\
\hline
\end{tabular}

Table A3. Target Costing Iteration Summary for $10 \%$ Cost Reduction

\begin{tabular}{|c|c|c|l|}
\hline It. No. & Unit Cost & Achieved & Description \\
\hline 1 & 22.58 & 33.72 & Cutting tool was changed from carbide insert to hss. \\
\hline 2 & 22.58 & 34.42 & Hss was replaced by carbide tip cutting tool. \\
\hline 3 & 22.58 & 21.36 & Carbide tip was replaced by carbide insert. \\
\hline 4 & 21.36 & 19.93 & Purchase price of material was reduced by 10\%. \\
\hline
\end{tabular}


Table A4. Target Costing Iteration Summary for $12 \%$ Cost Reduction

\begin{tabular}{|c|c|c|l|}
\hline It. No. & Unit Cost & Achieved & Description \\
\hline 1 & 22.58 & 33.72 & Cutting tool was changed from carbide insert to hss. \\
\hline 2 & 22.58 & 34.42 & Hss was replaced by carbide tip cutting tool. \\
\hline 3 & 22.58 & 21.36 & Carbide tip was replaced by carbide insert. \\
\hline 4 & 21.36 & 19.93 & Purchase price of material was reduced by $10 \%$. \\
\hline 5 & 19.93 & 19.82 & Loading and Unloading time was reduced by $10 \%$. \\
\hline
\end{tabular}

Table A5. Target Costing Iteration Summary for $13 \%$ Cost Reduction

\begin{tabular}{|c|c|c|l|}
\hline It. No. & Unit Cost & Achieved & \multicolumn{1}{|c|}{ Description } \\
\hline 1 & 22.58 & 33.72 & Cutting tool was changed from carbide insert to hss. \\
\hline 2 & 22.58 & 34.42 & Hss was replaced by carbide tip cutting tool. \\
\hline 3 & 22.58 & 21.36 & Carbide tip was replaced by carbide insert. \\
\hline 4 & 21.36 & 19.93 & Purchase price of material was reduced by $10 \%$. \\
\hline 5 & 19.93 & 19.82 & Loading and Unloading time was reduced by $10 \%$. \\
\hline 6 & 19.82 & 21.81 & Machine with rapid traverse rate 40 inches/min selected. \\
\hline 7 & 19.82 & 21.4 & Machine with rapid traverse rate 50 inches/min selected. \\
\hline 8 & 19.82 & 19.93 & Machine with rapid traverse rate 60 inches/min selected. \\
\hline 9 & 19.82 & 19.89 & Rework rate was reduced by 10\% \\
\hline 10 & 19.82 & 19.75 & Cost of carbide insert was reduced by 10\% \\
\hline 11 & 19.75 & 19.74 & Setup time was reduced by 10\% \\
\hline 12 & 19.74 & 19.55 & Tool changing time was reduced by $10 \%$ \\
\hline
\end{tabular}




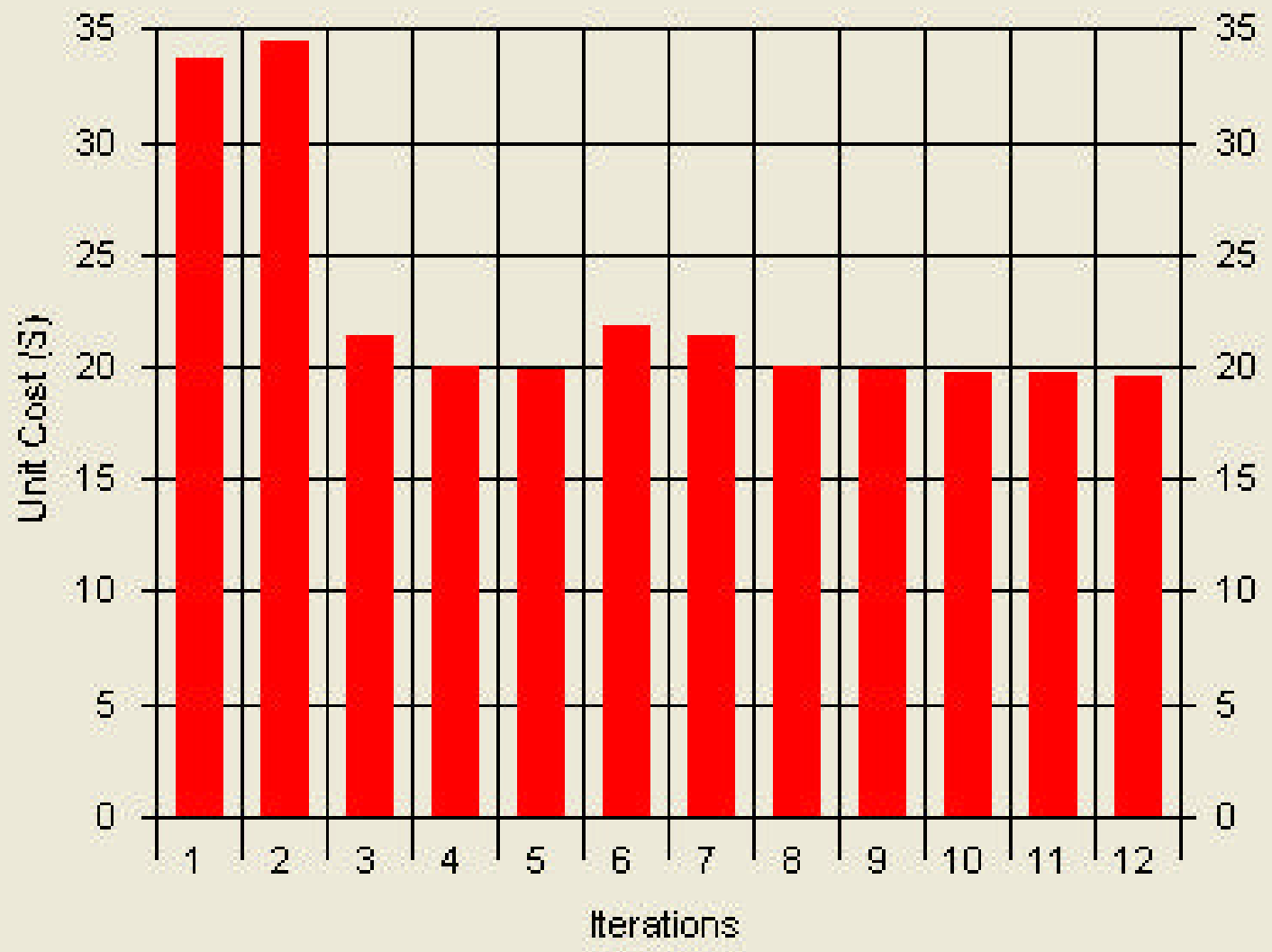

Figure A1. Target Costing Iteration Summary for 13\% Cost Reduction

Table A11. Target Costing Summary for Batch Size 500 Units

\begin{tabular}{|c|c|c|c|c|c|}
\hline Trial & $\begin{array}{c}\text { CPUC } \\
\$\end{array}$ & $\begin{array}{c}\text { Reduction } \\
\%\end{array}$ & $\begin{array}{c}\text { Target } \\
\$\end{array}$ & $\begin{array}{c}\text { Achieved } \\
\$\end{array}$ & Iterations \\
\hline 1 & 22.47 & 10 & 20.22 & 19.83 & 4 \\
\hline 2 & 22.47 & 12 & 19.77 & 19.72 & 5 \\
\hline 3 & 22.47 & 13 & 19.55 & 19.47 & 11 \\
\hline
\end{tabular}


Table A12. Target Costing Iteration Summary for $10 \%$ Cost Reduction

\begin{tabular}{|l|l|l|l|}
\hline It. No. & Unit Cost & Achieved & Description \\
\hline 1 & 22.47 & 33.6 & Cutting tool was changed from carbide insert to hss. \\
\hline 2 & 22.47 & 34.3 & Hss was replaced by carbide tip cutting tool. \\
\hline 3 & 22.47 & 21.26 & Carbide tip was replaced by carbide insert. \\
\hline 4 & 21.26 & 19.83 & Purchase price of material was reduced by $10 \%$. \\
\hline
\end{tabular}

Table A13. Target Costing Iteration Summary for $12 \%$ Cost Reduction

\begin{tabular}{|l|l|l|l|}
\hline It. No. & Unit Cost & Achieved & Description \\
\hline 1 & 22.47 & 33.6 & Cutting tool was changed from carbide insert to hss. \\
\hline 2 & 22.47 & 34.3 & Hss was replaced by carbide tip cutting tool. \\
\hline 3 & 22.47 & 21.26 & Carbide tip was replaced by carbide insert. \\
\hline 4 & 21.26 & 19.83 & Purchase price of material was reduced by $10 \%$. \\
\hline 5 & 19.83 & 19.72 & Loading and Unloading time was reduced by $10 \%$. \\
\hline
\end{tabular}


Table A14. Target Costing Iteration Summary for $13 \%$ Cost Reduction

\begin{tabular}{|l|l|l|l|}
\hline It. No. & Unit Cost & Achieved & \\
\hline 1 & 22.47 & 33.6 & Cutting tool was changed from carbide insert to hss. \\
\hline 2 & 22.47 & 34.3 & Hss was replaced by carbide tip cutting tool. \\
\hline 3 & 22.47 & 21.26 & Carbide tip was replaced by carbide insert. \\
\hline 4 & 21.26 & 19.83 & Purchase price of material was reduced by $10 \%$. \\
\hline 5 & 19.83 & 19.72 & Loading and Unloading time was reduced by $10 \%$. \\
\hline 6 & 19.72 & 21.71 & Machine with rapid traverse rate 40 inches/min selected. \\
\hline 7 & 19.72 & 21.3 & Machine with rapid traverse rate 50 inches/min selected. \\
\hline 8 & 19.72 & 19.83 & Machine with rapid traverse rate 60 inches/min selected. \\
\hline 9 & 19.72 & 19.8 & Rework rate was reduced by $10 \%$. \\
\hline 10 & 19.72 & 19.66 & Cost of carbide insert was reduced by $10 \%$. \\
\hline 11 & 19.66 & 19.47 & Tool changing time was reduced by $10 \%$. \\
\hline
\end{tabular}




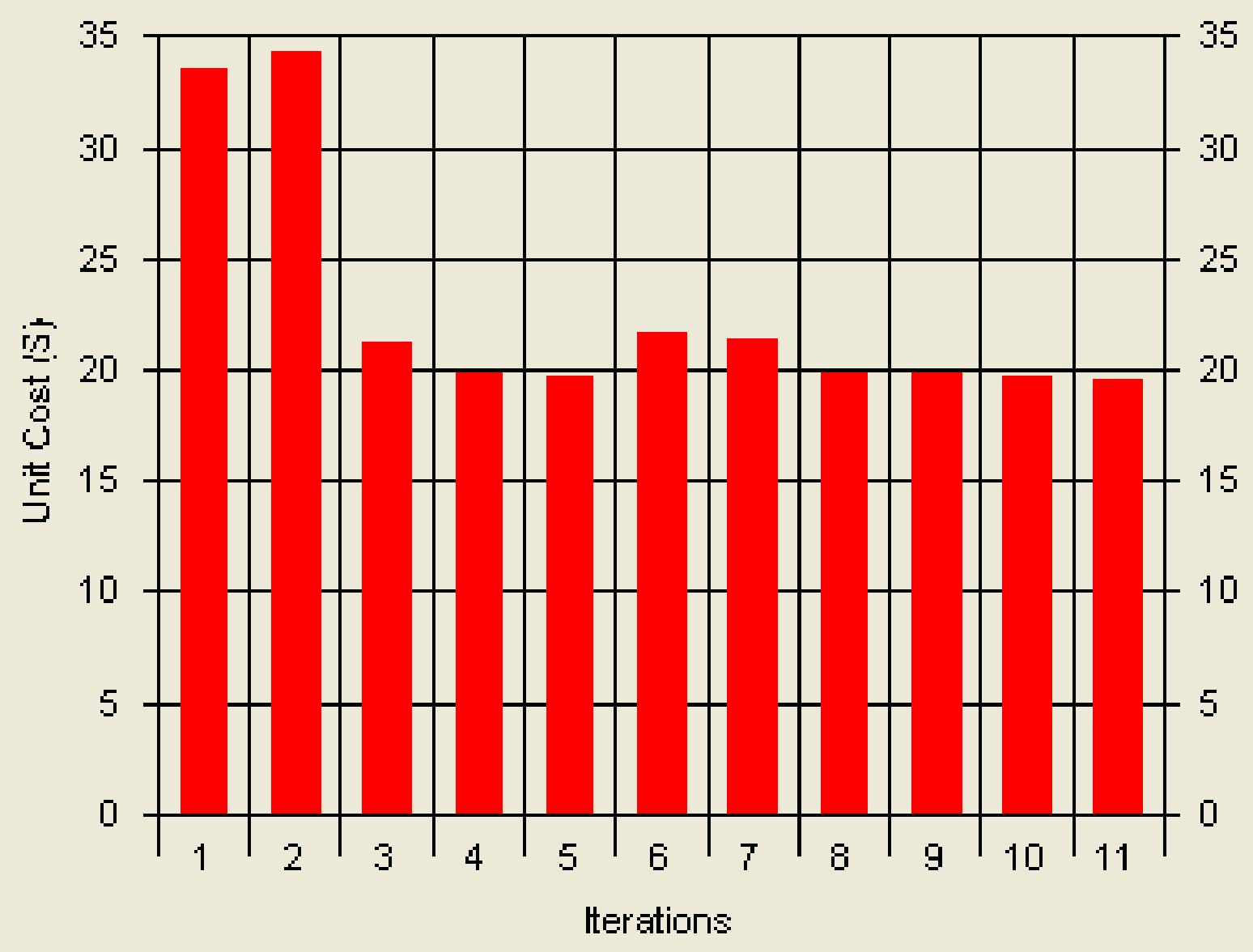

Figure A2. Target Costing Iteration Summary for 13\% Cost Reduction

Table A19. Target Costing Summary for Material Condition Hot Rolled and Annealed and Hardness 125 - 150 BHn.

\begin{tabular}{|c|c|c|c|c|c|}
\hline Trial & $\begin{array}{c}\text { CPUC } \\
\$\end{array}$ & $\begin{array}{c}\text { Reduction } \\
\%\end{array}$ & $\begin{array}{c}\text { Target } \\
\$\end{array}$ & $\begin{array}{c}\text { Achieved } \\
\$\end{array}$ & Iterations \\
\hline 1 & 22.58 & 10 & 20.32 & 20.27 & 10 \\
\hline 2 & 22.58 & 11 & 20.10 & 20.05 & 12 \\
\hline 3 & 22.58 & 13 & 19.87 & 20.05 & 13 \\
\hline
\end{tabular}


Table A20. Target Costing Iteration Summary for $10 \%$ Cost Reduction

\begin{tabular}{|l|l|l|l|}
\hline It. No. & Unit Cost & Achieved & Description \\
\hline 1 & 22.58 & 36 & Cutting tool was changed from carbide insert to hss. \\
\hline 2 & 22.58 & 36.5 & Hss was replaced by carbide tip cutting tool. \\
\hline 3 & 22.58 & 21.89 & Carbide tip was replaced by carbide insert. \\
\hline 4 & 21.89 & 20.46 & Purchase price of material was reduced by $10 \%$. \\
\hline 5 & 20.46 & 20.35 & Loading and unloading time was reduced by $10 \%$. \\
\hline 6 & 20.35 & 22.26 & Machine with rapid traverse rate 40 inches/min selected. \\
\hline 7 & 20.35 & 21.91 & Machine with rapid traverse rate 50 inches/min selected. \\
\hline 8 & 20.35 & 20.46 & Machine with rapid traverse rate 60 inches/min selected. \\
\hline 9 & 20.35 & 20.42 & Rework rate was reduced by $10 \%$. \\
\hline 10 & 20.35 & 20.27 & Cost of carbide insert was reduced by $10 \%$. \\
\hline
\end{tabular}




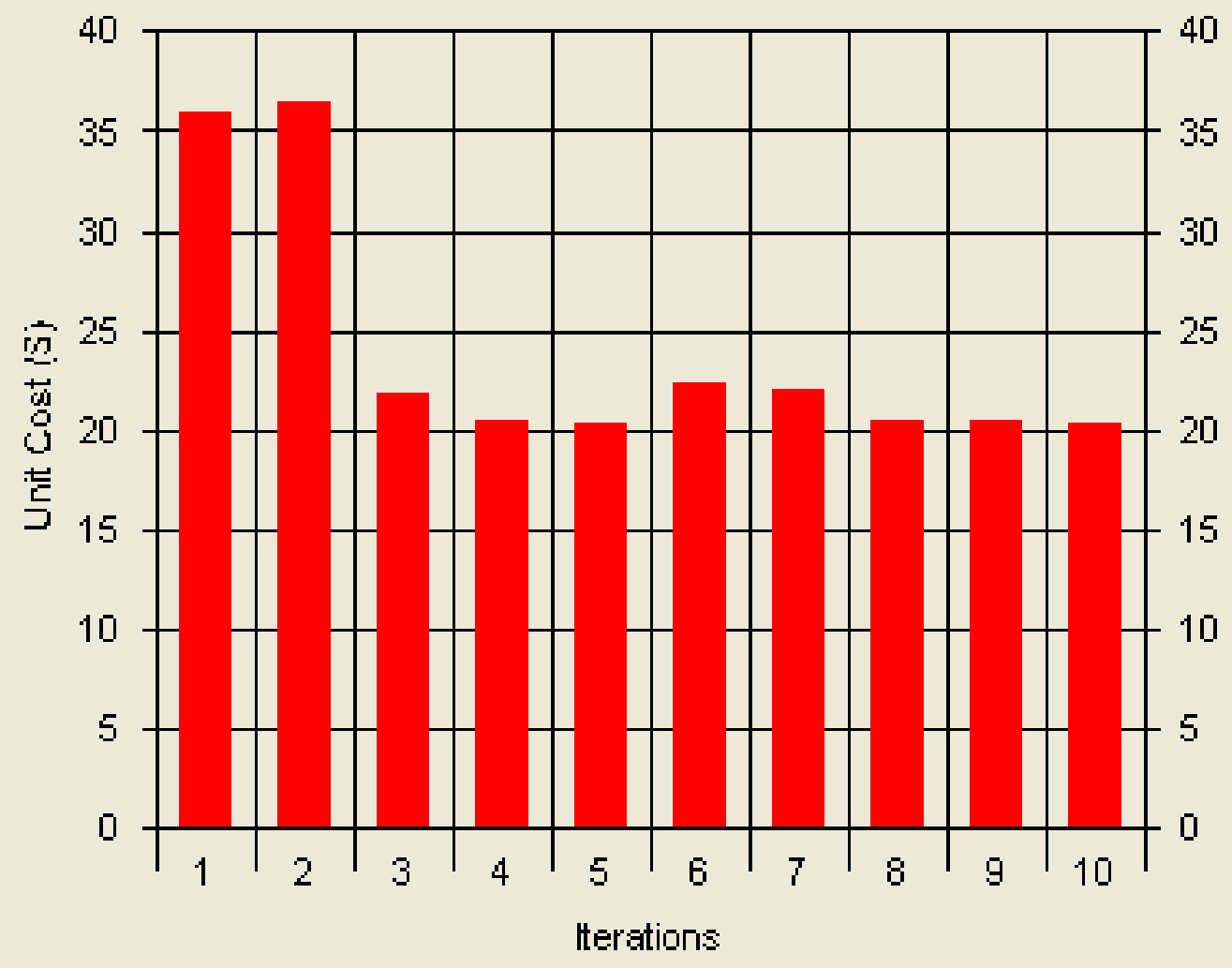

Figure A3. Target Cost Achieved in 10 iterations 
Table A21. Target Costing Iteration Summary for $12 \%$ Cost Reduction

\begin{tabular}{|c|c|c|l|}
\hline It. No. & Unit Cost & Achieved & \\
\hline 1 & 22.58 & 36 & Cutting tool was changed from carbide insert to hss. \\
\hline 2 & 22.58 & 36.5 & Hss was replaced by carbide tip cutting tool. \\
\hline 3 & 22.58 & 21.89 & Carbide tip was replaced by carbide insert. \\
\hline 4 & 21.89 & 20.46 & Purchase price of material was reduced by $10 \%$. \\
\hline 5 & 20.46 & 20.35 & Loading and unloading time was reduced by $10 \%$. \\
\hline 6 & 20.35 & 22.26 & Machine with rapid traverse rate 40 inches/min selected. \\
\hline 7 & 20.35 & 21.91 & Machine with rapid traverse rate 50 inches/min selected. \\
\hline 8 & 20.35 & 20.46 & Machine with rapid traverse rate 60 inches/min selected. \\
\hline 9 & 20.35 & 20.42 & Rework rate was reduced by $10 \%$. \\
\hline 10 & 20.35 & 20.27 & Cost of carbide insert was reduced by $10 \%$. \\
\hline 11 & 20.27 & 20.25 & Setup time was reduced by 10\%. \\
\hline 12 & 20.25 & 20.05 & Tool changing time was reduced by $10 \%$. \\
\hline
\end{tabular}


Table A22. Target Costing Iteration Summary for $13 \%$ Cost Reduction

\begin{tabular}{|c|c|c|l|}
\hline It. No. & Unit Cost & Achieved & \\
\hline 1 & 22.58 & 36 & Cutting tool was changed from carbide insert to hss. \\
\hline 2 & 22.58 & 36.5 & Hss was replaced by carbide tip cutting tool. \\
\hline 3 & 22.58 & 21.89 & Carbide tip was replaced by carbide insert. \\
\hline 4 & 21.89 & 20.46 & Purchase price of material was reduced by $10 \%$. \\
\hline 5 & 20.46 & 20.35 & Loading and unloading time was reduced by $10 \%$. \\
\hline 6 & 20.35 & 22.26 & Machine with rapid traverse rate 40 inche s/min selected. \\
\hline 7 & 20.35 & 21.91 & Machine with rapid traverse rate 50 inches/min selected. \\
\hline 8 & 20.35 & 20.46 & Machine with rapid traverse rate 60 inches/min selected. \\
\hline 9 & 20.35 & 20.42 & Rework rate was reduced by $10 \%$. \\
\hline 10 & 20.35 & 20.27 & Cost of carbide insert was reduced by $10 \%$. \\
\hline 11 & 20.27 & 20.25 & Setup time was reduced by 10\%. \\
\hline 12 & 20.25 & 20.05 & Tool changing time was reduced by $10 \%$. \\
\hline & 20.05 & 20.05 & Resharpening time was reduced by $10 \%$. \\
\hline 13 & & & \\
\hline
\end{tabular}


Table A27. Target Costing Summary for Percentage Rejection 5\%.

\begin{tabular}{|c|c|c|c|c|c|}
\hline Trial & $\begin{array}{c}\text { CPUC } \\
\$\end{array}$ & $\begin{array}{c}\text { Reduction } \\
\%\end{array}$ & $\begin{array}{c}\text { Target } \\
\$\end{array}$ & $\begin{array}{c}\text { Achieved } \\
\$\end{array}$ & Iterations \\
\hline 1 & 21.2 & 10 & 19.08 & 18.7 & 4 \\
\hline 2 & 21.2 & 12 & 18.66 & 18.59 & 5 \\
\hline 3 & 21.2 & 13 & 18.44 & 18.35 & 12 \\
\hline
\end{tabular}

Table A28. Target Costing Iteration Summary for $10 \%$ Cost Reduction

\begin{tabular}{|l|l|l|l|}
\hline It. No. & Unit Cost & Achieved & Description \\
\hline 1 & 21.2 & 31.74 & Cutting tool was changed from carbide insert to hss. \\
\hline 2 & 21.2 & 32.41 & Hss was replaced by carbide tip cutting tool. \\
\hline 3 & 21.2 & 20.05 & Carbide tip was replaced by carbide insert. \\
\hline 4 & 20.05 & 18.7 & Purchase price of material was reduced by $10 \%$. \\
\hline
\end{tabular}

Table A29. Target Costing Iteration Summary for $12 \%$ Cost Reduction

\begin{tabular}{|l|l|l|l|}
\hline It. No. & Unit Cost & Achieved & Description \\
\hline 1 & 21.2 & 31.74 & Cutting tool was changed from carbide insert to hss. \\
\hline 2 & 21.2 & 32.41 & Hss was replaced by carbide tip cutting tool. \\
\hline 3 & 21.2 & 20.05 & Carbide tip was replaced by carbide insert. \\
\hline 4 & 20.05 & 18.7 & Purchase price of material was reduced by $10 \%$. \\
\hline 5 & 18.7 & 18.59 & Loading and unloading time was reduced by $10 \%$. \\
\hline
\end{tabular}




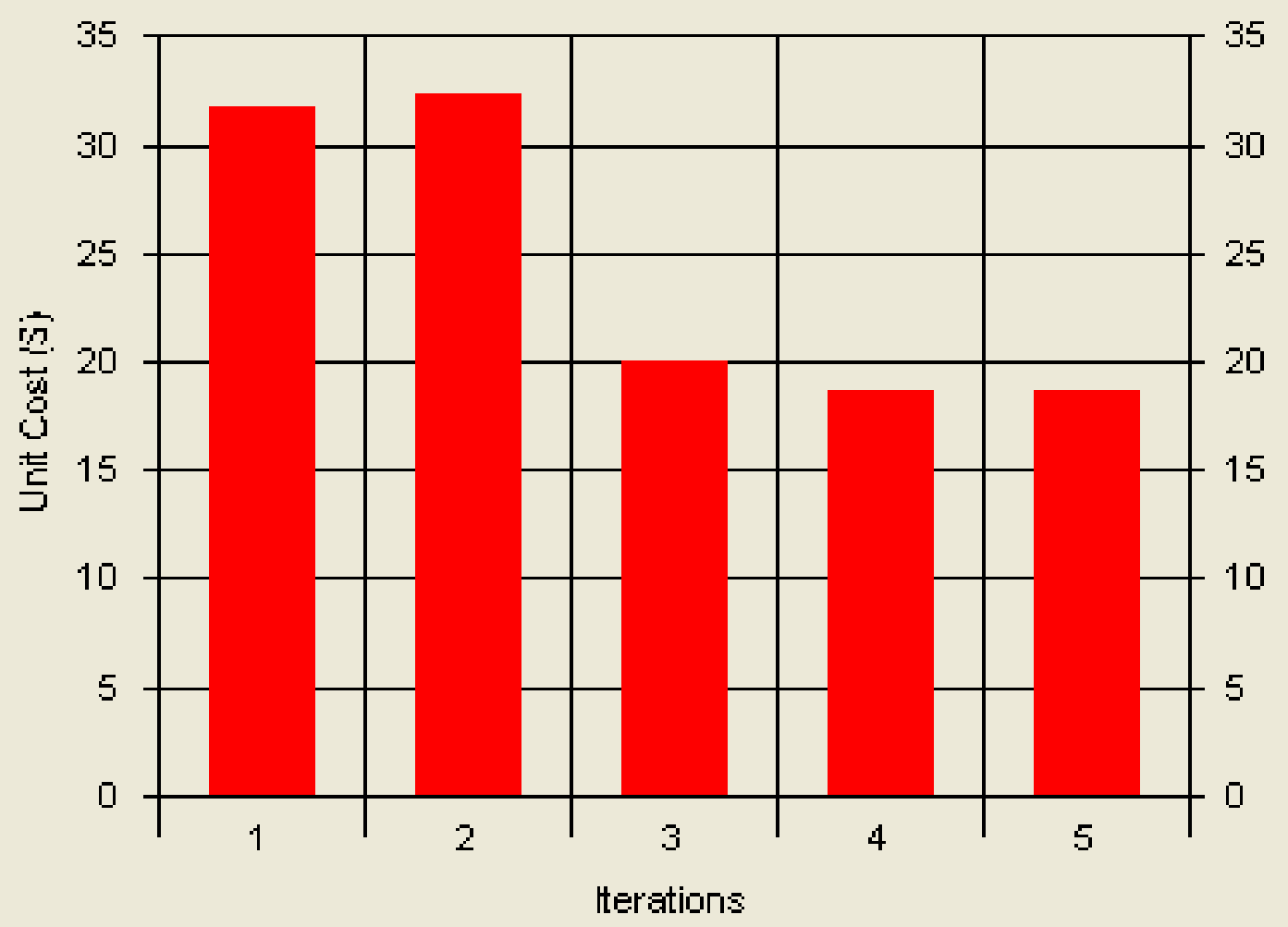

Figure A4. Target Cost Achieved in 5 Iterations 
Table A30. Target Costing Iteration Summary for $13 \%$ Cost Reduction

\begin{tabular}{|l|l|l|l|}
\hline It. No. & Unit Cost & Achie ved & Description \\
\hline 1 & 21.2 & 31.74 & Cutting tool was changed from carbide insert to hss. \\
\hline 2 & 21.2 & 32.41 & Hss was replaced by carbide tip cutting tool. \\
\hline 3 & 21.2 & 20.05 & Carbide tip was replaced by carbide insert. \\
\hline 4 & 20.05 & 18.7 & Purchase price of material was reduced by $10 \%$. \\
\hline 5 & 18.7 & 18.59 & Loading and unloading time was reduced by $10 \%$. \\
\hline 6 & 18.59 & 20.47 & Machine with rapid traverse rate 40 inches/min selected. \\
\hline 7 & 18.59 & 20.09 & Machine with rapid traverse rate 50 inches/min selected. \\
\hline 8 & 18.59 & 18.7 & Machine with rapid traverse rate 60 inches/min selected. \\
\hline 9 & 18.59 & 18.56 & Cost of carbide insert was reduced by $10 \%$. \\
\hline 10 & 18.56 & 18.54 & Rework rate was reduced by $10 \%$. \\
\hline 11 & 18.54 & 18.53 & Setup time was reduced by $10 \%$. \\
\hline 12 & 18.53 & 18.35 & Tool changing time was reduced by $10 \%$. \\
\hline
\end{tabular}

Table A39. Target Costing Summary for Material Price \$200/ton

\begin{tabular}{|c|c|c|c|c|c|}
\hline Trial & $\begin{array}{c}\text { CPUC } \\
\$\end{array}$ & $\begin{array}{c}\text { Reduction } \\
\%\end{array}$ & $\begin{array}{c}\text { Target } \\
\$\end{array}$ & $\begin{array}{c}\text { Achieved } \\
\$\end{array}$ & Iterations \\
\hline 1 & 16.41 & 10 & 14.77 & 22.72 & 4 \\
\hline 2 & 16.41 & 13 & 14.28 & 22.6 & 5 \\
\hline 3 & 16.41 & 14 & 14.11 & 14.00 & 12 \\
\hline
\end{tabular}


Table A40. Target Costing Iteration Summary for $10 \%$ Cost Reduction

\begin{tabular}{|l|l|l|l|}
\hline It. No. & Unit Cost & Achieved & Description \\
\hline 1 & 16.41 & 27.55 & Cutting tool was changed from carbide insert to hss. \\
\hline 2 & 16.41 & 28.25 & Hss was replaced by carbide tip cutting tool. \\
\hline 3 & 16.41 & 15.19 & Carbide tip was replaced by carbide insert. \\
\hline 4 & 15.19 & 14.38 & Purchase price of material was reduced by $10 \%$. \\
\hline
\end{tabular}




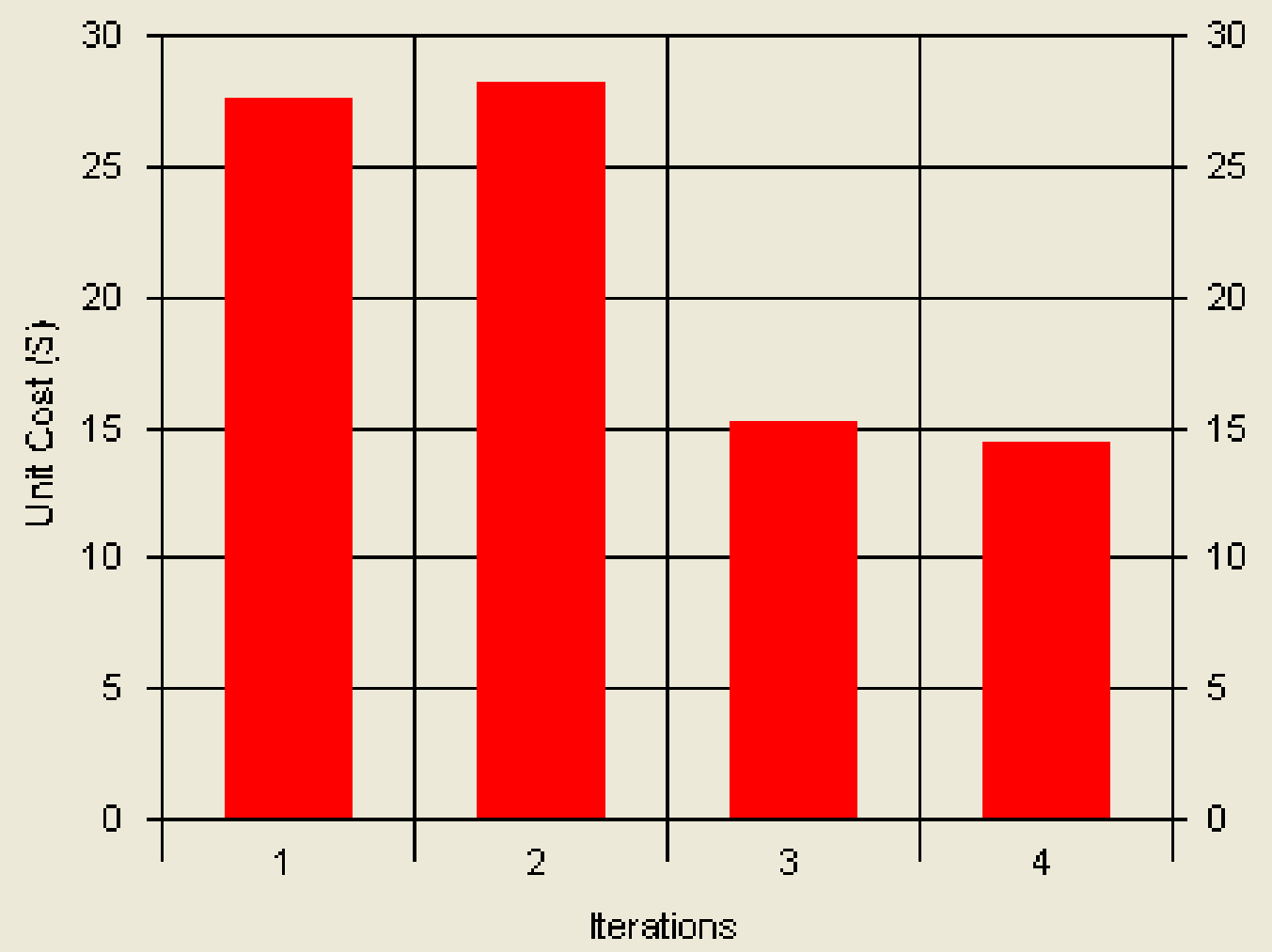

Figure A5. Target Cost Achieved in 4 Iterations

Table A41. Target Costing Iteration Summary for $13 \%$ Cost Reduction

\begin{tabular}{|l|l|l|l|}
\hline It. No. & Unit Cost & Achieved & Description \\
\hline 1 & 16.41 & 27.55 & Cutting tool was changed from carbide insert to hss. \\
\hline 2 & 16.41 & 28.25 & Hss was replaced by carbide tip cutting tool. \\
\hline 3 & 16.41 & 15.19 & Carbide tip was replaced by carbide insert. \\
\hline 4 & 15.19 & 14.38 & Purchase price of material was reduced by $10 \%$. \\
\hline 5 & 14.38 & 14.27 & Loading and unloading time was reduced by $10 \%$. \\
\hline
\end{tabular}


Table A42. Target Costing Iteration Summary for $14 \%$ Cost Reduction

\begin{tabular}{|l|l|l|l|}
\hline It. No. & Unit Cost & Achieved & Description \\
\hline 1 & 16.41 & 27.55 & Cutting tool was changed from carbide insert to hss. \\
\hline 2 & 16.41 & 28.25 & Hss was replaced by carbide tip cutting tool. \\
\hline 3 & 16.41 & 15.19 & Carbide tip was replaced by carbide insert. \\
\hline 4 & 15.19 & 14.38 & Purchase price of material was reduced by $10 \%$. \\
\hline 5 & 14.38 & 14.27 & Loading and unloading time was reduced by $10 \%$. \\
\hline 6 & 14.27 & 16.26 & Machine with rapid traverse rate 40 inches/min selected. \\
\hline 7 & 14.27 & 15.85 & Machine with rapid traverse rate 50 inches/min selected. \\
\hline 8 & 14.27 & 14.38 & Machine with rapid traverse rate 60 inches/min selected. \\
\hline 9 & 14.27 & 14.34 & Rework rate was reduced by $10 \%$. \\
\hline 10 & 14.27 & 14.2 & Cost of carbide insert was reduced by $10 \%$. \\
\hline 11 & 14.2 & 14.19 & Setup time was reduced by $10 \%$. \\
\hline 12 & 14.19 & 14.00 & Tool changing time was reduced by $10 \%$. \\
\hline
\end{tabular}




\title{
APPENDIX B
}

\section{Program to Control the Input Form 1}

\author{
Dim flag As Integer \\ Private Sub Command1_Click() \\ Form8.Show \\ End Sub
}

Private Sub conditionlist_MouseUp(Button As Integer, Shift As Integer, X As Single, Y As Single)

For $\mathrm{i}=0$ To conditionlist.ListIndex

Select Case (i)

Case 0 hardnesslist.Clear

hardnesslist.AddItem ("100 - 125")

hardnesslist.AddItem ("125 - 150")

Case 1

hardnesslist.Clear

hardnesslist.AddItem ("150 - 175")

hardnesslist.AddItem ("175 - 200")

Case 2

hardnesslist.Clear

hardnesslist.AddItem ("200 - 225")

hardnesslist.AddItem ("225 - 250")

Case 3

hardnesslist.Clear

hardnesslist.AddItem ("250 - 275")

hardnesslist.AddItem ("275 - 300")

End Select

Next i

End Sub

Private Sub Form_Load()

flag $=0$

For $\mathrm{i}=0$ To 3

Select Case (i)

Case 0 conditionlist.AddItem ("Hot Rolled or Annealed")

Case 1 conditionlist.AddItem ("Cold Drawn")

Case 2 conditionlist.AddItem ("Hot Rolled Nor, Ann or CD")

Case 3

conditionlist.AddItem ("Quenched and Temp") 
End Select

Next i

conditionlist.Selected $(0)=$ False

End Sub

Private Sub nextform1_Click()

ID = Val(IDtext.Text)

$\mathrm{L}=\mathrm{Val}$ (ILtext.Text)

Dfin $=\operatorname{Val}($ FDtext.Text $)$

$\mathrm{Nl}=\mathrm{Val}($ Bstext.Text $)$

den $=\operatorname{Val}($ dentext.Text $)$

matl_price $=\mathrm{Val}($ mptext.Text $)$

$\mathrm{d}=\operatorname{Val}($ doctext.Text)

$\mathrm{r}=\mathrm{Val}($ rapidtext.Text)

$\mathrm{tl}=\mathrm{Val}($ loadtext.Text $)$

$\mathrm{M}=\mathrm{Val}$ (machhrtext.Text)

$\mathrm{t} 0=\mathrm{Val}($ setuptext. Text)

tc $=$ Val(tchtext.Text)

$\mathrm{a}=\mathrm{Val}($ apptext.Text)

$\mathrm{e}=\mathrm{Val}($ overtext.Text)

rejectionrate $=(\operatorname{Val}($ rejectiontext.Text $)) / 100$

per_rework $=$ Val(reworktext.Text)

reworkrate $=\operatorname{Val}($ reworkratetext.Text $)$

$\mathrm{SF}=\mathrm{Val}($ SFmaxtext.Text)

$\mathrm{HP}=\mathrm{Val}(\mathrm{HPmaxtext}$. Text $)$

matl_cond $=$ conditionlist. Text

matl_hard = hardnesslist.Text

var $=$ hardnesslist.ListIndex

If (IDtext.Text = "" Or FDtext.Text = "" Or Fltext.Text = "" Or ILtext.Text = "" Or dentext.Text $=" "$ Or Bstext.Text $=$ " Or mptext.Text $=" "$ Or doctext.Text $=" "$ Or rapidtext.Text $=$ "" Or loadtext.Text $=$ "" Or machhrtext.Text $=$ "" Or _

rejectiontext.Text $=$ "" Or reworkratetext.Text $=$ "" Or reworktext.Text $=$ "" Or overtext.Text $=$ "" Or apptext.Text $=$ "" Or tchtext.Text $=$ "" Or

setuptext.Text $=$ "" Or HPmaxtext.Text $=$ "" Or SFmaxtext.Text = "" Or btext.Text $=$ "" Or ctext.Text $=$ "" Or etext.Text $=$ "" Or

gtext.Text $=$ "" Or htext.Text $=$ "" Or itext.Text $=$ "" Or Cmtext.Text $=$ "" Or_

Cstext.Text $=$ "") Then

MsgBox "Some data is missing. Please fill in all the data"

Exit Sub

End If

conditionlist.Refresh

If conditionlist.Selected $(0)=$ True Or conditionlist. Selected $(1)=$ True

Or conditionlist. Selected $(2)=$ True Or conditionlist.Selected $(3)=$ True Then

If hardnesslist.Selected $(0)=$ True Or hardnesslist.Selected $(1)=$ True Then

flag $=1$ 
Else

MsgBox " Please select the material hardness"

End If

Else

MsgBox " Please select the material condition"

End If

If flag $=1$ Then

Form2.Show

Form1.Hide

End If

End Sub 


\section{APPENDIX C}

\section{Program to Control the Input Form 2}

Dim D1, D2, D3, D4 As Double

Dim X1, X2, X3, X5, X6, X7, X8, X9, X10, X11, X12, X13 As Double

Dim flag As Integer

Private Sub backform2_Click()

Form1.Show

Form2.Hide

resultsform2.Enabled $=$ False

calculate .Enabled $=$ True

End Sub

Private Sub calculate_Click()

flag $=0$

If $(($ hss. Value $=$ False $)$ And $($ carbidetip. Value $=$ False $)$ And $($ carbideinsert Value $=$ False $))$

Then

MsgBox " Please Select the Tool Type"

Exit Sub

End If

If $($ mtext.Text $=$ "" Or ntext.Text $=$ "" Or ptext.Text $=$ "") Then

MsgBox " Please enter all Tool Life Exponents "

Exit Sub

End If

If hss. Value $=$ True Then

If Gwctext.Text = "" Or Tstext.Text = "" Or Lrgtext.Text = "" Or toolprice.Text $=$ "" Or Toollifeconsttext.Text $=$ "" Then

MsgBox "Please fill in all data"

Else

flag $=1$

End If

ElseIf carbidetip. Value $=$ True Then

If Gwctext.Text = "" Or Tstext.Text = "" Or Lrgtext.Text = "" Or toolprice. Text $=$ "" Or Lrbtext.Text $=$ "" Or k2text.Text $=$ "" Or_ Toollifeconsttext.Text $=$ "" Then

MsgBox "Please fill in all data"

Else

flag $=1$

End If

ElseIf carbideinsert. Value $=$ True Then

If Cictext.Text $=$ "" Or k3text.Text $=$ "" Or Toollifeconsttext.Text $=$ "" Then MsgBox "Please fill in all data"

Else 
flag $=1$

End If

End If

If flag $=1$ Then

$\mathrm{X} 1=\mathrm{Val}$ (Form1.btext.Text)

$\mathrm{X} 2=\mathrm{Val}$ (Form1.ctext.Text)

$\mathrm{X} 3=\mathrm{Val}($ Form1.etext.Text)

$\mathrm{X} 4=\mathrm{Val}$ (Form1.gtext.Text)

$\mathrm{X} 5=\mathrm{Val}$ (Form1.htext.Text)

$\mathrm{X} 6=\mathrm{Val}$ (Form1.itext.Text)

$\mathrm{X} 7=\operatorname{Val}($ mtext.Text $)$

$\mathrm{X} 8=\mathrm{Val}($ ntext.Text $)$

$\mathrm{X} 9=\mathrm{Val}($ ptext.Text $)$

$\mathrm{X} 10=\mathrm{Val}($ Form1.Cstext.Text $)$

$\mathrm{X} 11=\mathrm{Val}$ (Form1.Cmtext.Text)

D3 $=0$

$\mathrm{D} 4=(1-\mathrm{X} 7) /(\mathrm{X} 5-\mathrm{X} 4 * \mathrm{X} 7)$

$\mathrm{D} 2=(\mathrm{X} 8 *(\mathrm{X} 5-\mathrm{X} 4)) /(\mathrm{X} 5-\mathrm{X} 4 * \mathrm{X} 7)$

$\mathrm{D} 1=1-\mathrm{D} 2$

Csdash $=\mathrm{X} 10 *\left(\mathrm{Val}(\text { Form1.doctext.Text })^{\wedge} \mathrm{X} 6\right) / \mathrm{SF}$

Cmdash $=\mathrm{X} 11 *\left(\mathrm{Val}(\text { Form1.doctext.Text })^{\wedge} \mathrm{X} 3\right) / \mathrm{HP}$

$\mathrm{C} 1$ dash $=(3.14 * \mathrm{ID} * \mathrm{~L} * \mathrm{M}) /(12 * 60)$

$\mathrm{X} 12=\left(\mathrm{C} 1 \mathrm{dash} *\left(\mathrm{~d}^{\wedge}(\mathrm{X} 9 / \mathrm{X} 8)\right)\right) /\left(\mathrm{Val}(\text { Toollifeconsttext.Text })^{\wedge}(1 / \mathrm{X} 8)\right)$

If (hss. Value $=$ True Or carbidetip. Value $=$ True) Then

$\mathrm{X} 13=((\mathrm{M} * \mathrm{tc} / 60)+\mathrm{Val}($ toolprice.Text $)) * 60 / \mathrm{M}$

Else

$\mathrm{X} 13=((\mathrm{M} * \mathrm{tc} / 60)+\operatorname{Val}($ Cictext.Text $)) * 60 / \mathrm{M}$

End If

$\mathrm{C} 2$ dash $=\mathrm{X} 12 * \mathrm{X} 13$

If (D2 $>=0$ And D2 $<=1$ And D4 $>=0$ ) Then

Dual_D2 = D2

Else

Dual_D2 = "Not feasible"

End If

If $(\mathrm{D} 2>=0$ And D2 $<=1$ And D4 $>=0)$ Then

Dual_D4 = D4

Else

Dual_D4 = "Not feasible"

End If

$\mathrm{fr}=\left(\mathrm{Csdash}^{\wedge}(1 /(\mathrm{X} 7 * \mathrm{X} 4-\mathrm{X} 5))\right) *\left(\mathrm{C} 1\right.$ dash $\left.*(1-\mathrm{D} 1) /\left(\mathrm{C} 2 \operatorname{dash}^{*} \mathrm{D} 1\right)\right) \wedge(\mathrm{X} 8 * \mathrm{X} 4 /$

$(\mathrm{X} 7 * \mathrm{X} 4-\mathrm{X} 5))$

$\mathrm{v}=1 /\left(\mathrm{Csdash}^{*}\left(\mathrm{fr}^{\wedge} \mathrm{X} 5\right)\right)^{\wedge}(1 / \mathrm{X} 4)$

If (Dual_D2 = "Not feasible" Or Dual_D4 = "Not feasible") Then

z1 = "not feasible" ' case 1 


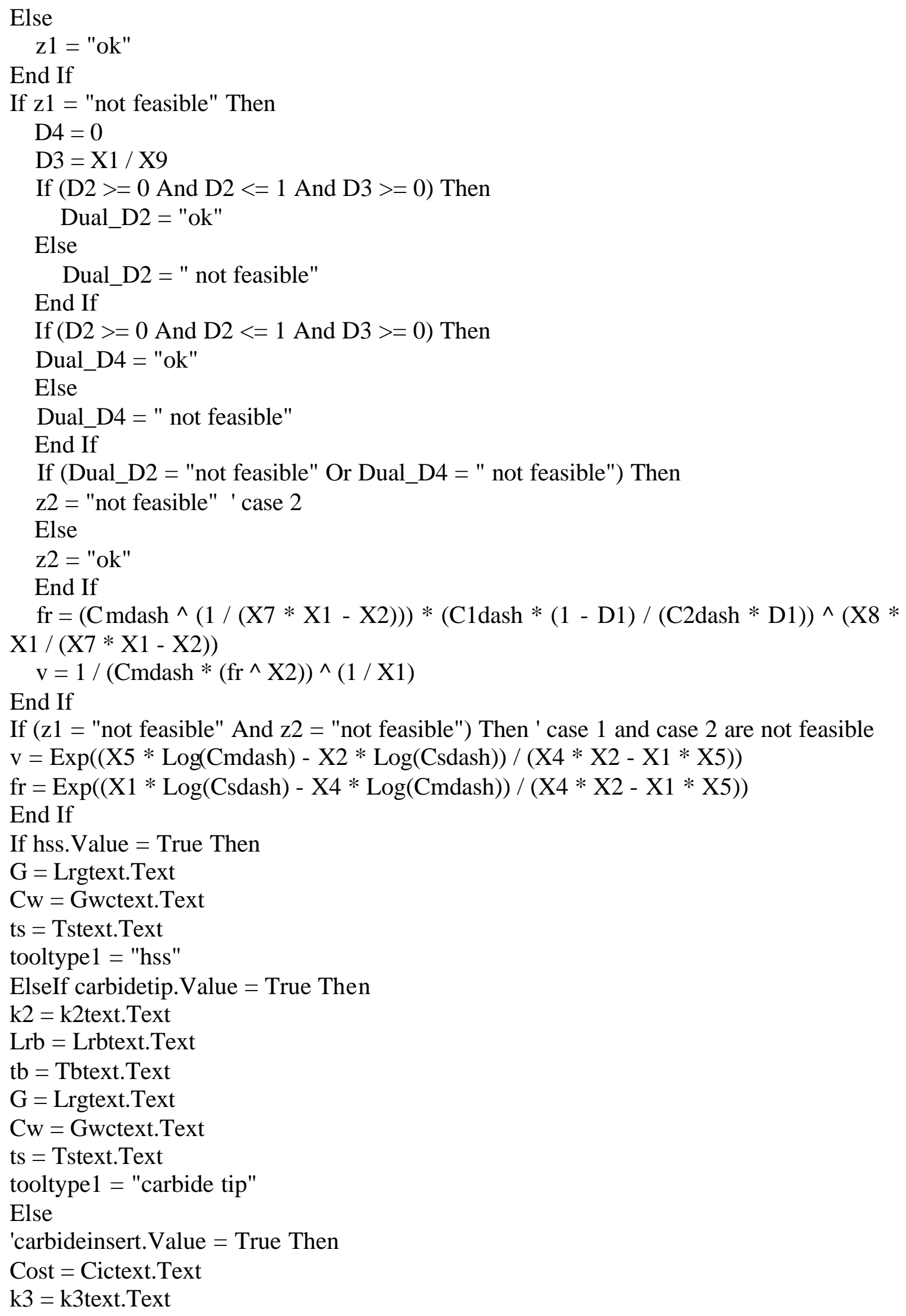




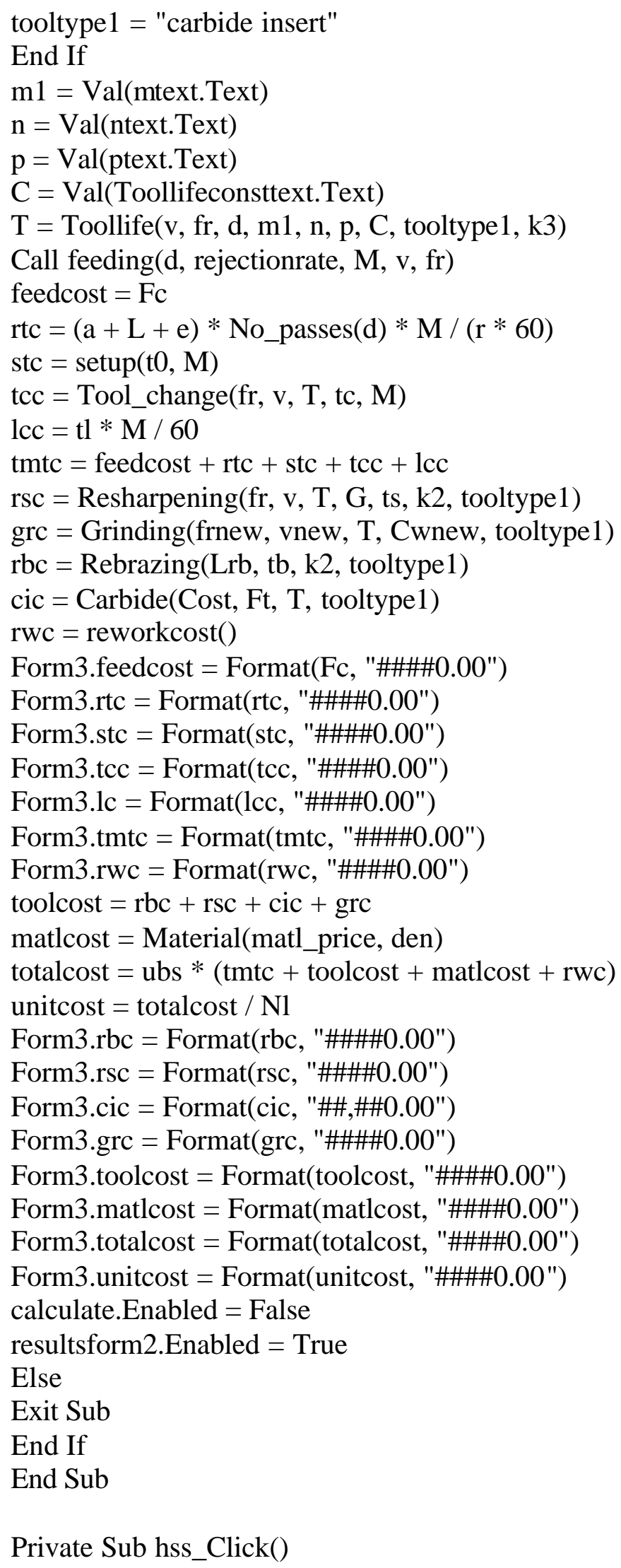




$$
\begin{aligned}
& \text { lrglabel.Visible }=\text { True } \\
& \text { Lrgtext.Visible }=\text { True } \\
& \text { gwclabel.Visible }=\text { True } \\
& \text { Gwctext.Visible }=\text { True } \\
& \text { tslabel.Visible }=\text { True } \\
& \text { Tstext.Visible }=\text { True } \\
& \text { tblabel.Visible }=\text { False } \\
& \text { Tbtext.Visible }=\text { False } \\
& \text { lrblabel.Visible }=\text { False } \\
& \text { Lrbtext.Visible }=\text { False } \\
& \text { ciclabel.Visible }=\text { False } \\
& \text { Cictext.Visible }=\text { False } \\
& \text { k2label.Visible }=\text { False } \\
& \text { k2text.Visible }=\text { False } \\
& \text { k3label.Visible }=\text { False } \\
& \text { k3text.Visible }=\text { False } \\
& \text { Tclabel.Visible }=\text { True } \\
& \text { toolprice.Visible }=\text { True } \\
& \text { Label6.Visible }=\text { True } \\
& \text { Label5.Visible }=\text { False } \\
& \text { Label2.Visible }=\text { False } \\
& \text { Label3.Visible }=\text { True } \\
& \text { Label4.Visible }=\text { True } \\
& \text { Label7. Visible }=\text { False } \\
& \text { Label8.Visible }=\text { True } \\
& \text { End Sub } \\
& \text { Private Sub carbidetip_Click() } \\
& \text { lrglabel.Visible }=\text { True } \\
& \text { Lrgtext.Visible }=\text { True } \\
& \text { gwclabel.Visible }=\text { True } \\
& \text { Gwctext.Visible }=\text { True } \\
& \text { tslabel.Visible }=\text { True } \\
& \text { Tstext.Visible }=\text { True } \\
& \text { tblabel.Visible }=\text { True } \\
& \text { Tbtext.Visible }=\text { True } \\
& \text { lrblabel.Visible }=\text { True } \\
& \text { Lrbtext.Visible }=\text { True } \\
& \text { k2label.Visible }=\text { True } \\
& \text { k2text.Visible }=\text { True } \\
& \text { k3label.Visible }=\text { False } \\
& \text { k3text.Visible }=\text { False } \\
& \text { ciclabel.Visible }=\text { False } \\
& \text { Cictext.Visible }=\text { False } \\
& \text { Tclabel.Visible }=\text { True } \\
& \text { toolprice.Visible }=\text { True } \\
& \text { Label6.Visible }=\text { True } \\
&
\end{aligned}
$$




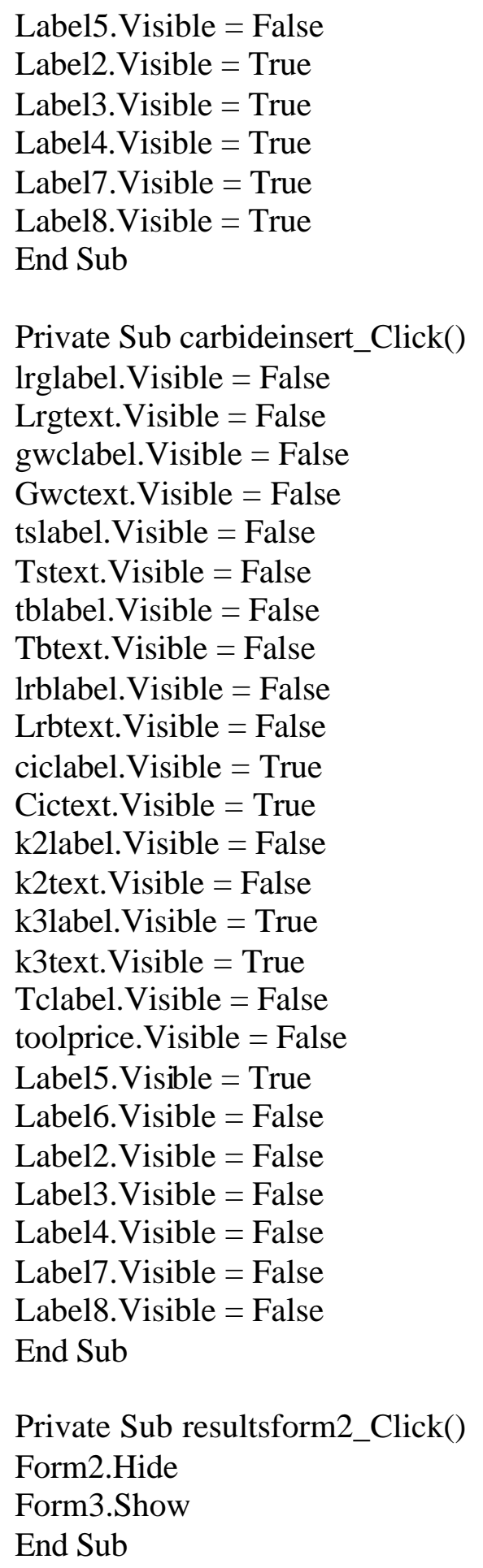




\section{APPENDIX D}

\section{Program to Control Form 3}

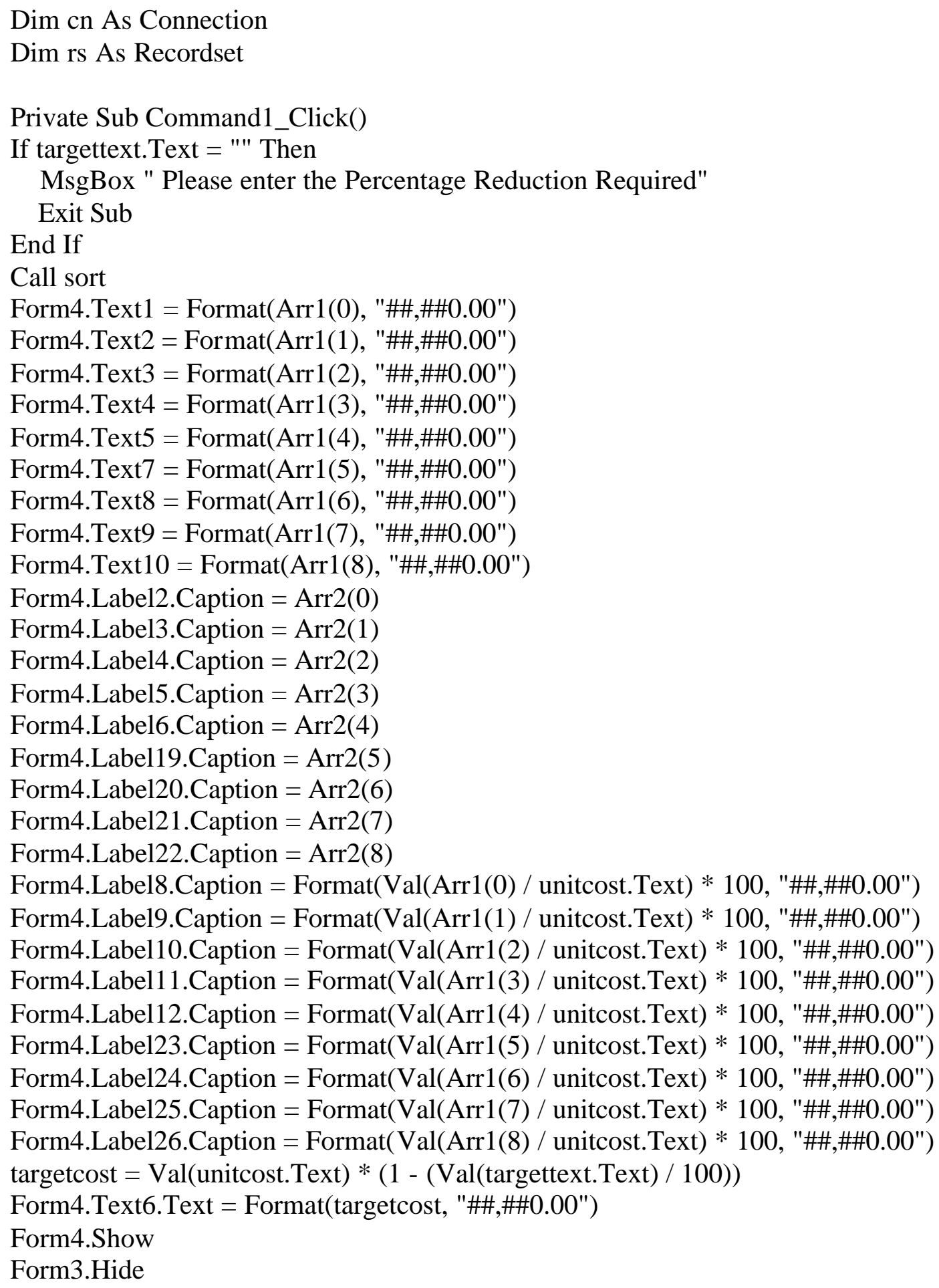


End Sub

Private Sub Command2_Click()

Form3.Hide

Form2.Show

End Sub 


\section{APPENDIX E}

\section{Program to Control Form 4}

Private Sub Achieve_Click()

Dim con As New ADODB.Connection

Dim cmd As New ADODB.Command

Dim rs As New ADODB.Recordset

Dim unitcost1 As Single con.Open "Provider=Microsoft.Jet.OLEDB.4.0;" \& _

"Data $\quad$ Source $=\quad C:$ Documents $\quad$ and SettingslameetlMy

Documents $\backslash$ researchlvbcodeltarget.mdb;" \&

"User Id=Admin;" \& _

"Password"

unitcost $1=1000$

Achieve.Enabled $=$ False

'For $\mathrm{j}=0$ To 10

'Select Case (Arr2(j))

'Case "Feeding Cost"

'stri $=$ "select $*$ from tools where Condition $=$ "' \& matl_cond \& "' and Hardness $=$ "' \& matl_hard \& "'"

'stri $=$ "select $*$ from HRA1 "

'rs.Open "select * from tools where Condition = "' \& matl_cond \& "' and Hardness = "' \& matl_hard \& "'", con, adOpenStatic, adLockPessimistic

If matl_cond = "Hot Rolled or Annealed" And matl_hard = "100 - 125" Then rs.Open "select* from HRAlo ", con, adOpenStatic, adLockPessimistic

End If

If matl_cond = "Hot Rolled or Annealed" And matl_hard = "125 - 150" Then

rs.Open "select* from HRAhi ", con, adOpenStatic, adLockPessimistic

End If

If matl_cond = "Cold Drawn" And matl_hard = "150 - 175" Then

rs.Open "select* from CDlo ", con, adOpenStatic, adLockPessimistic

End If

If matl_cond = 'Cold Drawn" And matl_hard = "175 - 200" Then

rs.Open "select* from CDhi ", con, adOpenStatic, adLockPessimistic

End If

If matl_cond = "Hot Rolled Nor, Ann or CD" And matl_hard = "200 - 225" Then rs.Open "select* from HRNACDlo ", con, adOpenStatic, adLockPessimistic

End If

If matl_cond = "Hot Rolled Nor, Ann or CD" And matl_hard = "225 - 250" Then rs.Open "select* from HRNACDhi ", con, adOpenStatic, adLockPessimistic End If

If matl_cond = "Quenched and Temp" And matl_hard = "250 - 275" Then rs.Open "select* from QTlo ", con, adOpenStatic, adLockPessimistic 


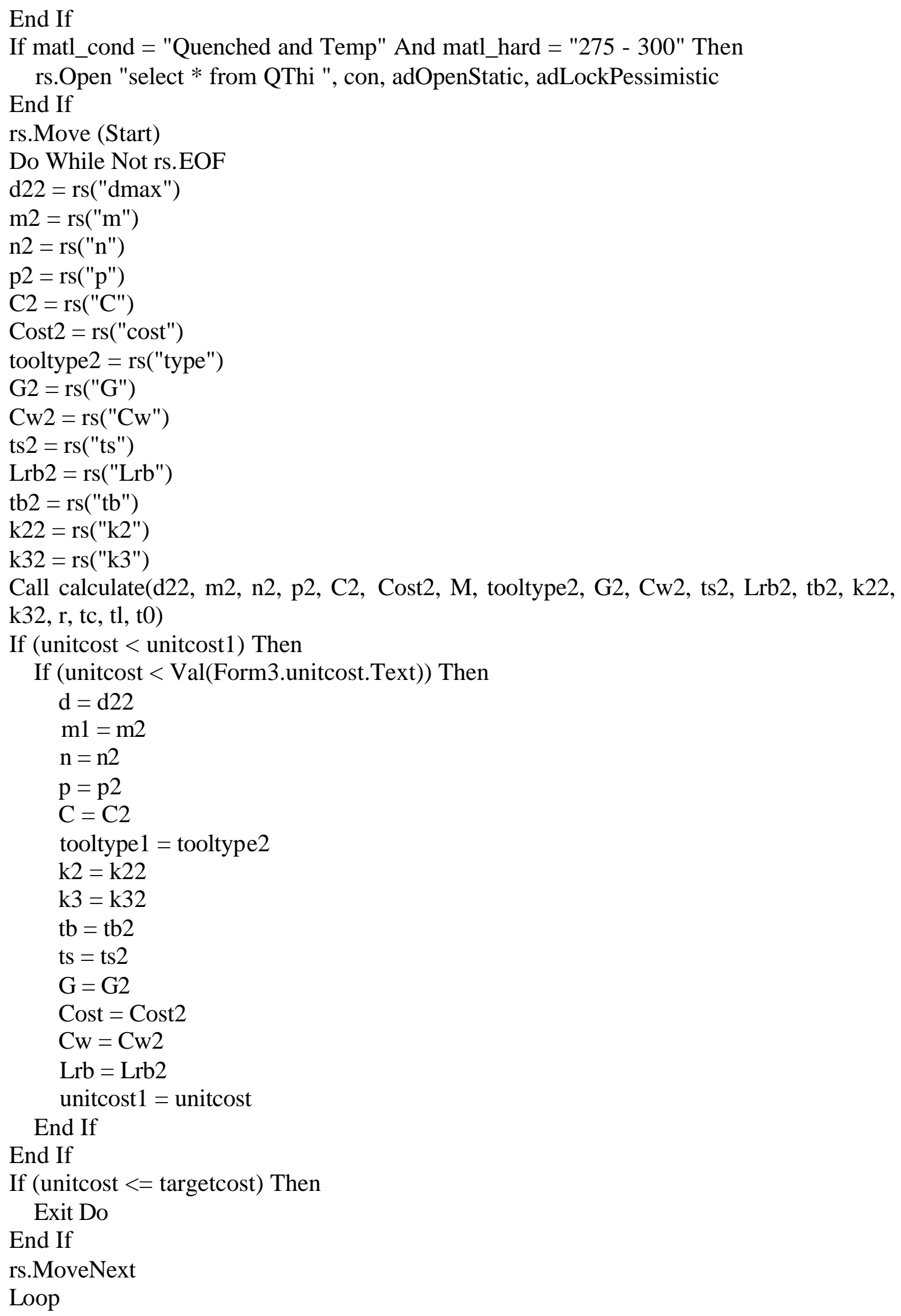


rs.Close

'If (unitcost $<=$ targetcost) Then

"targetlabel. Visible $=$ True

- Exit For

'End If

'Call sort

For $\mathrm{j}=1$ To 10

If (unitcost $<=$ targetcost) Then

Exit For

\section{End If}

Select Case (Arr2(j))

Case "Rapid Traverse Cost"

mcexplore $=$ yes

rs.Open "select * from machine ", con, adOpenForwardOnly, adLockReadOnly

Do While Not rs.EOF

M3 = rs("Machinehourrate")

r3 = rs("Rapidtraverserate")

t03 = rs("Settime")

$\mathrm{t} 13=\mathrm{rs}($ "Loadunloadtime")

tc3 = rs("Toolchtime")

mctype 3 = rs("Name")

Call calculate(d, m1, n, p, C, Cost, M3, tooltype1, G, Cw, ts, Lrb, tb, k2, k3, r3, tc3, t13, t03)

If (unitcost < unitcost1) Then

If (unitcost $<\mathrm{Val}$ (Form3.unitcost.Text)) Then

$\mathrm{M}=\mathrm{M} 3$

$\mathrm{r}=\mathrm{r} 3$

$\mathrm{t} 0=\mathrm{t} 03$

$\mathrm{tl}=\mathrm{tl} 3$

$\mathrm{tc}=\mathrm{tc} 3$

mctype $=$ mctype 3

unitcost $1=$ unitcost

End If

End If

If (unitcost $<=$ targetcost) Then

Exit Do

End If

rs.MoveNext

Loop

rs. Close

If (unitcost $<=$ targetcost) Then

'targetlabel. Visible $=$ True

Exit For

End If 
Case "Setup Cost"

response $=$ InputBox ("Can you reduce the Setup time? Please enter the percentage")

$\mathrm{t} 0=\mathrm{t} 0 *((100-\mathrm{Val}($ response $)) / 100)$

Call calculate(d, m1, n, p, C, Cost, M, tooltype1, G, Cw, ts, Lrb, tb, k2, k3, r, tc, tl, t0)

If (unitcost $<=$ targetcost) Then

'targetlabel. Visible $=$ True

Exit For

End If

Case "Loading and Unloading Cost"

response $=$ InputBox ("Can you reduce the Loading and Unloading Time? Please enter the percentage")

$\mathrm{tl}=\mathrm{tl} *((100-\mathrm{Val}($ response $)) / 100)$

Call calculate(d, m1, n, p, C, Cost, M, tooltype1, G, Cw, ts, Lrb, tb, k2, k3, r, tc, tl, t0)

If (unitcost $<=$ targetcost) Then

'targetlabel. Visible $=$ True

Exit For

End If

Case "Tool Changing Cost"

response $=$ InputBox("Can you reduce the Tool Changing Time? Please enter the percentage")

tc $=$ tc $*((100-\mathrm{Val}($ response $)) / 100)$

Call calculate(d, m1, n, p, C, Cost, M, tooltype1, G, Cw, ts, Lrb, tb, k2, k3, r, tc, tl, t0)

If (unitcost $<=$ targetcost) Then

'targetlabel.Visible $=$ True

Exit For

End If

Case "Rebrazing Cost"

response = InputBox ("Can you reduce the Rebrazing Time? Please enter the percentage") $\mathrm{tb}=\mathrm{tb} *((100-\mathrm{Val}($ response $)) / 100)$

Call calculate(d, m1, n, p, C, Cost, M, tooltype1, G, Cw, ts, Lrb, tb, k2, k3, r, tc, tl, t0)

If (unitcost $<=$ targetcost) Then

'targetlabel. Visible $=$ True

Exit For

End If

Case "Resharpening Cost"

response $=$ InputBox $($ "Can you reduce the Resharpening Time? Please enter the percentage")

ts $=$ ts $*((100-\operatorname{Val}($ response $)) / 100)$

Call calculate(d, m1, n, p, C, Cost, M, tooltype1, G, Cw, ts, Lrb, tb, k2, k3, r, tc, tl, t0)

If (unitcost $<=$ targetcost) Then 
'targetlabel. Visible $=$ True

Exit For

End If

Case "Carbide Insert Cost"

response $=$ InputBox("Can you reduce the Cost per carbide insert? Please enter the percentage")

Cost $=$ Cost $*((100-\operatorname{Val}($ response $)) / 100)$

Call calculate(d, m1, n, p, C, Cost, M, tooltype1, G, Cw, ts, Lrb, tb, k2, k3, r, tc, tl, t0)

If (unitcost $<=$ targetcost) Then

'targetlabel. Visible $=$ True

Exit For

End If

Case "Material Cost"

response = InputBox("Can you reduce the Material Price? Please enter the percentage", "Material_Cost", 0)

matl_price $=$ matl_price $*((100-\mathrm{Val}($ response $)) / 100)$

Call calculate(d, m1, n, p, C, Cost, M, tooltype1, G, Cw, ts, Lrb, tb, k2, k3, r, tc, tl, t0)

If (unitcost $<=$ targetcost) Then

'targetlabel. Visible $=$ True

Exit For

End If

Case "Rework Cost"

response = InputBox ("Can you reduce the Rework Rate? Please enter the percentage", "Material_Cost", 0)

reworkrate $=$ reworkrate $*((100-\mathrm{Val}($ response $)) / 100)$

Call calculate(d, m1, n, p, C, Cost, M, tooltype1, G, Cw, ts, Lrb, tb, k2, k3, r, tc, tl, t0)

If (unitcost $<=$ targetcost) Then

'targetlabel. Visible $=$ True

Exit For

End If

End Select

Next j

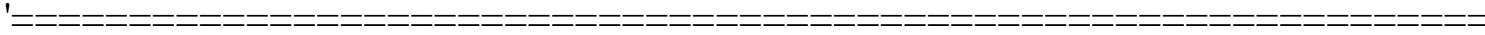

=ニニ=ニニ=ニ=ニニ=ニ=ニ

If (unitcost $<=$ targetcost) Then

targetlabel. Visible $=$ True

Else

Notarget. Visible $=$ True

End If

con.Close

Set $\operatorname{con}=$ Nothing

'If (unitcost > targetcost) Then 


\author{
' Label17. Visible $=$ True \\ 'Else \\ Command2.Enabled $=$ True \\ 'End If \\ End Sub \\ Private Sub Command1_Click() \\ Form4.Hide \\ Form3.Show \\ Achieve. Enabled $=$ True \\ targetlabel. Visible $=$ False \\ Notarget. Visible $=$ False \\ End Sub
}

Private Sub Command2_Click()

Form5.feedcosttgt = Format(feedcost, "\#\#\#\#0.00")

Form5.rtctgt = Format(rtc, "\#\#\#\#0.00")

Form5.stctgt $=$ Format(stc, "\#\#\#0.00")

Form5.tcctgt $=$ Format (tcc, "\#\#\#\#0.00")

Form5.lctgt = Format (lcc, "\#\#\#\#0.00")

Form5.tmtctgt = Format (tmtc, "\#\#\#\#0.00")

Form5.rsctgt = Format(rsc, "\#\#\#\#0.00")

Form5.rbctgt = Format(rbc, "\#\#\#\#0.00")

Form5.grctgt $=$ Format (grc, "\#\#\#\#0.00")

Form5.cictgt = Format (cic, "\#\#\#0.00")

Form5.toolcosttgt = Format(toolcost, "\#\#\#\#0.00")

Form5.matlcosttgt = Format (matlcost, "\#\#\#\#0.00")

Form5.reworktgt = Format(rwc, "\#\#\#\#0.00")

Form5.totalcosttgt = Format (totalcost, "\#\#\#\#0.00")

Form5.unitcosttgt = Format (unitcost, "\#\#\#0.00")

Form5.fcpre $=\mathrm{Val}($ Form3.feedcost $)$

Form5.stcpre $=$ Val (Form3.stc)

Form5.rtcpre $=$ Val(Form3.rtc)

Form5.tccpre $=\operatorname{Val}($ Form3.tcc $)$

Form5.1ccpre $=$ Val (Form3.1c)

Form5.rbcpre $=\mathrm{Val}($ Form3.rbc $)$

Form5.grcpre $=$ Val $($ Form3.grc $)$

Form5 .cicpre $=$ Val(Form3 .cic $)$

Form5.rscpre $=\operatorname{Val}($ Form3.rsc $)$

Form5.tmtcpre $=\mathrm{Val}($ Form3.tmtc $)$

Form5.reworkpre $=\mathrm{Val}($ Form3.rwc $)$

Form5.toolcostpre $=\mathrm{Val}($ Form3.toolcost $)$

Form5.matlcostpre $=$ Val $($ Form3.matlcost $)$

Form5. unitcostpre $=\mathrm{Val}($ Form3 .unitcost $)$

Form5.totalcostpre = Format(Val(Form3.totalcost.Text), "\#\#,\#\#0.00")

Form4.Hide 
Form5.Show

End Sub 


\section{APPENDIX F}

\section{Program to Control Form 5}

Private Sub Command1_Click()

Form4.Show

Form5.Hide

End Sub

Private Sub Command2_Click()

Form6.Show

Unload Me

End Sub 


\section{APPENDIX G}

\section{Program to Control Form 6}

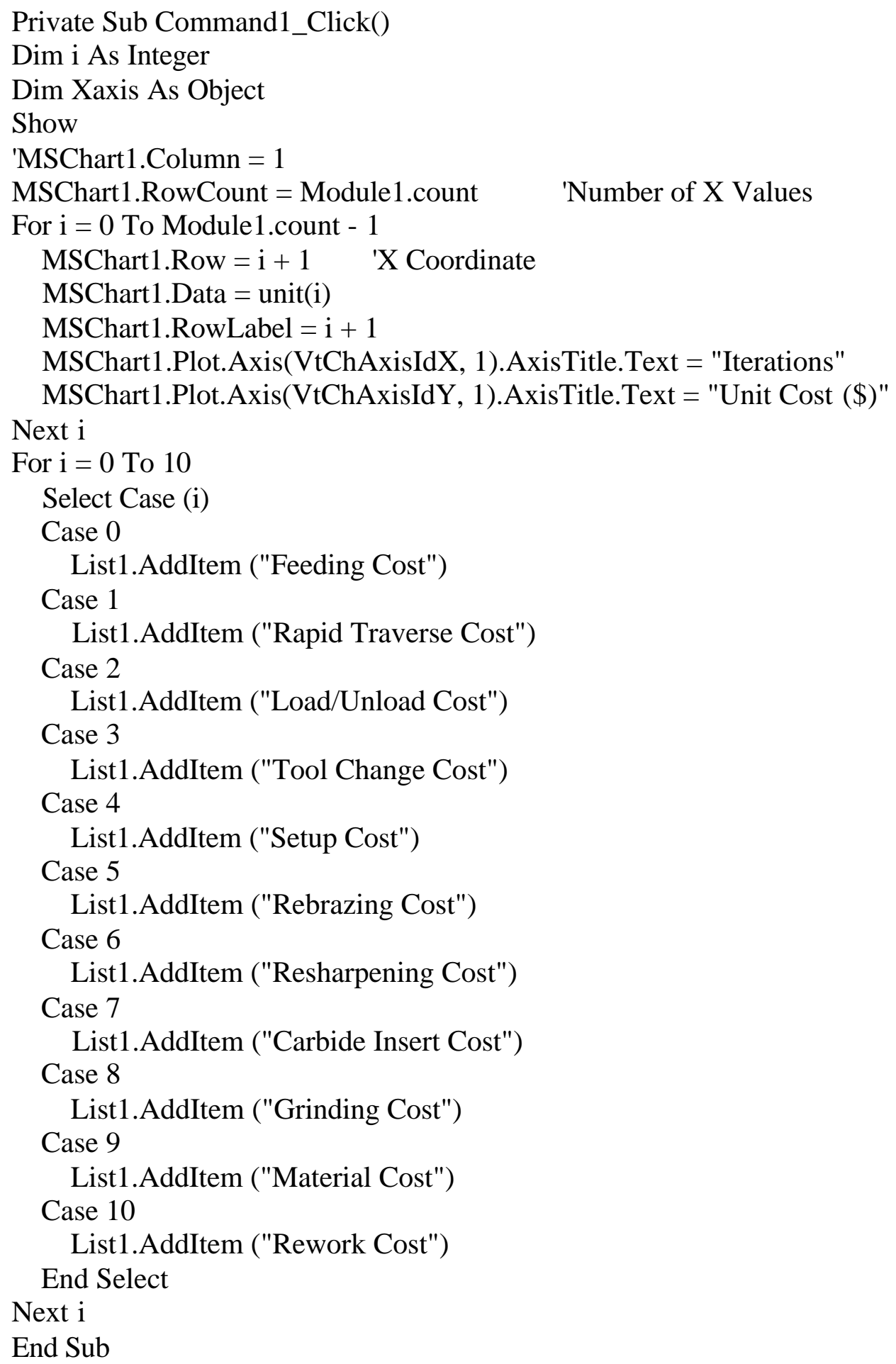


Private Sub Command2_Click()

num $=0$

Form7.MSFlexGrid1.Col $=0$ ' Setting the column number $=0$

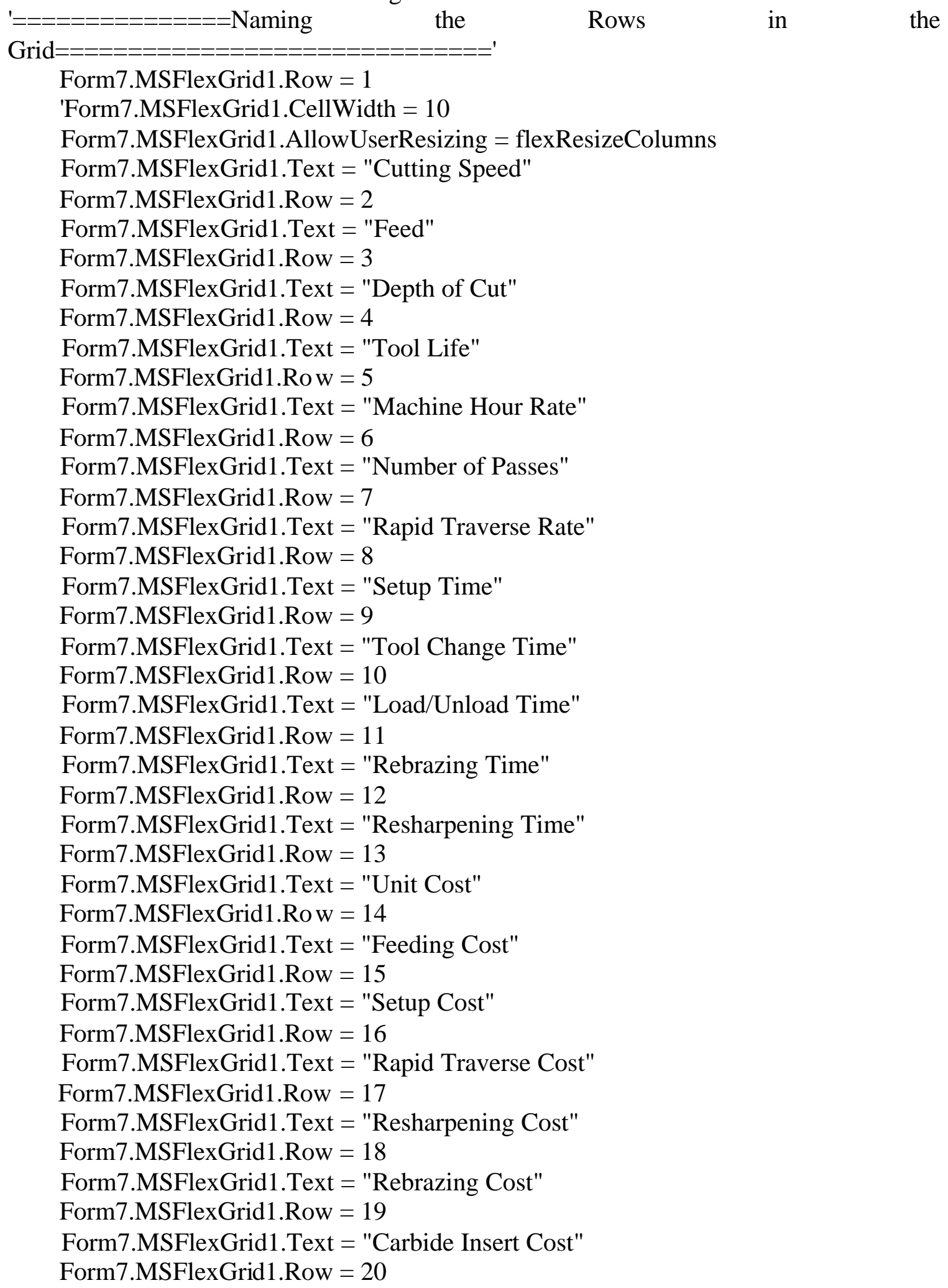




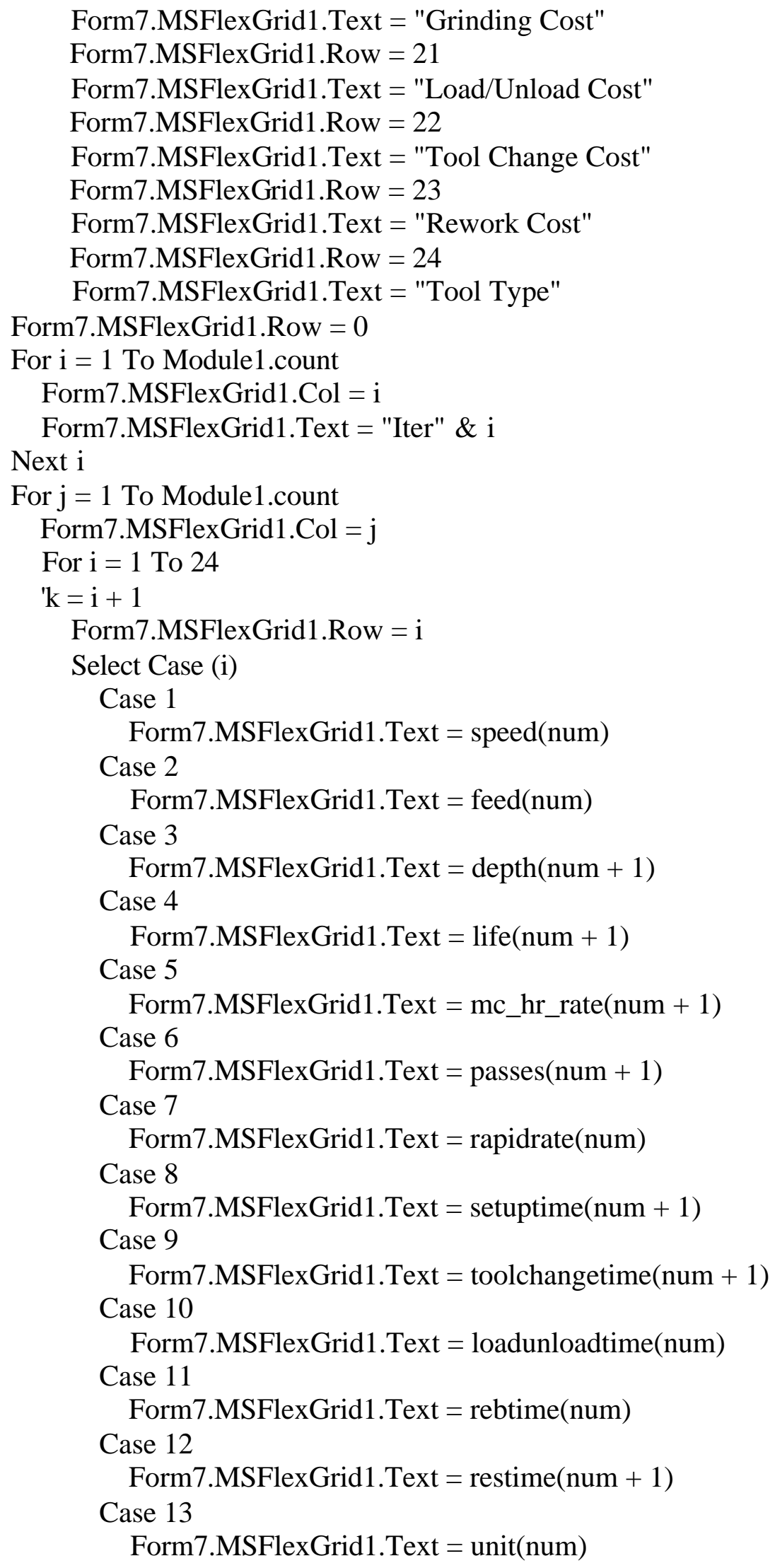


Case 14

Form7.MSFlexGrid1. Text $=$ feeding cost(num)

Case 15

Form7.MSFlexGrid1.Text $=$ setupcost $($ num $)$

Case 16

Form7.MSFlexGrid1. Text $=$ rapidcost $($ num $)$

Case 17

Form7.MSFlexGrid1. Text $=\operatorname{rescost}($ num $)$

Case 18

Form7.MSFlexGrid1. Text $=$ rebcost(num)

Case 19

Form7.MSFlexGrid1. Text $=$ carbidecost $($ num $)$

Case 20

Form7.MSFlexGrid1.Text $=$ grindcost $($ num $)$

Case 21

Form7.MSFlexGrid1.Text = loadcost $($ num $)$

Case 22

Form7.MSFlexGrid1. Text $=$ toolchcost $($ num $)$

Case 23

Form7.MSFlexGrid1. Text $=$ rew $($ num $)$

Case 24

Form7.MSFlexGrid1.Text = tool_type $($ num +1$)$

End Select

Next i

num $=$ num +1

Next j

Unload Me

Form7.Show

End Sub

Private Sub Command3_Click()

Dim flag As Integer

flag $=0$

If List1.Selected $(0)=$ True Or List1.Selected $(1)=$ True

Or List1.Selected $(2)=$ True Or List1.Selected $(3)=$ True Or List1.Selected(4) $=$ True

Or List1.Selected $(5)=$ True Or List1.Selected $(6)=$ True Or List1.Selected $(7)=$ True

Or List1.Selected $(8)=$ True Or List1.Selected $(9)=$ True Or List1.Selected $(10)=$ True

Then

flag $=1$

Else

MsgBox " Please select the Cost Component and the Parameter"

Exit Sub

End If

MSChart2.Column = 1

MSChart2.RowCount $=$ Module1. count

Select Case (List1.ListIndex) 


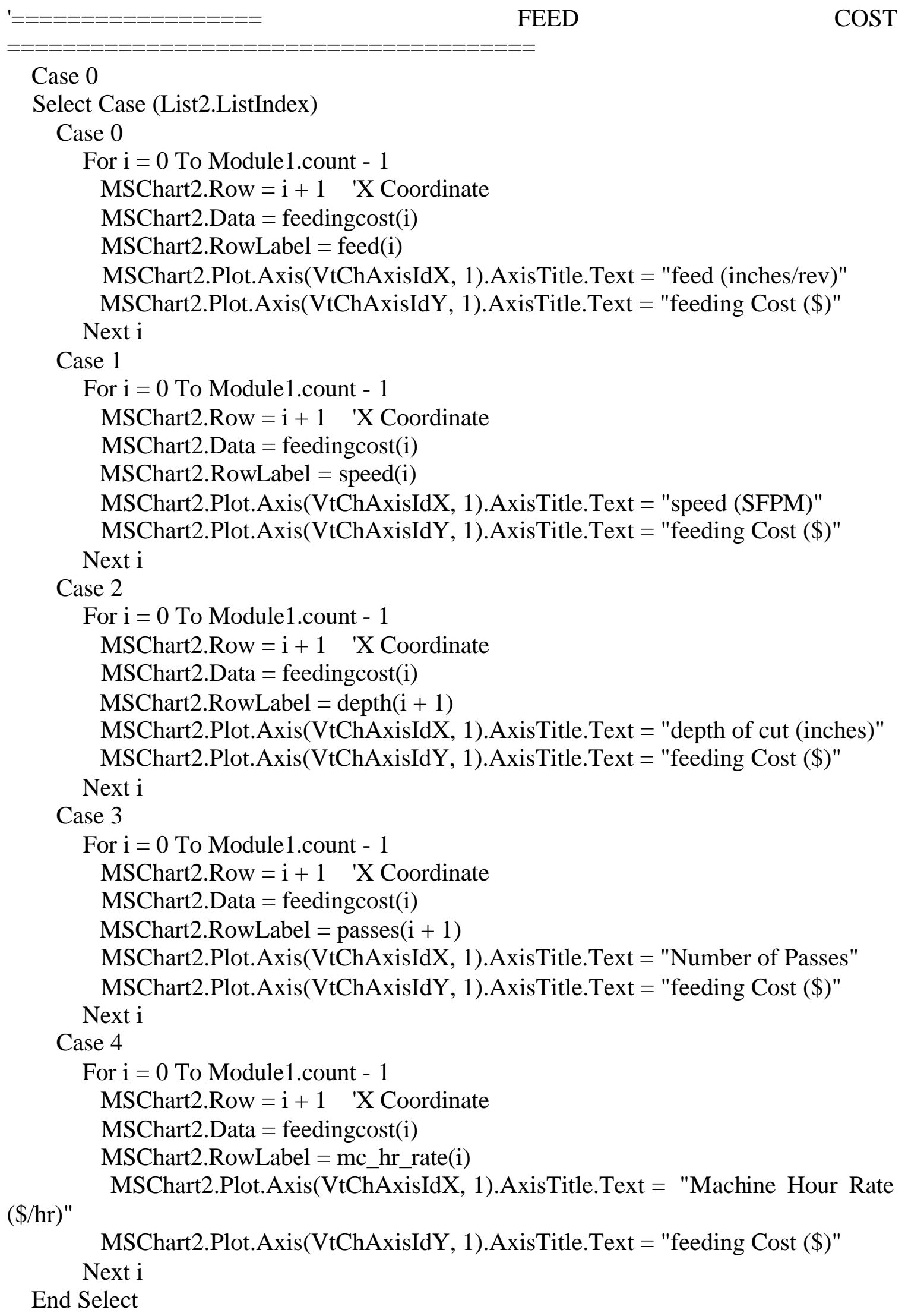

Case 0

Select Case (List2.ListIndex)

Case 0

For $\mathrm{i}=0$ To Module1.count -1

MSChart2.Row $=\mathrm{i}+1 \quad$ 'X Coordinate

MSChart2.Data $=$ feedingcost $(\mathrm{i})$

MSChart2.RowLabel = feed(i)

MSChart2.Plot.Axis(VtChAxisIdX, 1).AxisTitle.Text = "feed (inches/rev)"

MSChart2.Plot.Axis(VtChAxisIdY, 1).AxisTitle.Text = "feeding Cost (\$)"

Next i

Case 1

For $\mathrm{i}=0$ To Module1.count -1

MSChart2.Row $=\mathrm{i}+1 \quad$ 'X Coordinate

MSChart2.Data $=$ feedingcost(i)

MSChart2.RowLabel $=\operatorname{speed}(i)$

MSChart2.Plot.Axis(VtChAxisIdX, 1).AxisTitle.Text = "speed (SFPM)"

MSChart2.Plot.Axis(VtChAxisIdY, 1).AxisTitle.Text = "feeding Cost (\$)"

Next i

Case 2

For $\mathrm{i}=0$ To Module1.count -1

MSChart2.Row $=\mathrm{i}+1 \quad$ 'X Coordinate

MSChart2.Data $=$ feedingcost $(i)$

MSChart2.RowLabel $=\operatorname{depth}(i+1)$

MSChart2.Plot.Axis(VtChAxisIdX, 1).AxisTitle.Text = "depth of cut (inches)"

MSChart2.Plot.Axis(VtChAxisIdY, 1).AxisTitle.Text = "feeding Cost (\$)"

Next i

Case 3

For $\mathrm{i}=0$ To Module1.count -1

MSChart2.Row $=\mathrm{i}+1 \quad$ 'X Coordinate

MSChart2.Data $=$ feedingcost $(\mathrm{i})$

MSChart2.RowLabel $=\operatorname{passes}(\mathrm{i}+1)$

MSChart2.Plot.Axis(VtChAxisIdX, 1).AxisTitle.Text = "Number of Passes"

MSChart2.Plot.Axis(VtChAxisIdY, 1).AxisTitle.Text = "feeding Cost (\$)"

Next i

Case 4

For $\mathrm{i}=0$ To Module1.count -1

MSChart2.Row $=\mathrm{i}+1 \quad$ 'X Coordinate

MSChart2.Data $=$ feedingcost $(\mathrm{i})$

MSChart2.RowLabel = mc_hr_rate(i)

$(\$ / h r) "$

MSChart2.Plot.Axis(VtChAxisIdX, 1).AxisTitle.Text = "Machine Hour Rate

MSChart2.Plot.Axis(VtChAxisIdY, 1).AxisTitle.Text = "feeding Cost (\$)"

Next i

End Select 


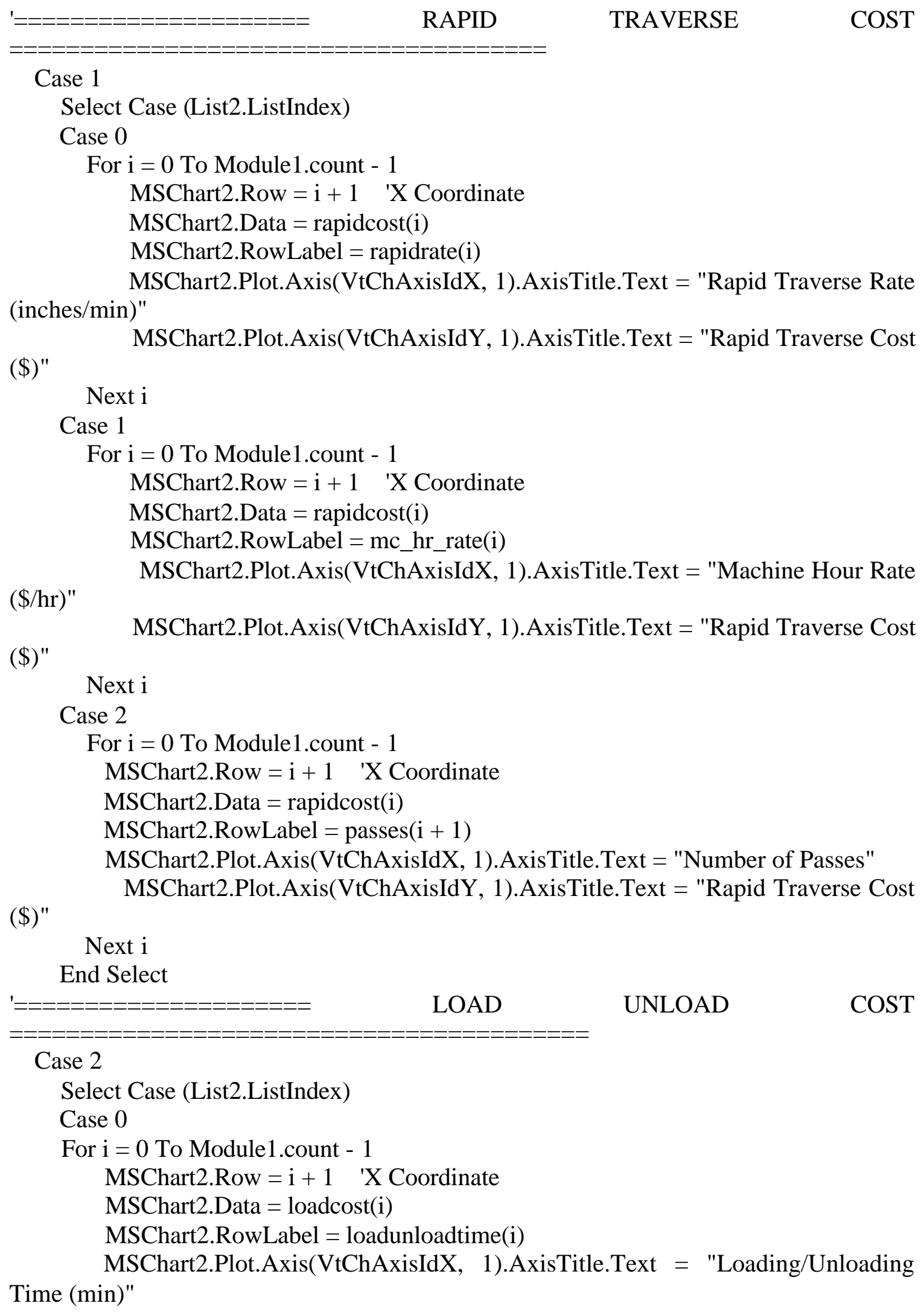



Cost (\$)"

MSChart2.Plot.Axis(VtChAxisIdY， 1).AxisTitle.Text = "Loading/Unloading

Next i

Case 1

For $\mathrm{i}=0$ To Module1.count -1

MSChart2.Row $=\mathrm{i}+1 \quad$ 'X Coordinate

MSChart2.Data $=$ loadcost $(\mathrm{i})$

MSChart2.RowLabel $=$ mc_hr_rate $(\mathrm{i})$

MSChart2.Plot.Axis(VtChAxisIdX, 1).AxisTitle.Text = "Machine Hour Rate $(\$ / h r) "$

MSChart2.Plot.Axis(VtChAxisIdY, 1).AxisTitle.Text = "Loading/Unloading Cost $(\$) "$

Next i

End Select

$=================$ TOOL CHANGE
$=================================$
Case 3
Select Case (List2.ListIndex)
Case 0
For i 0 O To Module1.count -1
MSChart2.Row $=\mathrm{i}+1$ 'X Coordinate
MSChart2.Data $=$ toolchcost(i)
MSChart2.RowLabel = toolchangetime(i)
MSChart2.Plot.Axis(VtChAxisIdX, 1).AxisTitle.Text = "Tool Change time
MSChart2.Plot.Axis(VtChAxisIdY, 1).AxisTitle.Text = "Tool Change Cost

(\$)"

Next i

Case 1

For $\mathrm{i}=0$ To Module1.count -1

MSChart2.Row $=i+1 \quad$ 'X Coordinate

MSChart2. Data $=$ toolchcost $(\mathrm{i})$

MSChart2.RowLabel $=$ feed(i)

MSChart2.Plot.Axis(VtChAxisIdX, 1).AxisTitle.Text = "feed (inches/rev)"

MSChart2.Plot.Axis(VtChAxisIdY, 1).AxisTitle.Text = "Tool Change Cost (\$)"

Next i

Case 2

For $\mathrm{i}=0$ To Module1.count -1

MSChart2.Row $=i+1 \quad$ 'X Coordinate

MSChart2.Data $=$ toolchcost $(\mathrm{i})$

MSChart2.RowLabel $=$ speed(i)

MSChart2.Plot.Axis(VtChAxisIdX, 1).AxisTitle.Text = "speed (SFPM)"

MSChart2.Plot.Axis(VtChAxisIdY, 1).AxisTitle.Text = "Tool Change Cost (\$)" Next i

Case 3

For $\mathrm{i}=0$ To Module1.count -1 


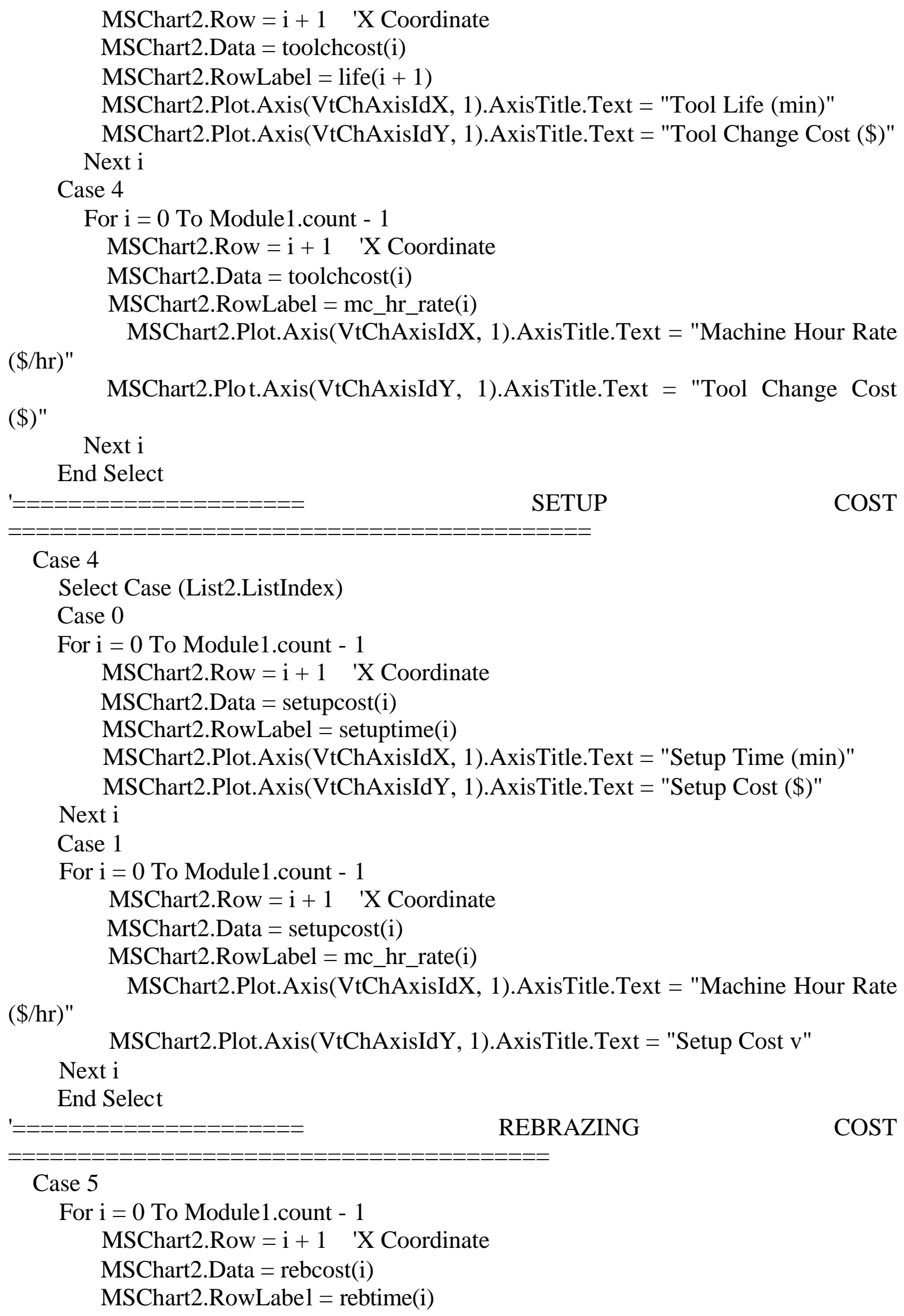

Case 5

For $\mathrm{i}=0$ To Module1.count -1

MSChart2.Row $=\mathrm{i}+1 \quad$ 'X Coordinate

MSChart2.Data $=$ rebcost $(\mathrm{i})$

MSChart2.RowLabel $=$ rebtime(i) 


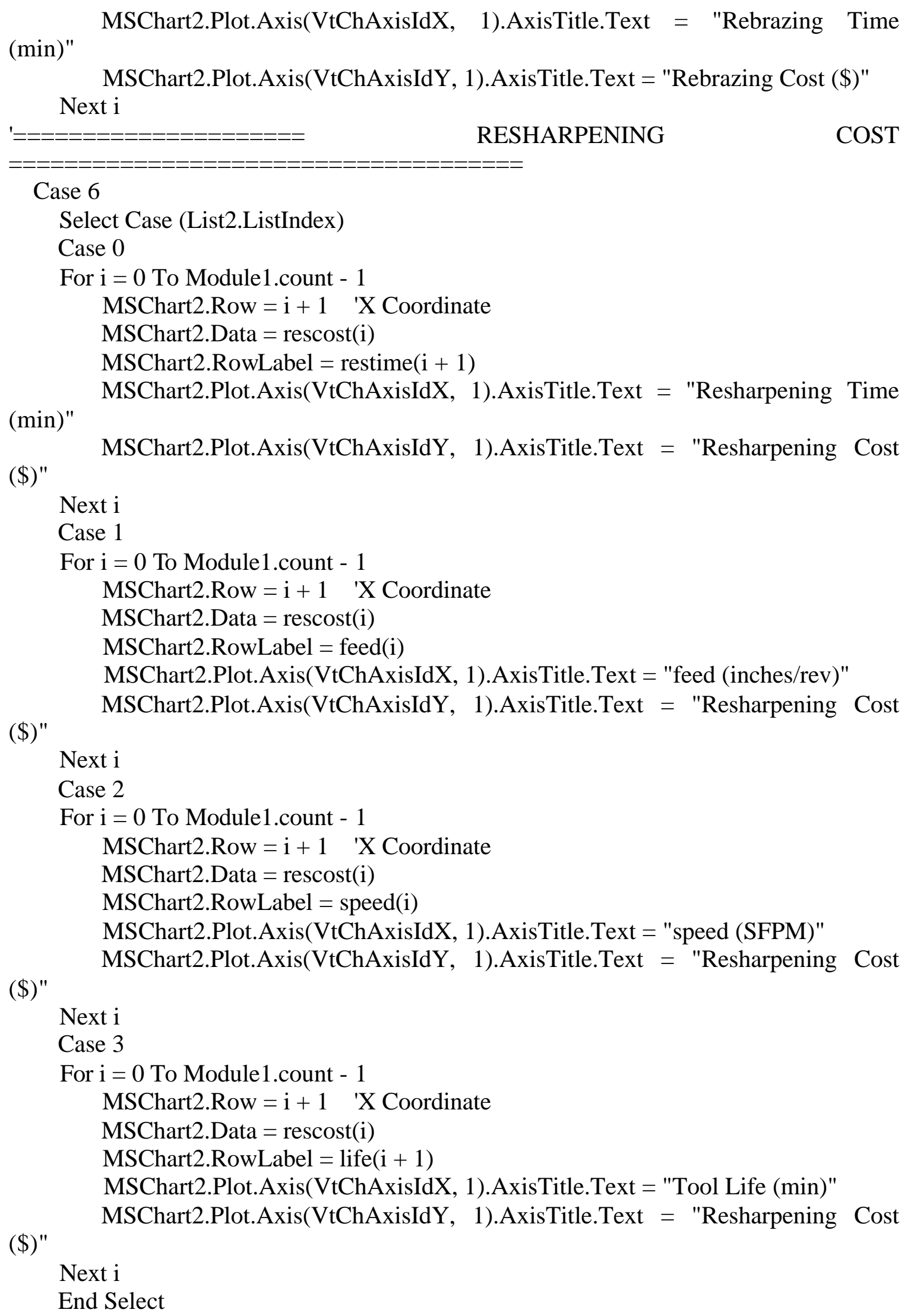




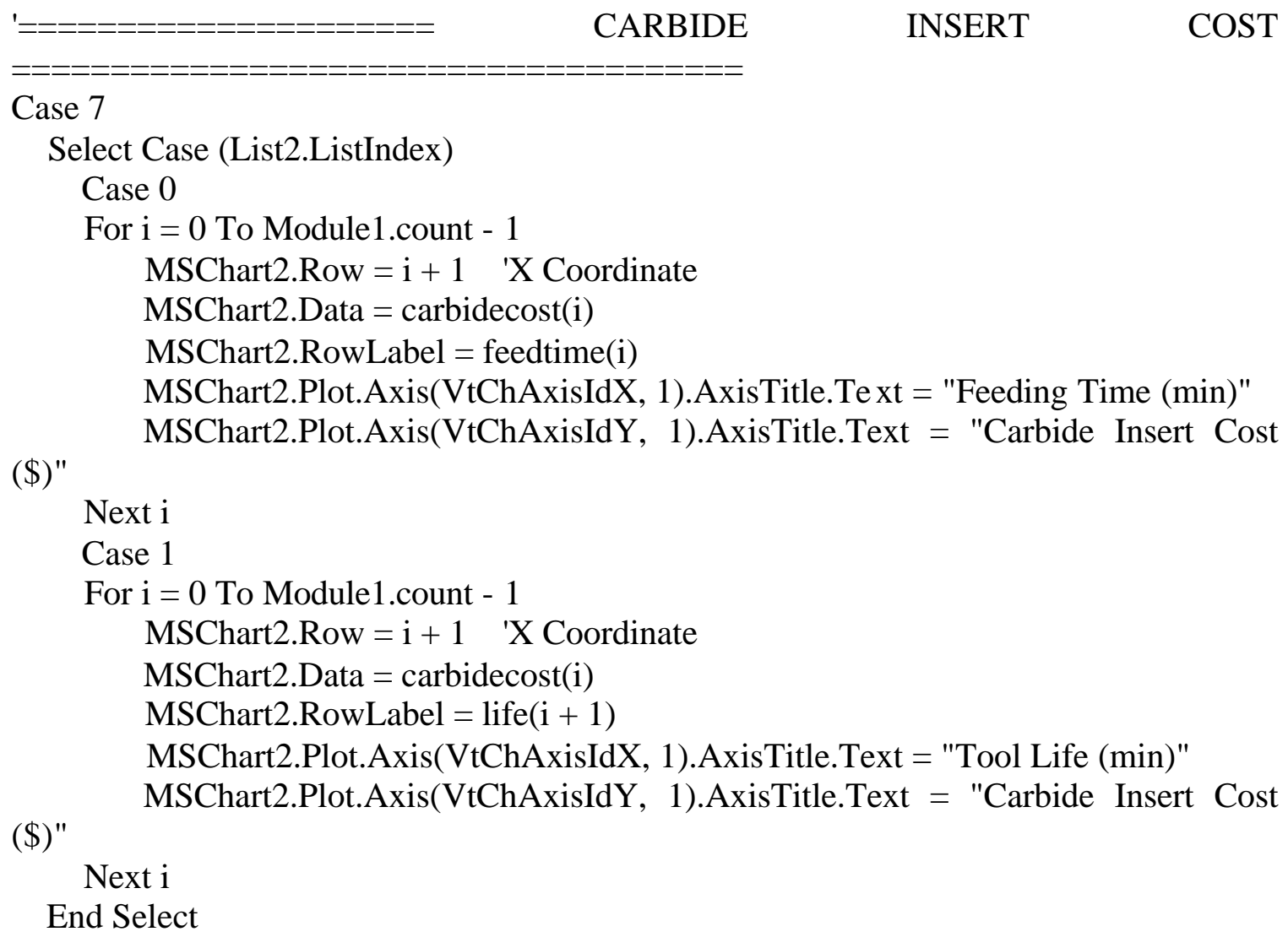

Case 8

Select Case (List2.ListIndex)

Case 0

For $\mathrm{i}=0$ To Module1.count -1

MSChart2.Row $=\mathrm{i}+1 \quad$ 'X Coordinate

MSChart2.Data $=$ grindcost $(\mathrm{i})$

MSChart2.RowLabel $=$ feed(i)

MSChart2.Plot.Axis(VtChAxisIdX, 1).AxisTitle.Text = "feed (inches/rev)"

MSChart2.Plot.Axis(VtChAxisIdY, 1).AxisTitle.Text = "Grinding Cost (\$)" Next i

Case 1

For $\mathrm{i}=0$ To Module1.count -1

MSChart2.Row $=\mathrm{i}+1 \quad$ 'X Coordinate

MSChart2.Data $=$ grindcost $(\mathrm{i})$

MSChart2.RowLabel = speed(i)

MSChart2.Plot.Axis(VtChAxisIdX, 1).AxisTitle.Text = "speed (SFPM)"

MSChart2.Plot.Axis(VtChAxisIdY, 1).AxisTitle.Text = "Grinding Cost (\$)" Next i

Case 2 
For $\mathrm{i}=0$ To Module1.count -1

MSChart2.Row $=\mathrm{i}+1 \quad$ 'X Coordinate

MSChart2.Data $=$ grindcost $(\mathrm{i})$

MSChart2.RowLabel $=$ life $(\mathrm{i}+1)$

MSChart2.Plot.Axis(VtChAxisIdX, 1).AxisTitle.Text = "Tool Life (min)"

MSChart2.Plot.Axis(VtChAxisIdY, 1).AxisTitle.Text = "Grinding Cost (\$)"

Next i

End Select

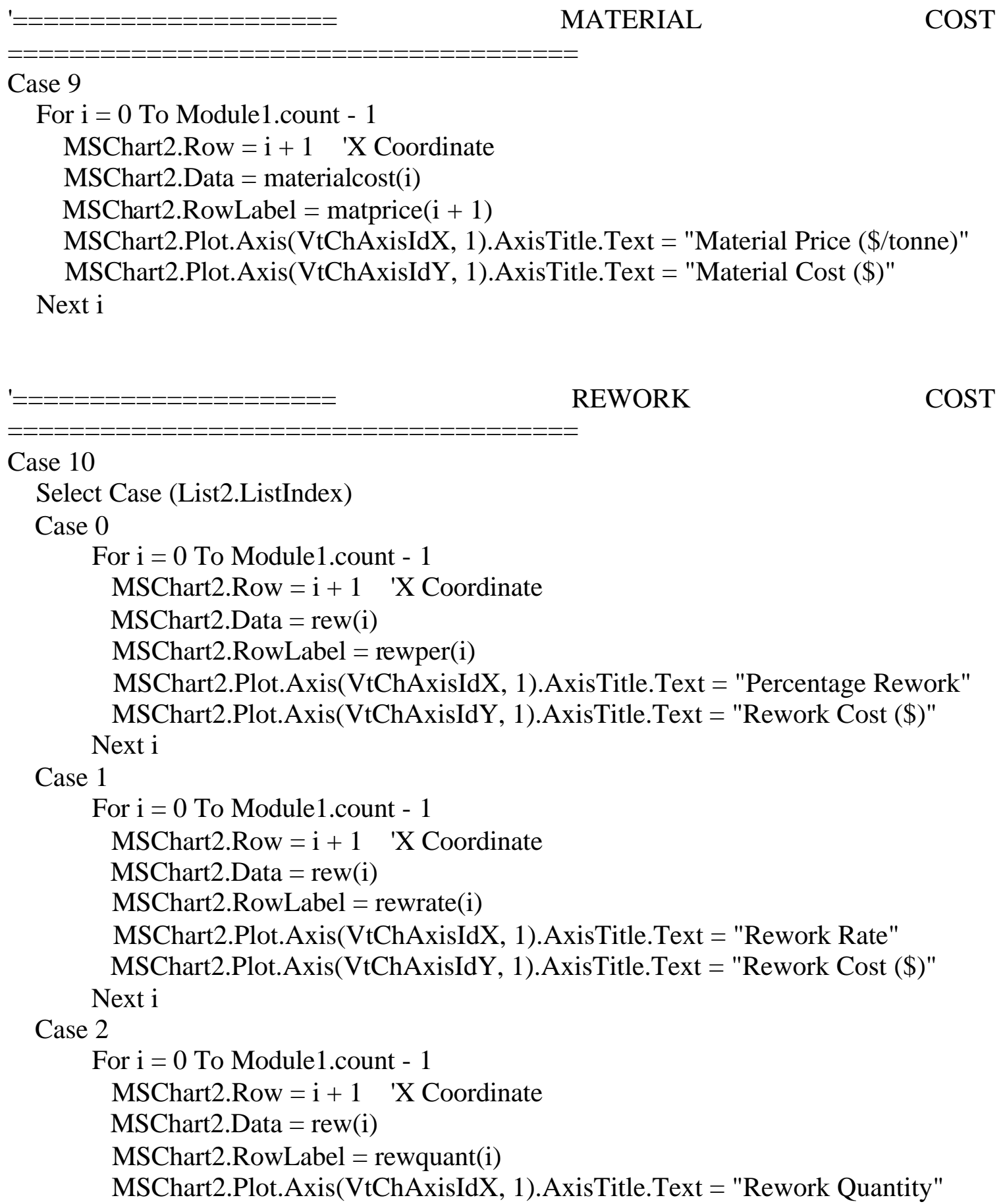


MSChart2.Plot.Axis(VtChAxisIdY, 1).AxisTitle.Text = "Rework Cost (\$)"

Next i

End Select

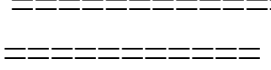

End Select

'End If

End Sub

Private Sub Command4_Click()

Form5.Show

Form6.Hide

End Sub

Private Sub List1_MouseUp(Button As Integer, Shift As Integer, X As Single, Y As Single)

For $\mathrm{i}=0$ To List1.ListIndex

Select Case (i)

Case 0

List2.Clear

List2.AddItem ("Feed Per Rev")

List2.AddItem ("Cutting Speed")

List2.AddItem ("Depth of Cut")

List2.AddItem ("No of Passes")

List2.AddItem ("Machine Hour Rate")

Case 1

List2.Clear

List2.AddItem ("Rapid Traverse Rate")

List2.AddItem ("Machine Hour Rate")

List2.AddItem ("No of Passes")

List2.AddItem ("Tool Approach")

List2.AddItem ("Tool Overtravel")

Case 2

List2.Clear

List2.AddItem ("Load/Unload Time")

List2.AddItem ("Machine Hour Rate")

Case 3

List2.Clear

List2.AddItem ("Tool Change Time")

List2.AddItem ("Feed Per Rev")

List2.AddItem ("Cutting Speed")

List2.AddItem ("Tool Life")

List2.AddItem ("Machine Hour Rate")

Case 4

List2.Clear 


\author{
List2.AddItem ("Setup Time") \\ List2.AddItem ("Machine Hour Rate") \\ Case 5 \\ List2.Clear \\ List2.AddItem ("Rebrazing Time") \\ List2.AddItem ("Brazing Labor Rate") \\ List2.AddItem ("Rebrazing Frequency") \\ Case 6 \\ List2.Clear \\ List2.AddItem ("Resharpening Time") \\ List2.AddItem ("Feed Per Rev") \\ List2.AddItem ("Cutting Speed") \\ List2.AddItem ("Tool Life") \\ List2.AddItem ("Grinding Labor Rate") \\ Case 7 \\ List2.Clear \\ List2.AddItem ("Feeding Time") \\ List2.AddItem ("Tool Life") \\ Case 8 \\ List2.Clear \\ List2.AddItem ("Feed Per Rev") \\ List2.AddItem ("Cutting Speed") \\ List2.AddItem ("Tool Life") \\ Case 9 \\ List2.Clear \\ List2.AddItem ("Material Price") \\ Case 10 \\ List2.Clear \\ List2.AddItem ("Percentage Rework") \\ List2.AddItem ("Rework Rate") \\ List2.AddItem ("Rework Quantity") \\ End Select \\ Next i \\ End Sub
}




\section{APPENDIX I}

\section{Program to Control Form 7}

Private Sub Command1_Click()

Unload Me

End

End Sub

Private Sub Command2_Click()

Form7.Hide

Form6.Show

End Sub 


\section{APPENDIX H}

\section{Module containing Subprograms}

Public ID As Single, L As Single, Dfin As Single, targetcost As Single Public den As Single, matl_price As Single, fr As Single, v As Single Public d As Single, $r$ As Single, tl As Single, M As Single, t0 As Single

Public tc As Single, a As Single, e As Single, rejectionrate As Single, per_rework As Single

Public G As Single, p As Single, Cw As Single, Cost As Single, tb As Single, reworkrate As Single

Public ts As Single, m1 As Single, n As Single, C As Single, Lrb As Single

Public k2 As Integer, k3 As Integer, ubs As Integer, N1 As Integer, count As Integer

Public T As Single, Ft As Single, Fc As Single, time_tool_fails As Single

Public X1 As Double, X2 As Double, X3 As Double, X4 As Double, X5 As Double, X6

As Double

Public X10 As Double, X11 As Double, X12 As Double, X13 As Double

Public Arr1(11) As Single, Arr2(11) As String, typenew As String

'Public m2 As Single, n2 As Single, p2 As Single, C2 As Single, Cost As Single

Public dnew As Single, unitcost As Single, frnew As Single, vnew As Single, Mnew As

Single

Public D1 As Single, D2 As Single, D3 As Single, D4 As Single, m1new As Single

Public feedcost As Single, rtc As Single, stc As Single, lcc As Single, tcc As Single

Public tmtc As Single, rbc As Single, grc As Single, rsc As Single, cic As Single

Public totalcost As Single, matlcost As Single, toolcost As Single

Public tooltype1 As String, tooltype2 As String, mcexplore As String

Public SF As Double, HP As Double, life(20) As Double, rwc As Double

Public unit(20) As Double, depth(20) As Double, speed(20) As Double, feed(20) As

Double

Public feedingcost(20) As Double, passes(20) As Integer, rapidcost(20) As Double

Public rescost(20) As Double, rebcost(20) As Double, carbidecost(20) As Double

Public grindcost(20) As Double, loadcost(20) As Double, toolchcost(20) As Double

Public setupcost(20) As Double, rapidrate(20) As Double, setuptime(20) As Double

Public toolchangetime(20) As Double, rebtime(20) As Double, restime(20) As Double

Public loadunloadtime(20) As Double, rew(20) As Double, mc_hr_rate(20) As Double

Public matl_cond As String, matl_hard As String, var As Integer, tool_type(40) As String

Public brazingrate(20) As Single, grindingrate(20) As Single, feedtime(20) As Single

Public matprice(20) As Single, rewquant(20) As Single, rewper(20) As Single

Public rewrate(20) As Single, materialcost(20) As Double

Public Sub feeding(dnew, rejectionrate, Mnew, vnew, frnew)

Dim Dmax(12) As Double

Dim Dmin(12) As Double

Dim Dav(12) As Double 
Dim feed_time(12) As Double

Dim feed_cost(12) As Double

Dim i As Integer, $n$ As Integer

Static i1

$\mathrm{n}=$ No_passes(dnew)

ubs $=$ Round $(\mathrm{Nl} /(1-$ rejectionrate $))+1$

$\mathrm{Fc}=0$

$\mathrm{Ft}=0$

For $\mathrm{i}=1$ To $\mathrm{n}$

If $(i=1)$ Then

$\operatorname{Dmax}(\mathrm{i})=\mathrm{ID}$

$\operatorname{Dmin}(\mathrm{i})=\operatorname{Dmax}(\mathrm{i})-($ dnew $* 2)$

$\operatorname{Dav}(\mathrm{i})=(\operatorname{Dmax}(\mathrm{i})+\operatorname{Dmin}(\mathrm{i})) / 2$

Else

$\operatorname{Dmax}(\mathrm{i})=\operatorname{Dmin}(\mathrm{i}-1)$

$\operatorname{Dmin}(\mathrm{i})=\operatorname{Dmax}(\mathrm{i})-($ dnew $* 2)$

If $(\operatorname{Dmin}(\mathrm{i})<\mathrm{Dfin})$ Then

$\operatorname{Dmin}(\mathrm{i})=$ Dfin

End If

$\operatorname{Dav}(\mathrm{i})=(\operatorname{Dmax}(\mathrm{i})+\operatorname{Dmin}(\mathrm{i})) / 2$

End If

feed_time $(\mathrm{i})=(\operatorname{Dav}(\mathrm{i}) * \mathrm{~L}) /(3.82 *$ frnew $*$ vnew $)$

feed_cost $(\mathrm{i})=($ Mnew / 60) $*(\operatorname{Dav}(\mathrm{i}) * \mathrm{~L}) /(3.82 *$ frnew $*$ vnew $)$

Next

For $\mathrm{i}=1$ To $\mathrm{n}$

$\mathrm{Ft}=\mathrm{Ft}+$ feed_time $(\mathrm{i})$

$\mathrm{Fc}=\mathrm{Fc}+$ feed_cost $(\mathrm{i})$

Next

$\operatorname{depth}(\mathrm{i} 1)=$ dnew

$\operatorname{depth}(\mathrm{i} 1)=\operatorname{Round}(\operatorname{depth}(\mathrm{i} 1), 2)$

$\operatorname{passes}(\mathrm{i} 1)=\mathrm{n}$

mc_hr_rate $(\mathrm{i} 1)=$ Mnew

feedtime $(\mathrm{i} 1)=\mathrm{Ft}$

$\mathrm{i} 1=\mathrm{i} 1+1$

End Sub

Public Function setup(t0new, Mnew)

Static i2

setup $=($ tOnew $/ \mathrm{Nl}) *$ Mnew $/ 60$

setuptime $(\mathrm{i} 2)=\mathrm{t} 0$ new

i $2=\mathrm{i} 2+1$

End Function

Public Function No_passes(dnew) As Integer

Dim max_matl As Single

max_matl $=($ ID - Dfin $) / 2$

If $\left(\left(\max \_m a t l * 100\right)\right.$ Mod $($ dnew $* 100)>0$ And (max_matl $\left.* 100\right)$ Mod (dnew $\left.* 100\right)$ $<=50)$ Then 
No_passes $=$ Round $($ max_matl $/$ dnew $)+1$

Else

No_passes $=$ Round $\left(\max \_\right.$matl $/$dnew $)$

End If

End Function

Public Function Tool_change(frnew, vnew, T, tcnew, Mnew)

Static i3

Tool_change $=(\mathrm{ID} * \mathrm{~L} *$ tcnew $*$ Mnew $) /(3.82 *$ vnew $*$ frne $\mathrm{w} * \mathrm{~T} * 60)$

toolchangetime $(\mathrm{i} 3)=$ tcnew

$\mathrm{i} 3=\mathrm{i} 3+1$

End Function

Public Function Rebrazing(Lrbnew, tbnew, k2new, typenew)

Static i4

If (typenew <> "carbide tip") Then

Rebrazing $=0$

Else

Rebrazing $=($ Lrbnew $*$ tbnew $) /(\mathrm{k} 2$ new $* 60)$

End If

rebtime $(\mathrm{i} 4)=$ tbnew

$\mathrm{i} 4=\mathrm{i} 4+1$

End Function

Public Function Resharpening(frnew, vnew, T, Gnew, tsnew, k2new, typenew)

Static i5

time_tool_fails $=(\mathrm{ID} * \mathrm{~L}) /(3.82 *$ frnew $*$ vnew $* \mathrm{~T})$

If (typenew $=$ "carbide insert") Then

Resharpening $=0$

Else

Resharpening $=$ time_tool_fails $*$ Gnew $*$ tsnew $/ 60$

End If

restime $(\mathrm{i} 5)=$ tsnew

i5 $=$ i5 + 1

End Function

Public Function Carbide(Ccnew, Ft, T, typenew)

'Static i6

If (typenew <> "carbide insert") Then

Carbide $=0$

Else

Carbide $=($ Ccnew $/ \mathrm{T}) * \mathrm{Ft}$

End If

'carbidecost(i6) $=$ Carbide

'i6 $=\mathrm{i} 6+1$

End Function

Public Function Grinding(frnew, vnew, T, Cw, typenew) 
'Static i6

If (typenew = "carbide insert") Then

Grinding $=0$

Else

Grinding $=$ time_tool_fails $* \mathrm{Cw}$

End If

'grindcost(i6) $=$ Grinding

'i6 = i6 + 1

End Function

Public Function Material(matl_price, den)

Static i7

Dim vol As Single, wt As Single

$\mathrm{vol}=\left(3.14 *(\mathrm{ID} / 2)^{\wedge} 2\right) * \mathrm{~L} * 16.38706$

$\mathrm{wt}=\mathrm{vol} * \operatorname{den} * 0.000001$

Material $=\mathrm{wt} *$ matl_price

matprice $(\mathrm{i} 7)=$ matl_price

'materialcost $(\mathrm{i} 7)=$ Material

matprice $(\mathrm{i} 7)=$ Round $($ matprice $(\mathrm{i} 7), 2)$

'materialcost(i7) = Round(Material(i7), 2)

$\mathrm{i} 7=\mathrm{i} 7+1$

End Function

Public Function Toollife(vnew, frnew, dnew, m1new, nnew, pnew, Cnew, typenew, k3new)

Static i11

If (typenew <> "carbide insert") Then

Toollife $=\left(\text { Cnew } /\left(\left(\text { frnew }{ }^{\wedge} \text { m1new }\right) *\left(\text { dnew }{ }^{\wedge} \text { pnew }\right) * \text { vnew }\right)\right)^{\wedge}(1 /$ nnew $)$

Else

Toollife $=\left((\text { Cnew } /((\text { frnew } \wedge \text { m } 1 \text { new }) *(\text { dnew } \wedge \text { pnew }) * \text { vnew }))^{\wedge}(1 /\right.$ nnew $\left.)\right) *$ k3new

End If

life(i11) $=$ Toollife

tool_type(i11) = typenew

life(i11) = Round(life(i11), 2)

$\mathrm{i} 11=\mathrm{i} 11+1$

End Function

Public Sub optimum(X7, X8, X9, C2, Costnew, dnew, Mnew)

Static i8

$\mathrm{X} 1=\mathrm{Val}($ Form1.btext.Text $)$

$\mathrm{X} 2=\mathrm{Val}($ Form1.ctext.Text $)$

$\mathrm{X} 3=\mathrm{Val}($ Form1.etext.Text $)$

$\mathrm{X} 4=\mathrm{Val}($ Form1.gtext.Text $)$

$\mathrm{X} 5=\mathrm{Val}($ Form 1. htext.Text $)$ 


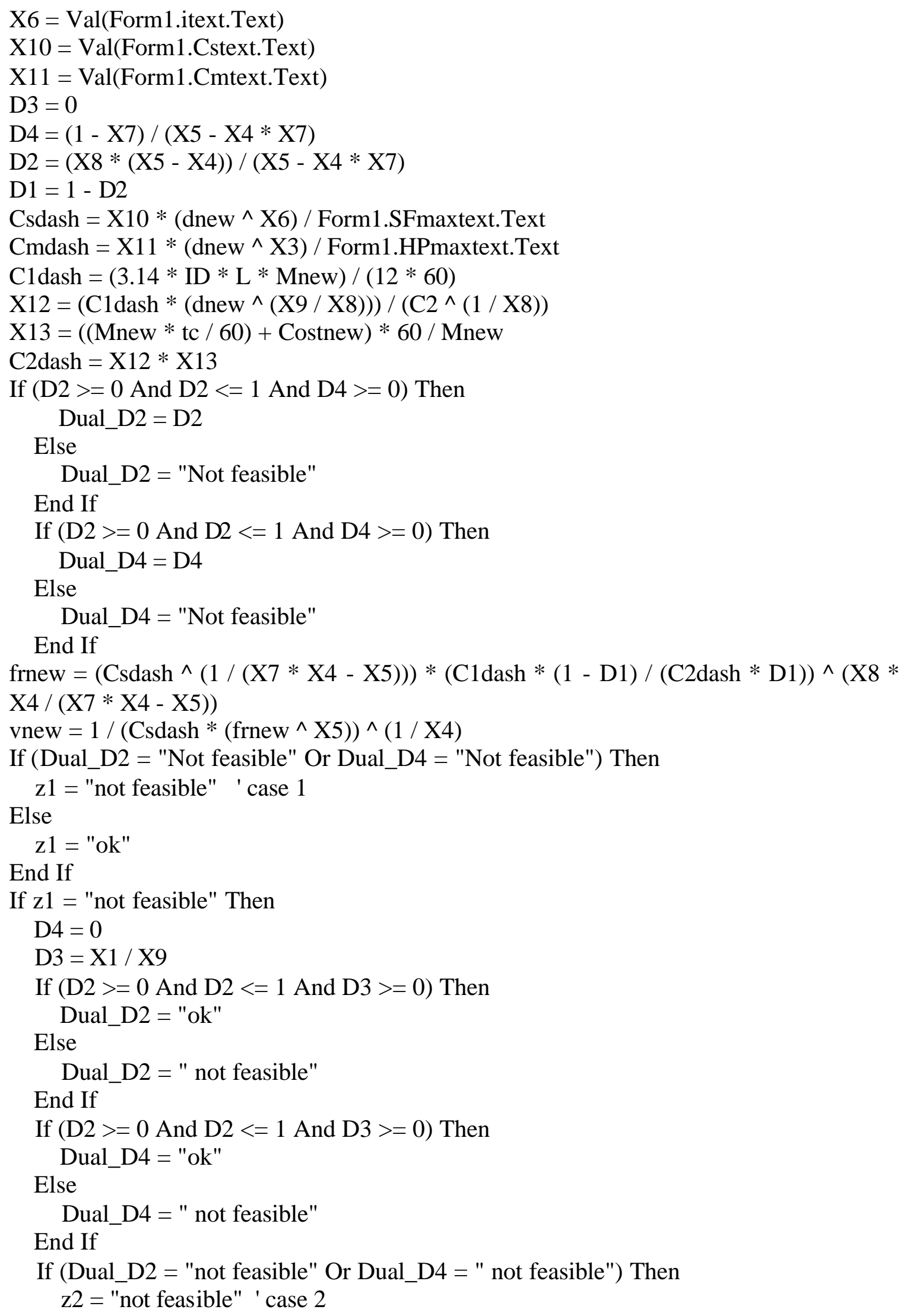


Else

$$
\mathrm{z} 2=\text { "ok" }
$$

\section{End If}

\section{End If}

If (z1 = "not feasible" And z2 = "not feasible") Then

vnew $=\operatorname{Exp}((\mathrm{X} 5 * \log ($ Cmdash $)-\mathrm{X} 2 * \log ($ Csdash $)) /(\mathrm{X} 4 * \mathrm{X} 2-\mathrm{X} 1 * \mathrm{X} 5))$

frnew $=\operatorname{Exp}((\mathrm{X} 1 * \log (\mathrm{Csdash})-\mathrm{X} 4 * \log (\mathrm{Cmdash})) /(\mathrm{X} 4 * \mathrm{X} 2-\mathrm{X} 1 * \mathrm{X} 5))$

\section{End If}

speed $(\mathrm{i} 8)=$ vnew

speed $(\mathrm{i} 8)=$ Round $(\operatorname{speed}(\mathrm{i} 8), 2)$

feed $(\mathrm{i} 8)=$ frnew

feed $($ i8 $)=$ Round $($ feed $($ i8 $), 4)$

$\mathrm{i} 8=\mathrm{i} 8+1$

End Sub

Public Function reworkcost()

Static i10

no_parts_reworked $=($ ubs $-\mathrm{Nl}) *($ per_rework / 100)

reworkcost $=$ (no_parts_reworked $*$ reworkrate $) /$ ubs

'rew $($ i10 $)=$ reworkcost

rewrate $(\mathrm{i} 10)=$ reworkrate

rewquant(i10) $=$ no_parts_reworked

rewper(i10) $=$ per_rework

'rew(i10) $=\operatorname{Round}(\operatorname{rew}(\mathrm{i} 10), 2)$

rewrate $(\mathrm{i} 10)=\operatorname{Round}(\operatorname{rewrate}(\mathrm{i10}), 2)$

rewquant $(\mathrm{i} 10)=\operatorname{Round}(\operatorname{rewquant}(\mathrm{i10}), 2)$

rewper(i10) $=$ Round $($ rewper $(\mathrm{i} 10), 2)$

$\mathrm{i} 10=\mathrm{i} 10+1$

End Function

Public Sub sort()

Dim Per(5) As Single

Dim i As Integer, $\mathrm{j}$ As Integer

Dim tempA As Single, tempB As String

$\operatorname{Arr} 1(0)=$ feedcost

$\operatorname{Arr1}(1)=\operatorname{rtc}$

$\operatorname{Arr1}(2)=$ stc

$\operatorname{Arr1}(3)=\operatorname{tcc}$

$\operatorname{Arr1}(4)=1 c c$

$\operatorname{Arr1}(5)=\operatorname{rbc}$

$\operatorname{Arr1}(6)=\operatorname{rsc}$

$\operatorname{Arr1}(7)=\operatorname{cic}$

$\operatorname{Arr1}(8)=$ grc

$\operatorname{Arr1}(9)=$ matlcost

$\operatorname{Arr} 1(10)=$ rwc

Arr2(0) = "Feeding Cost"

Arr2(1) = "Rapid Traverse Cost"

Arr2(2) = "Setup Cost" 


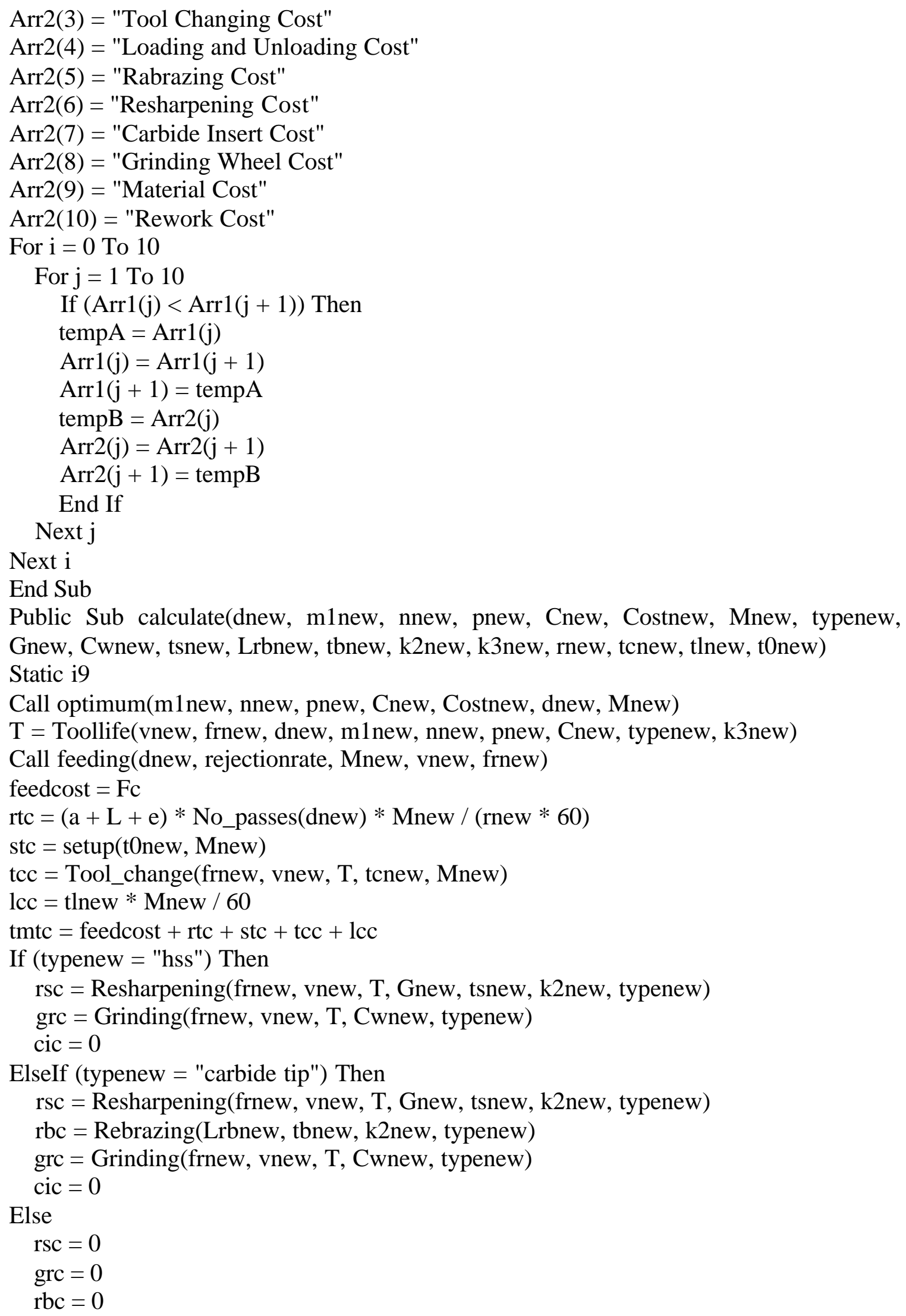




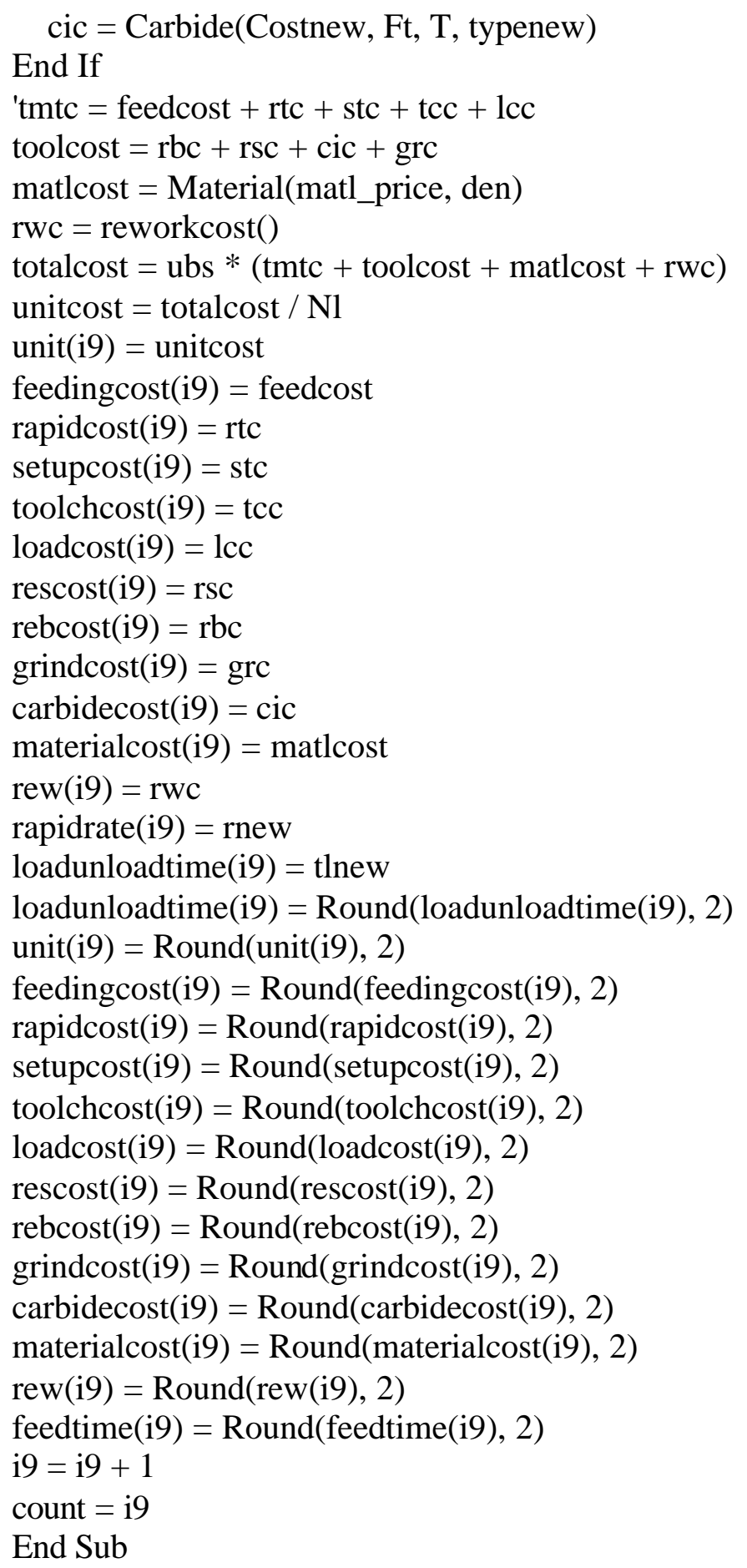

